\title{
A glycaemic index compendium of non-western foods
}

\author{
Christiani Jeyakumar Henry (1, ${ }^{1,2}$, Rina Yu Chin Quek $\mathbb{1}^{1}$, Bhupinder Kaur', Sangeetha Shyam ${ }^{3,4}$ and \\ Harvinder Kaur Gilcharan Singh ${ }^{3,5}$
}

\begin{abstract}
Current international tables published on the glycaemic index $(\mathrm{Gl})$ of foods represent valuable resources for researchers and clinicians. However, the vast majority of published Gl values are of Western origin, notably European, Australian and North American. Since these tables focus on Western foods with minimal inclusion of other foods from non-Western countries, their application is of limited global use. The objective of this review is to provide the Gl values for a variety of foods that are consumed in non-Western countries. Our review extends and expands on the current $\mathrm{Gl}$ tables in an attempt to widen its application in many other regions of the world.
\end{abstract}

\section{Introduction}

In many non-Western countries, cereal-based carbohydrates provide $\sim 60 \%$ of total energy intake ${ }^{1}$ compared with $42 \%$ for Caucasians ${ }^{2}$. The consumption of such highcarbohydrate diets yield high glucose and insulin response, thus contributing to insulin resistance. Nonetheless, the quality of carbohydrate consumed is as important as the quantity. Poor quality carbohydrates are quickly digested and absorbed, thereby giving rise to high blood glucose and insulin 'spikes'. Observational studies have shown that the consumption of low glycaemic index (GI) foods is associated with a lower risk of type 2 diabetes mellitus (T2DM) ${ }^{3}$, significantly less insulin resistance and a lower prevalence of the metabolic syndrome ${ }^{4}$. However, the vast majority of these published GI values are of European, Australian and North America origin.

\section{Glycaemic index}

The GI is defined as a numerical figure used to represent the ability of a carbohydrate food to raise blood

\footnotetext{
Correspondence: Christiani Jeyakumar Henry (jeya_henry@sifbi.a-star.edu.sg) ${ }^{1}$ Singapore Institute of Food and Biotechnology Innovation (SIFBI), Clinical Nutrition Research Centre (CNRC), 14 Medical Drive, \#07-02, Singapore 117599, Singapore

${ }^{2}$ Department of Biochemistry, National University of Singapore (NUS), 8 Medical Drive, Singapore 117596, Singapore

Full list of author information is available at the end of the article
}

glucose levels. It is expressed as a percentage of the incremental area under the glycaemic response curve (AUC) elicited by a portion of food containing $50 \mathrm{~g}$ available carbohydrate in comparison with the AUC elicited by a standard reference food of $50 \mathrm{~g}$ glucose or white bread in the same participant ${ }^{5}$. The principle is that the slower the rate of carbohydrate absorption into the bloodstream, the lower the rise of blood glucose level and the lower the GI value. A GI value of $\geq 70$ is considered high, a GI value 56-69 inclusive is medium and a GI value $\leq 55$ is low, where glucose $=100$.

Following the approach of these authors, we are for the first time providing a compendium of GI values of nonWestern foods ${ }^{6}$. Since many of these GI values were published in uncommon journals or located in various sources, it is not surprising that many previous authors may have found it a challenge to access and retrieve such information.

With a global pandemic of T2DM escalating, especially in emerging countries ${ }^{7}$, it is now recognised that the GI food-based intervention is an important tool in the management and prevention of $\mathrm{T}_{2} \mathrm{DM}^{8}$. Ironically, in regions of the world where there is a pandemic of T2DM, there is a shortage of a taxonomy of GI data of non-Western foods (e.g. Middle East, South Asia, Indian sub-continent) in contrast to the current international GI tables ${ }^{6,9}$. 
In 1997, the FAO/WHO Expert Consultation suggested that the concept of GI might provide a useful means of helping to select the most appropriate carbohydratecontaining foods for the maintenance of health and the treatment of several diseases ${ }^{10}$. A meta-analysis by BrandMiller et $\mathrm{al}^{11}$. demonstrated that choosing low GI foods in place of conventional or high GI foods exhibited a small but clinically important effect on medium-term glycaemic control in patients with diabetes. Low GI foods have been shown to reduce insulin demand and lipid concentrations, improve blood glucose control and reduce body weight, thus preventing diabetes-related cardiovascular events ${ }^{12-15}$.

A typical non-Western diet, such as in South Asia, is high in carbohydrates with cereals such as polished rice, white flour, finger millet, semolina and wheat providing the bulk of the energy ${ }^{16}$. Furthermore, it has been shown that a unique metabolic feature of South Asians, for an identical carbohydrate load, elicits postprandial glucose peaks that are 2-3 times larger than Caucasians ${ }^{17-19}$. Hence, a compilation of the GI of non-Western foods is necessary for proper selection and modifications that may be of particular benefit to not only these groups of people but to a wider audience.

The objective of this review is, therefore, to consolidate the GI values for a variety of foods that are consumed in non-Western countries. This is in order to capture and encapsulate all the data available on GI that have not been reported in the general literature. Given that the largest preponderance of type 2 diabetes is in Asia, the Middle East, South America and parts of Africa, it is imperative that the database on GI is expanded in order for it to have global utility. With this in mind, papers were critically evaluated based on a strict criterion. The emphasis of this review has inevitably been to record and document the GI of various foods.

\section{Research design and method}

We conducted a comprehensive literature search for relevant, original articles published from January 2000 through May 2020. Since 2000 marked the exponential growth in GI testing in non-Western countries, we have decided to take this as the year of data analysis. Briefly, the following string of search terms was used in PubMed and Google Scholar, with no language or other restrictions: (glycaemic index) AND (foods) AND ('country'). The electronic search was supplemented by manual searches through the reference sections of selected publications, as well as with linked articles that were found to have cited these particular publications. Non-Western countries included in this search were as follows: Singapore, Malaysia, Indonesia, Brunei, Cambodia, Thailand, Japan, Korea, China, Taiwan, Hong Kong, Nepal, India, Myanmar,
Vietnam, Sri Lanka, Philippines, United Arab Emirates, Yemen, Oman, Saudi, Qatar, Kuwait, Lebanon, Egypt, Pakistan and Bangladesh. The compiled GI studies in our article have utilised the recommended GI testing method $^{10,20}$ and fulfilled the minimum requirements for the following inclusion criteria for GI testing studies: minimum 10 participants (healthy/T2DM), instruments such as Yellow Spring Instruments (YSIs) and the use of handheld glucometers such as HemoCue ${ }^{\circledR}$ and other similar devices widely used in clinical studies for GI testing, amount of available carbohydrate and reference food (glucose/white bread/white rice). In the table, most of the foods are based on $50 \mathrm{~g}$ available carbohydrate. However, for foods with low to moderate carbohydrate density, it is justified by Brouns et al. ${ }^{20}$ to use a lower amount of carbohydrate to prevent consumption of an excessively large amount of food. Finally, the GI of non-Western foods were grouped according to the countries. The food list was arranged according to the country of origin so as to allow individuals who are keener on knowing the GI variability of foods from their own country to retrieve this information conveniently.

\section{Results}

Table 1 lists 940 food items, citing 159 separate studies, representing reliable data derived from healthy subjects or individuals with type 2 diabetes. Figure 1 shows a flow diagram indicating a number of studies screened, excluded and included in this article. Non-Western countries included in this compilation were as follows: Singapore, Malaysia, Thailand, Indonesia, Philippines, Japan, Korea, China, Taiwan, Hong Kong, India, Sri Lanka, Emirates, Oman, Saudi and Lebanon. These countries were chosen based on published studies on GI from these locations, with validated methodologies used and the papers followed the inclusion criteria as described in our paper. The GI of non-Western foods was firstly arranged according to the country it was derived from. This was followed by the food item, the GI, serving size (if any), available carbohydrate portion, subject type and number, and lastly the reference food with time period of GI testing. An important feature of our paper is to encourage readers to interpret the data in a way that will enable them to select healthy foods from the GI range of foods available. Therefore, using the data generated from our GI tables, the illustrative example presented below are simple methods that may be adapted to reduce the GI values of carbohydrate-rich staples (Fig. 2).

\section{Conclusion}

We believe that the inclusion of the additional GI values of foods from non-Western countries will enhance the use 
Table 1 Gl values of non-Western foods.

\begin{tabular}{|c|c|c|c|c|c|c|c|c|c|}
\hline & \multirow[t]{2}{*}{ Reference } & \multirow[t]{2}{*}{ Country } & \multirow[t]{2}{*}{ Food item } & \multicolumn{2}{|c|}{ GI (glucose $=100)$} & \multirow{2}{*}{$\begin{array}{l}\text { Serving size (g) per experimental } \\
\text { portion size }\end{array}$} & \multirow{2}{*}{$\begin{array}{l}\text { Available CHO } \\
\text { (g) per } \\
\text { experimental } \\
\text { portion }\end{array}$} & \multirow{2}{*}{$\begin{array}{l}\text { Participants } \\
\text { (type and } \\
\text { number) }\end{array}$} & \multirow{2}{*}{$\begin{array}{l}\text { Reference } \\
\text { food and } \\
\text { time perioc }\end{array}$} \\
\hline & & & & Mean & SEM & & & & \\
\hline 1 & 21 & Singapore & Malay-style fried rice & 99 & 7 & 377 & 50 & $\begin{array}{l}11 \text { Healthy } \\
\text { participants }\end{array}$ & Glucose $/ 2 \mathrm{~h}$ \\
\hline 2 & 21 & Singapore & Nasi lemak & 100 & 14 & 210 & 50 & $\begin{array}{l}11 \text { Healthy } \\
\text { participants }\end{array}$ & Glucose $/ 2 \mathrm{~h}$ \\
\hline 3 & 21 & Singapore & Mee goreng & 91 & 9 & 309 & 50 & $\begin{array}{l}11 \text { Healthy } \\
\text { participants }\end{array}$ & Glucose $/ 2 \mathrm{~h}$ \\
\hline 4 & 21 & Singapore & Mee siam & 88 & 11 & 655 & 50 & $\begin{array}{l}11 \text { Healthy } \\
\text { participants }\end{array}$ & Glucose $/ 2 \mathrm{~h}$ \\
\hline 5 & 21 & Singapore & Loi mai kai & 94 & 9 & 149 & 50 & $\begin{array}{l}11 \text { Healthy } \\
\text { participants }\end{array}$ & Glucose $/ 2 \mathrm{~h}$ \\
\hline 6 & 21 & Singapore & Red bean pau & 91 & 6 & 67 & 50 & $\begin{array}{l}11 \text { Healthy } \\
\text { participants }\end{array}$ & Glucose $/ 2 \mathrm{~h}$ \\
\hline 7 & 21 & Singapore & Chicken Curry Puff & 92 & 8 & 71 & 50 & $\begin{array}{l}11 \text { Healthy } \\
\text { participants }\end{array}$ & Glucose $/ 2 \mathrm{~h}$ \\
\hline 8 & 21 & Singapore & Cheese bun & 95 & 9 & 52 & 50 & $\begin{array}{l}11 \text { Healthy } \\
\text { participants }\end{array}$ & Glucose $/ 2 \mathrm{~h}$ \\
\hline 9 & 22 & Singapore & White rice & 96 & 6.6 & $194 \mathrm{~g}$ cooked rice & 50 & $\begin{array}{l}12 \text { Healthy } \\
\text { participants }\end{array}$ & Glucose $/ 2 \mathrm{~h}$ \\
\hline 10 & 22 & Singapore & White rice cooked with oil & 68 & 4.3 & $\begin{array}{l}194 \mathrm{~g} \text { cooked white rice } \\
30 \mathrm{~g} \text { ground nut oil }\end{array}$ & 50 & $\begin{array}{l}12 \text { Healthy } \\
\text { participants }\end{array}$ & Glucose $/ 2 \mathrm{~h}$ \\
\hline 11 & 22 & Singapore & $\begin{array}{l}\text { White rice served with chicken breast } \\
\text { without skin }\end{array}$ & 73 & 4.1 & $\begin{array}{l}194 \mathrm{~g} \text { cooked white rice } \\
100 \mathrm{~g} \text { chicken breast }\end{array}$ & 50 & $\begin{array}{l}12 \text { Healthy } \\
\text { participants }\end{array}$ & Glucose $/ 2 \mathrm{~h}$ \\
\hline 12 & 22 & Singapore & White rice served with leaf vegetables & 82 & 5.8 & $\begin{array}{r}194 \mathrm{~g} \text { cooked rice } \\
120 \mathrm{~g} \text { vegetables }\end{array}$ & 50 & $\begin{array}{l}12 \text { Healthy } \\
\text { participants }\end{array}$ & Glucose $/ 2 \mathrm{~h}$ \\
\hline 13 & 22 & Singapore & $\begin{array}{l}\text { White rice cooked with oil, served with chicken } \\
\text { breast and leafy vegetables }\end{array}$ & 50 & 4.0 & $\begin{array}{l}194 \mathrm{~g} \text { cooked rice } \\
30 \mathrm{~g} \text { ground nut oil } \\
100 \mathrm{~g} \text { chicken breast } \\
120 \mathrm{~g} \text { vegetables }\end{array}$ & 50 & $\begin{array}{l}12 \text { Healthy } \\
\text { participants }\end{array}$ & Glucose $/ 2 \mathrm{~h}$ \\
\hline 14 & 23 & Singapore & Jasmine rice & $\begin{array}{l}\text { C: } 91.2 \\
\text { M: } 92.0 \\
\text { I: } 90.2\end{array}$ & $\begin{array}{l}\text { C: } 19.2 \\
\text { M: } 20.0 \\
\text { I: } 23.4\end{array}$ & $63.6 \mathrm{~g}$ raw (cooked with $130 \mathrm{ml}$ water) & 50 & $\begin{array}{l}75 \text { Healthy } \\
\text { participants }\end{array}$ & Glucose $/ 2 \mathrm{~h}$ \\
\hline 15 & 23 & Singapore & Basmati rice & $\begin{array}{l}\text { C: } 55.7 \\
\text { M: } 62.6 \\
\text { I: } 59.5\end{array}$ & $\begin{array}{l}\text { C: } 13.3 \\
\text { M: } 13.1 \\
\text { I: } 18.1\end{array}$ & $66.5 \mathrm{~g}$ raw (cooked with $170 \mathrm{ml}$ water) & 50 & $\begin{array}{l}75 \text { Healthy } \\
\text { participants }\end{array}$ & Glucose $/ 2 \mathrm{~h}$ \\
\hline 16 & 24 & Singapore & Ice green tea & 50 & 5 & $833(\mathrm{ml})$ & 50 & $\begin{array}{l}13 \text { Healthy } \\
\text { participants }\end{array}$ & Glucose $/ 2 \mathrm{~h}$ \\
\hline 17 & 24 & Singapore & Ice lemon tea & 74 & 7 & $500(\mathrm{ml})$ & 50 & $\begin{array}{l}14 \text { Healthy } \\
\text { participants }\end{array}$ & Glucose $/ 2 \mathrm{~h}$ \\
\hline 18 & 24 & Singapore & Barley drink & 62 & 6 & $658(\mathrm{ml})$ & 50 & $\begin{array}{l}11 \text { Healthy } \\
\text { participants }\end{array}$ & Glucose $/ 2 \mathrm{~h}$ \\
\hline 19 & 24 & Singapore & Chinese carrot cake & 77 & 8 & 316.9 & 50 & $\begin{array}{l}10 \text { Healthy } \\
\text { participants }\end{array}$ & Glucose $/ 2 \mathrm{~h}$ \\
\hline 20 & 24 & Singapore & Beehoon & 35 & 3 & 61.9 & 50 & $\begin{array}{l}11 \text { Healthy } \\
\text { participants }\end{array}$ & Glucose $/ 2 \mathrm{~h}$ \\
\hline 21 & 24 & Singapore & Chinese yam cake & 86 & 11 & 391.5 & 50 & $\begin{array}{l}10 \text { Healthy } \\
\text { participants }\end{array}$ & Glucose $/ 2 \mathrm{~h}$ \\
\hline 22 & 24 & Singapore & Pandan waffle & 46 & 6 & 148.3 & 50 & $\begin{array}{l}11 \text { Healthy } \\
\text { participants }\end{array}$ & Glucose $/ 2 \mathrm{~h}$ \\
\hline 23 & 24 & Singapore & Chee cheong fun & 81 & 7 & 277.4 & 50 & $\begin{array}{l}10 \text { Healthy } \\
\text { participants }\end{array}$ & Glucose $/ 2 \mathrm{~h}$ \\
\hline 24 & 24 & Singapore & Lo mai gai & 106 & 12 & 176.6 & 50 & $\begin{array}{l}12 \text { Healthy } \\
\text { participants }\end{array}$ & Glucose $/ 2 \mathrm{~h}$ \\
\hline 25 & 24 & Singapore & Pink rice cake & 97 & 12 & 184.8 & 50 & $\begin{array}{l}11 \text { Healthy } \\
\text { participants }\end{array}$ & Glucose $/ 2 \mathrm{~h}$ \\
\hline 26 & 24 & Singapore & Curry puff & 41 & 4 & 129.6 & 50 & $\begin{array}{l}11 \text { Healthy } \\
\text { participants }\end{array}$ & Glucose $/ 2 \mathrm{~h}$ \\
\hline 27 & 24 & Singapore & Char siew (pork) pau & 66 & 7 & 154.7 & 50 & $\begin{array}{l}10 \text { Healthy } \\
\text { participants }\end{array}$ & Glucose $/ 2 \mathrm{~h}$ \\
\hline 28 & 24 & Singapore & Youtiao & 55 & 4 & 109.6 & 50 & $\begin{array}{l}11 \text { Healthy } \\
\text { participants }\end{array}$ & Glucose $/ 2 \mathrm{~h}$ \\
\hline 29 & 24 & Singapore & Kaya butter toast & 49 & 4 & 108.7 & 50 & $\begin{array}{l}11 \text { Healthy } \\
\text { participants }\end{array}$ & Glucose $/ 2 \mathrm{~h}$ \\
\hline 30 & 24 & Singapore & Nasi lemak & 66 & 5 & 179.2 & 50 & $\begin{array}{l}12 \text { Healthy } \\
\text { participants }\end{array}$ & Glucose $/ 2 \mathrm{~h}$ \\
\hline 31 & 25 & Singapore & White bread_Gardenia Brand & 83 & 8.8 & 91.4 & 50 & $\begin{array}{l}10 \text { Healthy } \\
\text { participants }\end{array}$ & Glucose $/ 2 \mathrm{~h}$ \\
\hline 32 & 25 & Singapore & $\begin{array}{l}\text { White bread_Gardenia brand with essence of } \\
\text { chicken (Cerebos Pacific Ltd., Singapore, } \\
\text { Singapore) }\end{array}$ & 56.9 & 7.5 & 91.4 & 50 & $\begin{array}{l}10 \text { Healthy } \\
\text { participants }\end{array}$ & Glucose $/ 2 \mathrm{~h}$ \\
\hline 33 & 26 & Singapore & Wheat flour muffin & 74.4 & 8.1 & 126.1 & 50 & $\begin{array}{l}12 \text { Healthy } \\
\text { participants }\end{array}$ & Glucose $/ 2 \mathrm{~h}$ \\
\hline
\end{tabular}


Table 1 continued

\begin{tabular}{|c|c|c|c|c|c|c|c|c|c|}
\hline & \multirow[t]{2}{*}{ Reference } & \multirow[t]{2}{*}{ Country } & \multirow[t]{2}{*}{ Food item } & \multicolumn{2}{|c|}{ GI (glucose $=100)$} & \multirow{2}{*}{$\begin{array}{l}\text { Serving size }(\mathrm{g}) \text { per experimental } \\
\text { portion size }\end{array}$} & \multirow{2}{*}{$\begin{array}{l}\text { Available } \mathrm{CHO} \\
\text { (g) per } \\
\text { experimental } \\
\text { portion }\end{array}$} & \multirow{2}{*}{$\begin{array}{l}\text { Participants } \\
\text { (type and } \\
\text { number) }\end{array}$} & \multirow{2}{*}{$\begin{array}{l}\text { Reference } \\
\text { food and } \\
\text { time period }\end{array}$} \\
\hline & & & & Mean & SEM & & & & \\
\hline 34 & 26 & Singapore & Rice flour muffin & 79.1 & 6.3 & 119.4 & 50 & $\begin{array}{l}12 \text { Healthy } \\
\text { participants }\end{array}$ & Glucose/2 h \\
\hline 35 & 26 & Singapore & Corn flour muffin & 74.4 & 5.4 & 136.9 & 50 & $\begin{array}{l}12 \text { Healthy } \\
\text { participants }\end{array}$ & Glucose/2 h \\
\hline 36 & 26 & Singapore & Oat flour muffin & 53.6 & 4.8 & 146.8 & 50 & $\begin{array}{l}12 \text { Healthy } \\
\text { participants }\end{array}$ & Glucose/2 h \\
\hline 37 & 26 & Singapore & Barley flour muffin & 55.4 & 4.6 & 139.7 & 50 & $\begin{array}{l}12 \text { Healthy } \\
\text { participants }\end{array}$ & Glucose/2 h \\
\hline 38 & 27 & Singapore & White bread + soy milk & 77.2 & 7.1 & $\begin{array}{l}58 \mathrm{~g} \text { White bread } \\
322 \mathrm{ml} \text { Soy milk }\end{array}$ & 50 & $\begin{array}{l}12 \text { Healthy } \\
\text { participants }\end{array}$ & Glucose/2 h \\
\hline 39 & 27 & Singapore & White bread + dairy milk & 74.3 & 6.7 & $\begin{array}{l}58 \mathrm{~g} \text { White bread } \\
322 \mathrm{ml} \text { Dairy milk }\end{array}$ & 50 & $\begin{array}{l}12 \text { Healthy } \\
\text { participants }\end{array}$ & Glucose/2 h \\
\hline 40 & 28 & Singapore & Guava bites & 28 & 7 & NA & 25 & $\begin{array}{l}10 \text { Healthy } \\
\text { participants }\end{array}$ & Glucose/2 h \\
\hline 41 & 28 & Singapore & Guava puree & 45 & 6 & NA & 25 & $\begin{array}{l}10 \text { Healthy } \\
\text { participants }\end{array}$ & Glucose/2 h \\
\hline 42 & 28 & Singapore & Papaya bites & 38 & 4 & NA & 25 & $\begin{array}{l}10 \text { Healthy } \\
\text { participants }\end{array}$ & Glucose/2 h \\
\hline 43 & 28 & Singapore & Papaya puree & 40 & 6 & NA & 25 & $\begin{array}{l}10 \text { Healthy } \\
\text { participants }\end{array}$ & Glucose/2 h \\
\hline 44 & 29 & Singapore & Chinese steamed white bun & 58 & 3 & 88 & 50 & $\begin{array}{l}19 \text { Healthy } \\
\text { participants }\end{array}$ & Glucose/2 h \\
\hline 45 & 29 & Singapore & White bun filled with red bean paste & 58 & 4 & 106 & 50 & $\begin{array}{l}19 \text { Healthy } \\
\text { participants }\end{array}$ & Glucose $/ 2 \mathrm{~h}$ \\
\hline 46 & 29 & Singapore & Rice idli & 85 & 4 & 162 & 50 & $\begin{array}{l}19 \text { healthy } \\
\text { participants }\end{array}$ & Glucose/2 h \\
\hline 47 & 29 & Singapore & Rice dosa & 76 & 5 & 193 & 50 & $\begin{array}{l}19 \text { Healthy } \\
\text { participants }\end{array}$ & Glucose/2 h \\
\hline 48 & 29 & Singapore & Upma & 71 & 6 & 310 & 50 & $\begin{array}{l}19 \text { Healthy } \\
\text { participants }\end{array}$ & Glucose/2 h \\
\hline 49 & 29 & Singapore & Whole-grain biscuit & 54 & 5 & 82 & 50 & $\begin{array}{l}19 \text { Healthy } \\
\text { participants }\end{array}$ & Glucose/2 h \\
\hline 50 & 29 & Singapore & Whole-grain biscuit filled with peanut butter & 44 & 3 & 102 & 50 & $\begin{array}{l}19 \text { Healthy } \\
\text { participants }\end{array}$ & Glucose/2 h \\
\hline 51 & 29 & Singapore & Whole-grain oat muesli & 55 & 4 & 84 & 50 & $\begin{array}{l}19 \text { Healthy } \\
\text { participants }\end{array}$ & Glucose/2 h \\
\hline 52 & 29 & Singapore & Whole-grain oat protein granola & 51 & 4 & 87 & 50 & $\begin{array}{l}19 \text { Healthy } \\
\text { participants }\end{array}$ & Glucose $/ 2 \mathrm{~h}$ \\
\hline 53 & 29 & Singapore & Whole-grain protein cereal & 49 & 3 & 99 & 50 & $\begin{array}{l}19 \text { Healthy } \\
\text { participants }\end{array}$ & Glucose/2 h \\
\hline 54 & 30 & Singapore & White bread + rice bran soy milk (RBS) & 83.1 & 7.7 & 89.5 bread $+195(\mathrm{ml})$ RBS & 50 & $\begin{array}{l}17 \text { Healthy } \\
\text { participants }\end{array}$ & $\begin{array}{l}\text { White bread/ } \\
2 \mathrm{~h}\end{array}$ \\
\hline 55 & 30 & Singapore & White bread + sugar-free soy milk (SFS) & 77.5 & 10.1 & 91.4 bread $+195(\mathrm{ml})$ SFS & 50 & $\begin{array}{l}17 \text { Healthy } \\
\text { participants }\end{array}$ & $\begin{array}{l}\text { White bread/ } \\
2 \mathrm{~h}\end{array}$ \\
\hline 56 & 30 & Singapore & White bread & 100 & NA & 95.8 bread $+195(\mathrm{ml})$ water & 50 & $\begin{array}{l}17 \text { Healthy } \\
\text { participants }\end{array}$ & $\begin{array}{l}\text { White Bread/ } \\
2 \mathrm{~h}\end{array}$ \\
\hline 57 & 31 & Singapore & Basmati rice (Dreamrice ${ }^{T M}$, Singapore) & 55 & $15(S D)$ & $66.5 \mathrm{~g}$ (with $170 \mathrm{ml}$ water) & 50 & $\begin{array}{l}75 \text { Healthy } \\
\text { participants }\end{array}$ & Glucose $/ 2 \mathrm{~h}$ \\
\hline 58 & 31 & Singapore & $\begin{array}{l}\text { Jasmine rice (Double FP Thai Hom Mali } \\
\text { premium quality fragrant rice, Thailand) }\end{array}$ & 91 & $21(S D)$ & $63.6 \mathrm{~g}$ (with $130 \mathrm{ml}$ water) & 50 & $\begin{array}{l}75 \text { Healthy } \\
\text { participants }\end{array}$ & Glucose/2 h \\
\hline 59 & 32 & Malaysia & Multi-grains bread & 56 & 6.2 & 57.9 & 25 & $\begin{array}{l}12 \text { Healthy } \\
\text { participants }\end{array}$ & Glucose $/ 2 \mathrm{~h}$ \\
\hline 60 & 32 & Malaysia & Wholemeal bread with oatmeal & 67 & 6.9 & 56.3 & 25 & $\begin{array}{l}12 \text { Healthy } \\
\text { participants }\end{array}$ & Glucose $/ 2 \mathrm{~h}$ \\
\hline 61 & 32 & Malaysia & Wholemeal bread & 85 & 5.9 & 89.0 & 25 & $\begin{array}{l}12 \text { Healthy } \\
\text { participants }\end{array}$ & Glucose $/ 2 \mathrm{~h}$ \\
\hline 62 & 32 & Malaysia & White bread & 83 & 6.5 & 51.9 & 25 & $\begin{array}{l}12 \text { Healthy } \\
\text { participants }\end{array}$ & Glucose $/ 2 \mathrm{~h}$ \\
\hline 63 & 33 & Malaysia & Banana (Musa paradisiaca) & 55 & 12 & 211 & 50 & $\begin{array}{l}12 \text { Healthy } \\
\text { participants }\end{array}$ & $\begin{array}{l}\text { White bread/ } \\
2 \mathrm{~h}\end{array}$ \\
\hline 64 & 33 & Malaysia & Sweet potato (Ipomoea batatas) & 77 & 12 & 162 & 50 & $\begin{array}{l}12 \text { Healthy } \\
\text { participants }\end{array}$ & $\begin{array}{l}\text { White bread/ } \\
2 \mathrm{~h}\end{array}$ \\
\hline 65 & 33 & Malaysia & Rice noodles/kuay teow (Oryza sativa) & 85 & 15 & 157 & 50 & $\begin{array}{l}12 \text { Healthy } \\
\text { participants }\end{array}$ & $\begin{array}{l}\text { White bread/ } \\
2 \mathrm{~h}\end{array}$ \\
\hline 66 & 33 & Malaysia & White rice (Oryza Sativa) & 90 & 12 & 64 & 50 & $\begin{array}{l}12 \text { Healthy } \\
\text { participants }\end{array}$ & $\begin{array}{l}\text { White bread/ } \\
2 \mathrm{~h}\end{array}$ \\
\hline 67 & 34 & Malaysia & Watermelon (Citrulius vulgaris—red variety) & 55 & 3 & 893 & 50 & $\begin{array}{l}10 \text { Healthy } \\
\text { participants }\end{array}$ & Glucose/2 h \\
\hline
\end{tabular}


Table 1 continued

\begin{tabular}{|c|c|c|c|c|c|c|c|c|c|}
\hline & \multirow[t]{2}{*}{ Reference } & \multirow[t]{2}{*}{ Country } & \multirow[t]{2}{*}{ Food item } & \multicolumn{2}{|c|}{ Gl (glucose $=100)$} & \multirow{2}{*}{$\begin{array}{l}\text { Serving size }(g) \text { per experimental } \\
\text { portion size }\end{array}$} & \multirow{2}{*}{$\begin{array}{l}\text { Available } \mathrm{CHO} \\
\text { (g) per } \\
\text { experimental } \\
\text { portion }\end{array}$} & \multirow{2}{*}{$\begin{array}{l}\text { Participants } \\
\text { (type and } \\
\text { number) }\end{array}$} & \multirow{2}{*}{$\begin{array}{l}\text { Reference } \\
\text { food and } \\
\text { time period }\end{array}$} \\
\hline & & & & Mean & SEM & & & & \\
\hline 68 & 35 & Malaysia & Brown rice & 51 & 8 & NA & 50 & $\begin{array}{l}10 \text { Healthy } \\
\text { participants }\end{array}$ & Glucose $/ 2 \mathrm{~h}$ \\
\hline 69 & 35 & Malaysia & Polished brown rice & 86 & 14 & NA & 50 & $\begin{array}{l}10 \text { Healthy } \\
\text { participants }\end{array}$ & Glucose $/ 2 \mathrm{~h}$ \\
\hline 70 & 35 & Malaysia & White rice & 79 & 14 & NA & 50 & $\begin{array}{l}10 \text { Healthy } \\
\text { participants }\end{array}$ & Glucose $/ 2 \mathrm{~h}$ \\
\hline 71 & 36 & Malaysia & Rice & 48 & 6 & 32 & 25 & $\begin{array}{l}10 \text { T2DM } \\
\text { participants }\end{array}$ & Glucose $/ 2 \mathrm{~h}$ \\
\hline 72 & 36 & Malaysia & Lacy panckaes & 49 & 6 & 35 & 25 & $\begin{array}{l}10 \mathrm{~T} 2 \mathrm{DM} \\
\text { participants }\end{array}$ & Glucose $/ 2 \mathrm{~h}$ \\
\hline 73 & 36 & Malaysia & Flatbread & 71 & 2 & 54 & 25 & $\begin{array}{l}10 \mathrm{~T} 2 \mathrm{DM} \\
\text { participants }\end{array}$ & Glucose $/ 2 \mathrm{~h}$ \\
\hline 74 & 36 & Malaysia & Noodles & 60 & 6 & 67 & 25 & $\begin{array}{l}10 \mathrm{~T} 2 \mathrm{DM} \\
\text { participants }\end{array}$ & Glucose $/ 2 \mathrm{~h}$ \\
\hline 75 & 36 & Malaysia & Coconut milk rice & 49 & 7 & NA & 33 & $\begin{array}{l}10 \mathrm{~T} 2 \mathrm{DM} \\
\text { participants }\end{array}$ & Glucose $/ 2 \mathrm{~h}$ \\
\hline 76 & 36 & Malaysia & Lacy pancake with chicken curry & 81 & 10 & NA & 32 & $\begin{array}{l}10 \text { T2DM } \\
\text { participants }\end{array}$ & Glucose $/ 2 \mathrm{~h}$ \\
\hline 77 & 36 & Malaysia & Flatbread with dhal curry & 69 & 7 & NA & 33 & $\begin{array}{l}10 \mathrm{~T} 2 \mathrm{DM} \\
\text { participants }\end{array}$ & Glucose/2 h \\
\hline 78 & 36 & Malaysia & Fried noodles with chicken and prawns & 55 & 8 & NA & 28 & $\begin{array}{l}10 \mathrm{~T} 2 \mathrm{DM} \\
\text { participants }\end{array}$ & Glucose $/ 2 \mathrm{~h}$ \\
\hline 79 & 37 & Malaysia & Chiffon cake & 60 & 6 & $\sim 122$ & 25 & $\begin{array}{l}11 \text { Healthy } \\
\text { participants }\end{array}$ & Glucose $/ 2 \mathrm{~h}$ \\
\hline 80 & 37 & Malaysia & $\begin{array}{l}\text { Chiffon cake with 10\% wheat flour replaced by } \\
\text { young corn ear }\end{array}$ & 49 & 4 & $\sim 116$ & 25 & $\begin{array}{l}11 \text { Healthy } \\
\text { participants }\end{array}$ & Glucose $/ 2 \mathrm{~h}$ \\
\hline 81 & 38 & Malaysia & Bario celum rice & 60.9 & 7.2 & 50 & 50 & $\begin{array}{l}12 \text { Healthy } \\
\text { participants }\end{array}$ & Glucose $/ 2 \mathrm{~h}$ \\
\hline 82 & 38 & Malaysia & Bario tuan rice & 62.2 & 8.9 & 50 & 50 & $\begin{array}{l}12 \text { Healthy } \\
\text { participants }\end{array}$ & Glucose/2 h \\
\hline 83 & 38 & Malaysia & Adan halus & 72.1 & 9.5 & 50 & 50 & $\begin{array}{l}12 \text { Healthy } \\
\text { participants }\end{array}$ & Glucose $/ 2 \mathrm{~h}$ \\
\hline 84 & 38 & Malaysia & Beras merah (red rice) & 78.3 & 9.9 & 50 & 50 & $\begin{array}{l}12 \text { Healthy } \\
\text { participants }\end{array}$ & Glucose $/ 2 \mathrm{~h}$ \\
\hline 85 & 39 & Malaysia & White rice (5\% broken) & 87.3 & 14.4 & 90.85 & 25 & $\begin{array}{l}11 \text { Healthy } \\
\text { participants }\end{array}$ & Glucose $/ 2 \mathrm{~h}$ \\
\hline 86 & 39 & Malaysia & Fragrant white rice & 124.2 & 16.4 & 102.87 & 25 & $\begin{array}{l}11 \text { Healthy } \\
\text { participants }\end{array}$ & Glucose $/ 2 \mathrm{~h}$ \\
\hline 87 & 40 & Malaysia & Biscuit & 61 & 13 & 37 & 25 & $\begin{array}{l}11 \text { Healthy } \\
\text { participants }\end{array}$ & Glucose $/ 2 \mathrm{~h}$ \\
\hline 88 & 40 & Malaysia & Biscuit with $10 \%$ cornllete powder & 46 & 11 & 39 & 25 & $\begin{array}{l}11 \text { Healthy } \\
\text { participants }\end{array}$ & Glucose $/ 2 \mathrm{~h}$ \\
\hline 89 & 40 & Malaysia & Muffin & 58 & 6 & 49 & 25 & $\begin{array}{l}11 \text { Healthy } \\
\text { participants }\end{array}$ & Glucose $/ 2 \mathrm{~h}$ \\
\hline 90 & 40 & Malaysia & Muffin with $10 \%$ cornllete powder & 57 & 9 & 63 & 25 & $\begin{array}{l}11 \text { Healthy } \\
\text { participants }\end{array}$ & Glucose $/ 2 \mathrm{~h}$ \\
\hline 91 & 41 & Malaysia & Flatbread & 63 & 4 & 71.4 & 50 & $\begin{array}{l}10 \text { Healthy } \\
\text { participants }\end{array}$ & Glucose $/ 2 \mathrm{~h}$ \\
\hline 92 & 41 & Malaysia & Flatbread with $10 \%$ fenugreek & 43 & 5 & 72 & 50 & $\begin{array}{l}10 \text { Healthy } \\
\text { participants }\end{array}$ & Glucose $/ 2 \mathrm{~h}$ \\
\hline 93 & 41 & Malaysia & Bun & 82 & 5 & 74 & 50 & $\begin{array}{l}10 \text { Healthy } \\
\text { participants }\end{array}$ & Glucose $/ 2 \mathrm{~h}$ \\
\hline 94 & 41 & Malaysia & Bun with $10 \%$ fenugreek & 138 & 51 & 91.1 & 50 & $\begin{array}{l}10 \text { Healthy } \\
\text { participants }\end{array}$ & Glucose $/ 2 \mathrm{~h}$ \\
\hline 95 & 42 & Malaysia & Thai red & 55 & 8.6 & 174.2 & 50 & $\begin{array}{l}12 \text { Healthy } \\
\text { participants }\end{array}$ & Glucose $/ 2 \mathrm{~h}$ \\
\hline 96 & 42 & Malaysia & Basmati & 50 & 5.8 & 188.3 & 50 & $\begin{array}{l}12 \text { Healthy } \\
\text { participants }\end{array}$ & Glucose $/ 2 \mathrm{~h}$ \\
\hline 97 & 42 & Malaysia & Jasmine & 78.7 & 11.6 & 180.3 & 50 & $\begin{array}{l}12 \text { Healthy } \\
\text { participants }\end{array}$ & Glucose $/ 2 \mathrm{~h}$ \\
\hline 98 & 43 & Malaysia & $\begin{array}{l}\text { Control biscuits without Pleurotus sajor- } \\
\text { caju powder }\end{array}$ & 57.2 & 4.8 & 76 & 25 & $\begin{array}{l}11 \text { Healthy } \\
\text { participants }\end{array}$ & Glucose $/ 2 \mathrm{~h}$ \\
\hline 99 & 43 & Malaysia & $\begin{array}{l}\text { Biscuits made with } 4 \% \text { Pleurotus sajor- } \\
\text { caju powder }\end{array}$ & 52 & 6.2 & 81 & 25 & $\begin{array}{l}11 \text { Healthy } \\
\text { participants }\end{array}$ & Glucose $/ 2 \mathrm{~h}$ \\
\hline 100 & 43 & Malaysia & $\begin{array}{l}\text { Biscuits made with } 8 \% \text { Pleurotus sajor- } \\
\text { caju powder }\end{array}$ & 49 & 6.5 & 85 & 25 & $\begin{array}{l}11 \text { Healthy } \\
\text { participants }\end{array}$ & Glucose/2 h \\
\hline 101 & 43 & Malaysia & $\begin{array}{l}\text { Biscuits made with } 12 \% \text { Pleurotus sajor- } \\
\text { caju powder }\end{array}$ & 47.4 & 4.4 & 88 & 25 & $\begin{array}{l}11 \text { Healthy } \\
\text { participants }\end{array}$ & Glucose $/ 2 \mathrm{~h}$ \\
\hline
\end{tabular}


Table 1 continued

\begin{tabular}{|c|c|c|c|c|c|c|c|c|c|}
\hline & \multirow[t]{2}{*}{ Reference } & \multirow[t]{2}{*}{ Country } & \multirow[t]{2}{*}{ Food item } & \multicolumn{2}{|c|}{ GI (glucose $=100)$} & \multirow{2}{*}{$\begin{array}{l}\text { Serving size }(g) \text { per experimental } \\
\text { portion size }\end{array}$} & \multirow{2}{*}{$\begin{array}{l}\text { Available CHO } \\
\text { (g) per } \\
\text { experimental } \\
\text { portion }\end{array}$} & \multirow{2}{*}{$\begin{array}{l}\text { Participants } \\
\text { (type and } \\
\text { number) }\end{array}$} & \multirow{2}{*}{$\begin{array}{l}\text { Reference } \\
\text { food and } \\
\text { time perioc }\end{array}$} \\
\hline & & & & Mean & SEM & & & & \\
\hline 102 & 44 & Malaysia & $\begin{array}{l}\text { Fragrant white rice (Super fragrant AAA, } \\
\text { Thailand) }\end{array}$ & 67 & 7 & 77 & 25 & $\begin{array}{l}11 \text { Healthy } \\
\text { participants }\end{array}$ & Glucose $/ 2 \mathrm{~h}$ \\
\hline 103 & 44 & Malaysia & Red rice (Jasmine Nutri Rice, Thailand) & 68 & 8 & 84 & 25 & $\begin{array}{l}11 \text { Healthy } \\
\text { participants }\end{array}$ & Glucose $/ 2 \mathrm{~h}$ \\
\hline 104 & 44 & Malaysia & Parboiled rice (Faiza Basmati, Malaysia & 61 & 8 & 110 & 25 & $\begin{array}{l}11 \text { Healthy } \\
\text { participants }\end{array}$ & Glucose $/ 2 \mathrm{~h}$ \\
\hline 105 & 44 & Malaysia & $\begin{array}{l}\text { Fried fragrant white rice (Super fragrant AAA, } \\
\text { Thailand), }\end{array}$ & 50 & 7 & 129 & 25 & $\begin{array}{l}11 \text { Healthy } \\
\text { participants }\end{array}$ & Glucose $/ 2 \mathrm{~h}$ \\
\hline 106 & 44 & Malaysia & Fried red rice (Jasmine Nutri Rice, Thailand) & 41 & 4 & 139 & 25 & $\begin{array}{l}11 \text { Healthy } \\
\text { participants }\end{array}$ & Glucose $/ 2 \mathrm{~h}$ \\
\hline 107 & 44 & Malaysia & Fried parboiled rice (Faiza Basmati, Malaysia & 41 & 4 & 157 & 25 & $\begin{array}{l}11 \text { Healthy } \\
\text { participants }\end{array}$ & Glucose $/ 2 \mathrm{~h}$ \\
\hline 108 & 45 & Malaysia & Red-fleshed seedless watermelon & 51 & 2 & 236 & 25 & $\begin{array}{l}14 \text { Healthy } \\
\text { participants }\end{array}$ & Glucose $/ 2 \mathrm{~h}$ \\
\hline 109 & 45 & Malaysia & Red-fleshed seeded watermelon & 48 & 1 & 239 & 25 & $\begin{array}{l}14 \text { Healthy } \\
\text { participants }\end{array}$ & Glucose $/ 2 \mathrm{~h}$ \\
\hline 110 & 45 & Malaysia & Yellow-fleshed watermelon & 47 & 2 & 233 & 25 & $\begin{array}{l}14 \text { Healthy } \\
\text { participants }\end{array}$ & Glucose $/ 2 \mathrm{~h}$ \\
\hline 111 & 45 & Malaysia & Red-fleshed seedless watermelon juice & 51 & 1 & 236 & 25 & $\begin{array}{l}14 \text { Healthy } \\
\text { participants }\end{array}$ & Glucose $/ 2 \mathrm{~h}$ \\
\hline 112 & 46 & Malaysia & Fried mihun—Terengganu & 45.40 & 7.43 & 149 & 50 & $\begin{array}{l}10 \text { Healthy } \\
\text { participants }\end{array}$ & Glucose $/ 2 \mathrm{~h}$ \\
\hline 113 & 46 & Malaysia & Fried kuay teow-Terengganu & 79.50 & 9.34 & 178 & 50 & $\begin{array}{l}10 \text { Healthy } \\
\text { participants }\end{array}$ & Glucose $/ 2 \mathrm{~h}$ \\
\hline 114 & 46 & Malaysia & Kuih (apam ayu) & 90.56 & 12.0 & 106.2 & 50 & $\begin{array}{l}10 \text { Healthy } \\
\text { participants }\end{array}$ & Glucose $/ 2 \mathrm{~h}$ \\
\hline 115 & 46 & Malaysia & $\begin{array}{l}\text { Fish snacks (boiled keropok lekor) + chilli sauce } \\
(23 \mathrm{~g})\end{array}$ & 79 & 9.5 & 129 & 50 & $\begin{array}{l}10 \text { Healthy } \\
\text { participants }\end{array}$ & Glucose $/ 2 \mathrm{~h}$ \\
\hline 116 & 47 & Malaysia & Coconut sap sugar & 42 & 4 & 27.7 & 25 & $\begin{array}{l}10 \text { Healthy } \\
\text { participants }\end{array}$ & Glucose $/ 2 \mathrm{~h}$ \\
\hline 117 & 47 & Malaysia & Coconut sap syrup & 39 & 4 & 32 & 25 & $\begin{array}{l}10 \text { Healthy } \\
\text { participants }\end{array}$ & Glucose $/ 2 \mathrm{~h}$ \\
\hline 118 & 47 & Malaysia & Kaong sugar & 43 & 3 & 26.4 & 25 & $\begin{array}{l}10 \text { Healthy } \\
\text { participants }\end{array}$ & Glucose $/ 2 \mathrm{~h}$ \\
\hline 119 & 47 & Malaysia & Sorghum sugar & 60 & 3 & 27.2 & 25 & $\begin{array}{l}10 \text { Healthy } \\
\text { participants }\end{array}$ & Glucose $/ 2 \mathrm{~h}$ \\
\hline 120 & 47 & Malaysia & Buri sugar & 57 & 3 & 29.3 & 25 & $\begin{array}{l}10 \text { Healthy } \\
\text { participants }\end{array}$ & Glucose $/ 2 \mathrm{~h}$ \\
\hline 121 & 47 & Malaysia & Nipa sugar & 58 & 2 & 28.8 & 25 & $\begin{array}{l}10 \text { Healthy } \\
\text { participants }\end{array}$ & Glucose $/ 2 \mathrm{~h}$ \\
\hline 122 & 47 & Malaysia & Sugarcane granules & 68 & 3 & 25.2 & 25 & $\begin{array}{l}10 \text { Healthy } \\
\text { participants }\end{array}$ & Glucose $/ 2 \mathrm{~h}$ \\
\hline 123 & 47 & Malaysia & Muscovado sugar & 69 & 3 & 26.3 & 25 & $\begin{array}{l}10 \text { Healthy } \\
\text { participants }\end{array}$ & Glucose $/ 2 \mathrm{~h}$ \\
\hline 124 & 48 & Malaysia & Biscuit with durian $(\sim 19 \% \mathrm{w} / \mathrm{w})$ & 63.8 & NA & 6.0 & 50 & $\begin{array}{l}10 \text { Healthy } \\
\text { participants }\end{array}$ & Glucose $/ 2 \mathrm{~h}$ \\
\hline 125 & 48 & Malaysia & Biscuit with oats $(\sim 9 \% \mathrm{w} / \mathrm{w})$ & 71.8 & NA & 5.5 & 50 & $\begin{array}{l}10 \text { Healthy } \\
\text { participants }\end{array}$ & Glucose $/ 2 \mathrm{~h}$ \\
\hline 126 & 48 & Malaysia & $\begin{array}{l}\text { Biscuit with durian }(\sim 17 \% \mathrm{w} / \mathrm{w}) \text { and oats } \\
(\sim 8 \% \mathrm{w} / \mathrm{w})\end{array}$ & 59.4 & NA & 6.0 & 50 & $\begin{array}{l}10 \text { Healthy } \\
\text { participants }\end{array}$ & Glucose $/ 2 \mathrm{~h}$ \\
\hline 127 & 49 & Malaysia & $\begin{array}{l}\text { Beta-glucan drink (oat beta-1,3/1,4 glucan, } \\
\text { Zhuhai City, China) with } 80 \% \text { purity }\end{array}$ & 117 & 98 & $250 \mathrm{ml}$ & 50 & $\begin{array}{l}10 \text { Healthy } \\
\text { participants }\end{array}$ & Glucose $/ 2 \mathrm{~h}$ \\
\hline 128 & 49 & Malaysia & $\begin{array}{l}\text { Whey protein drink (Mesotropin Platinum } \\
\text { Hydro Whey, Terengganu, Malaysia) }\end{array}$ & 124 & 98 & $250 \mathrm{ml}$ & 50 & $\begin{array}{l}10 \text { Healthy } \\
\text { participants }\end{array}$ & Glucose $/ 2 \mathrm{~h}$ \\
\hline 129 & 49 & Malaysia & $\begin{array}{l}\text { Whey protein beta-glucan drink ( } 4 \mathrm{~g} \text { of beta- } \\
\text { glucan per and } 5 \mathrm{~g} \text { whey protein per } 250 \mathrm{ml} \text { ) }\end{array}$ & 114 & 97 & $250 \mathrm{ml}$ & 50 & $\begin{array}{l}10 \text { Healthy } \\
\text { participants }\end{array}$ & Glucose $/ 2 \mathrm{~h}$ \\
\hline 130 & 50 & Thailand & Thailand Chiang brown rice_-pressure cooked & 58 & 8 & 92.2 & 25 & $\begin{array}{l}10 \text { Healthy } \\
\text { participants }\end{array}$ & Glucose $/ 2 \mathrm{~h}$ \\
\hline 131 & 50 & Thailand & $\begin{array}{l}\text { Thailand Sungyod brown rice- } \\
\text { pressure cooked }\end{array}$ & 81 & 9 & 91.3 & 25 & $\begin{array}{l}10 \text { Healthy } \\
\text { participants }\end{array}$ & Glucose $/ 2 \mathrm{~h}$ \\
\hline 132 & 50 & Thailand & Thailand Lepnok brown rice_-pressure cooked & 59 & 6 & 90.5 & 25 & $\begin{array}{l}10 \text { Healthy } \\
\text { participants }\end{array}$ & Glucose $/ 2 \mathrm{~h}$ \\
\hline 133 & 50 & Thailand & $\begin{array}{l}\text { Malaysian Long grain specialty brown rice-1 } \\
\text { (LS1)_-pressure cooked }\end{array}$ & 73 & 11 & 86.9 & 25 & $\begin{array}{l}10 \text { Healthy } \\
\text { participants }\end{array}$ & Glucose $/ 2 \mathrm{~h}$ \\
\hline 134 & 50 & Thailand & $\begin{array}{l}\text { Malaysian Long grain specialty brown rice-2 } \\
\text { (LS2) _ pressure cooked }\end{array}$ & 65 & 6 & 87.9 & 25 & $\begin{array}{l}10 \text { Healthy } \\
\text { participants }\end{array}$ & Glucose $/ 2 \mathrm{~h}$ \\
\hline 135 & 50 & Thailand & $\begin{array}{l}\text { Thailand Chiang brown rice-cooked in } \\
\text { rice cooker }\end{array}$ & 65 & 7 & 89.8 & 25 & $\begin{array}{l}10 \text { Healthy } \\
\text { participants }\end{array}$ & Glucose $/ 2 \mathrm{~h}$ \\
\hline
\end{tabular}


Table 1 continued

\begin{tabular}{|c|c|c|c|c|c|c|c|c|c|}
\hline & \multirow[t]{2}{*}{ Reference } & \multirow[t]{2}{*}{ Country } & \multirow[t]{2}{*}{ Food item } & \multicolumn{2}{|c|}{ Gl (glucose $=100)$} & \multirow{2}{*}{$\begin{array}{l}\text { Serving size }(g) \text { per experimental } \\
\text { portion size }\end{array}$} & \multirow{2}{*}{$\begin{array}{l}\text { Available } \mathrm{CHO} \\
\text { (g) per } \\
\text { experimental } \\
\text { portion }\end{array}$} & \multirow{2}{*}{$\begin{array}{l}\text { Participants } \\
\text { (type and } \\
\text { number) }\end{array}$} & \multirow{2}{*}{$\begin{array}{l}\text { Reference } \\
\text { food and } \\
\text { time period }\end{array}$} \\
\hline & & & & Mean & SEM & & & & \\
\hline 136 & 50 & Thailand & $\begin{array}{l}\text { Thailand Sungyod brown rice-cooked in } \\
\text { rice cooker }\end{array}$ & 72 & 10 & 90.5 & 25 & $\begin{array}{l}10 \text { Healthy } \\
\text { participants }\end{array}$ & Glucose $/ 2 \mathrm{~h}$ \\
\hline 137 & 50 & Thailand & $\begin{array}{l}\text { Thailand Lepnok brown rice-cooked in } \\
\text { rice cooker }\end{array}$ & 62 & 10 & 89.4 & 25 & $\begin{array}{l}10 \text { Healthy } \\
\text { participants }\end{array}$ & Glucose $/ 2 \mathrm{~h}$ \\
\hline 138 & 50 & Thailand & $\begin{array}{l}\text { Malaysian Long grain specialty brown rice-1 } \\
\text { (LS1)—cooked in rice cooker }\end{array}$ & 64 & 6 & 88.0 & 25 & $\begin{array}{l}10 \text { Healthy } \\
\text { participants }\end{array}$ & Glucose $/ 2 \mathrm{~h}$ \\
\hline 139 & 50 & Thailand & $\begin{array}{l}\text { Malaysian Long grain specialty brown rice-2 } \\
\text { (LS2)—cooked in rice cooker }\end{array}$ & 72 & 7 & 85.9 & 25 & $\begin{array}{l}10 \text { Healthy } \\
\text { participants }\end{array}$ & Glucose $/ 2 \mathrm{~h}$ \\
\hline 140 & 51 & Thailand & $\begin{array}{l}\text { Big rice noodles from mixed sago palm flour } \\
\text { (Metroxylon spp.) and Chiang rice flour }\end{array}$ & 63.1 & 9.8 & 176 (fresh wet basis) & 50 & $\begin{array}{l}12 \text { Healthy } \\
\text { participants }\end{array}$ & Glucose $/ 2 \mathrm{~h}$ \\
\hline 141 & 51 & Thailand & $\begin{array}{l}\text { Small rice noodles from mixed sago palm flour } \\
\text { (Metroxylon spp.) and Chiang rice flour } 60 ; 40\end{array}$ & 53.6 & 8.3 & $61 \mathrm{~g}$ (fresh wet basis) & 50 & $\begin{array}{l}12 \text { Healthy } \\
\text { participants }\end{array}$ & Glucose $/ 2 \mathrm{~h}$ \\
\hline 142 & 52 & Thailand & Wheat bread & 77.8 & 4.6 & 128.1 & 50 & $\begin{array}{l}16 \text { Healthy } \\
\text { participants }\end{array}$ & Glucose $/ 2 \mathrm{~h}$ \\
\hline 143 & 52 & Thailand & Riceberry rice bread & 69.3 & 4.4 & 128.2 & 50 & $\begin{array}{l}16 \text { Healthy } \\
\text { participants }\end{array}$ & Glucose $/ 2 \mathrm{~h}$ \\
\hline 144 & 52 & Thailand & Hom mali bread & 130.6 & 7.9 & 115.7 & 50 & $\begin{array}{l}16 \text { Healthy } \\
\text { participants }\end{array}$ & Glucose $/ 2 \mathrm{~h}$ \\
\hline 145 & 53 & Thailand & Parboiled brown rice (Leuang Awn) & 50.10 & 5.37 & 167 & 50 & $\begin{array}{l}12 \text { Healthy } \\
\text { participants }\end{array}$ & Glucose $/ 2 \mathrm{~h}$ \\
\hline 146 & 53 & Thailand & $\begin{array}{l}\text { Germinated parboiled brown rice } \\
\text { (Leuang Awn) }\end{array}$ & 60.58 & 6.48 & 176 & 50 & $\begin{array}{l}12 \text { Healthy } \\
\text { participants }\end{array}$ & Glucose $/ 2 \mathrm{~h}$ \\
\hline 147 & 53 & Thailand & Brown rice (Leuang Awn) & 66.21 & 7.78 & 176 & 50 & $\begin{array}{l}12 \text { Healthy } \\
\text { participants }\end{array}$ & Glucose $/ 2 \mathrm{~h}$ \\
\hline 148 & 53 & Thailand & Polished rice (Leuang Awn) & 83.10 & 5.10 & 187 & 50 & $\begin{array}{l}12 \text { Healthy } \\
\text { participants }\end{array}$ & Glucose $/ 2 \mathrm{~h}$ \\
\hline 149 & 54 & Indonesia & Steamed white rice & 80 & NA & NA & 50 & $\begin{array}{l}11 \text { Healthy } \\
\text { participants }\end{array}$ & $\begin{array}{l}\text { White bread/ } \\
2 \mathrm{~h}\end{array}$ \\
\hline 150 & 54 & Indonesia & Sukun (Artocarpus communis Forst) & 90 & NA & NA & 50 & $\begin{array}{l}11 \text { Healthy } \\
\text { participants }\end{array}$ & $\begin{array}{l}\text { White bread/ } \\
2 \mathrm{~h}\end{array}$ \\
\hline 151 & 54 & Indonesia & $\begin{array}{l}\text { Banana (Musa paradisiaca fa. Typical), } \\
\text { Pisang kepok }\end{array}$ & 92 & NA & NA & 50 & $\begin{array}{l}11 \text { Healthy } \\
\text { participants }\end{array}$ & $\begin{array}{l}\text { White bread/ } \\
2 \mathrm{~h}\end{array}$ \\
\hline 152 & 54 & Indonesia & Cassava & 78 & NA & NA & 50 & $\begin{array}{l}11 \text { Healthy } \\
\text { participants }\end{array}$ & $\begin{array}{l}\text { White bread/ } \\
2 \mathrm{~h}\end{array}$ \\
\hline 153 & 54 & Indonesia & Ubi/uwi (Dioscorea alata Linn.) & 73 & NA & NA & 50 & $\begin{array}{l}11 \text { Healthy } \\
\text { participants }\end{array}$ & $\begin{array}{l}\text { White bread/ } \\
2 \mathrm{~h}\end{array}$ \\
\hline 154 & 54 & Indonesia & Sorghum & 160 & NA & NA & 50 & $\begin{array}{l}11 \text { Healthy } \\
\text { participants }\end{array}$ & $\begin{array}{l}\text { White bread/ } \\
2 \mathrm{~h}\end{array}$ \\
\hline 155 & 55 & Indonesia & Taro (Xanthosorna violaceum Schott) & 95 & NA & 128 & 50 & $\begin{array}{l}10 \text { Healthy } \\
\text { participants }\end{array}$ & $\begin{array}{l}\text { White bread/ } \\
2 \mathrm{~h}\end{array}$ \\
\hline 156 & 55 & Indonesia & Yam (Dioscorea aculeata Linn.) & 90 & NA & 186 & 50 & $\begin{array}{l}10 \text { Healthy } \\
\text { participants }\end{array}$ & $\begin{array}{l}\text { White bread/ } \\
2 \mathrm{~h}\end{array}$ \\
\hline 157 & 55 & Indonesia & Edible canna (Canna edulis Ker) & 105 & NA & 224 & 50 & $\begin{array}{l}10 \text { Healthy } \\
\text { participants }\end{array}$ & $\begin{array}{l}\text { White bread/ } \\
2 \mathrm{~h}\end{array}$ \\
\hline 158 & 55 & Indonesia & Arrowroot (Maranta arundinacea Linn. & 14 & NA & 300 & 25 & $\begin{array}{l}10 \text { Healthy } \\
\text { participants }\end{array}$ & $\begin{array}{l}\text { White bread/ } \\
2 \mathrm{~h}\end{array}$ \\
\hline 159 & 55 & Indonesia & Sweet potato (Ipomoea balatas Poir) & 179 & NA & 212 & 50 & $\begin{array}{l}10 \text { Healthy } \\
\text { participants }\end{array}$ & $\begin{array}{l}\text { White bread/ } \\
2 \mathrm{~h}\end{array}$ \\
\hline 160 & 56 & Indonesia & Red bean (Vigna umbellata) & 26 & NA & 84 & 25 & $\begin{array}{l}11 \text { Healthy } \\
\text { participants }\end{array}$ & $\begin{array}{l}\text { White bread/ } \\
2 \mathrm{~h}\end{array}$ \\
\hline 161 & 56 & Indonesia & Mung bean (Phaseolus aureus) & 76 & NA & 95 & 25 & $\begin{array}{l}11 \text { Healthy } \\
\text { participants }\end{array}$ & $\begin{array}{l}\text { White bread/ } \\
2 \mathrm{~h}\end{array}$ \\
\hline 162 & 56 & Indonesia & Cowpea (Vigna sinensis Endl.) & 35 & NA & 130 & 25 & $\begin{array}{l}11 \text { Healthy } \\
\text { participants }\end{array}$ & $\begin{array}{l}\text { White bread/ } \\
2 \mathrm{~h}\end{array}$ \\
\hline 163 & 56 & Indonesia & Pigeon pea (Cajanus cajan Millspaugh) & 51 & NA & 106 & 25 & $\begin{array}{l}11 \text { Healthy } \\
\text { participants }\end{array}$ & $\begin{array}{l}\text { White bread/ } \\
2 \mathrm{~h}\end{array}$ \\
\hline 164 & 56 & Indonesia & Edible podded peas (Pisum sativum Linn.) & 30 & NA & 178 & 25 & $\begin{array}{l}11 \text { Healthy } \\
\text { participants }\end{array}$ & $\begin{array}{l}\text { White bread/ } \\
2 \mathrm{~h}\end{array}$ \\
\hline 165 & 56 & Indonesia & Soybean (Glycine max Merr.) & 31 & NA & 138 & 25 & $\begin{array}{l}11 \text { Healthy } \\
\text { participants }\end{array}$ & $\begin{array}{l}\text { White bread/ } \\
2 \mathrm{~h}\end{array}$ \\
\hline 166 & 57 & Indonesia & Kacang panjang/snap bean (Phaseolus vulgaris) & 86 & NA & 146.39 & 25 & $\begin{array}{l}10 \text { Healthy } \\
\text { participants }\end{array}$ & $\begin{array}{l}\text { White bread/ } \\
2 \mathrm{~h}\end{array}$ \\
\hline 167 & 57 & Indonesia & Buncis/yardlong Bean (Vigna sesquipedalis) & 43 & NA & 105.28 & 25 & $\begin{array}{l}10 \text { Healthy } \\
\text { participants }\end{array}$ & $\begin{array}{l}\text { White bread/ } \\
2 \mathrm{~h}\end{array}$ \\
\hline 168 & 58 & Indonesia & Arrowroot oyek & 41 & NA & 65.95 & 50 & $\begin{array}{l}10 \text { Healthy } \\
\text { participants }\end{array}$ & Glucose $/ 2 \mathrm{~h}$ \\
\hline
\end{tabular}


Table 1 continued

\begin{tabular}{|c|c|c|c|c|c|c|c|c|c|}
\hline & \multirow[t]{2}{*}{ Reference } & \multirow[t]{2}{*}{ Country } & \multirow[t]{2}{*}{ Food item } & \multicolumn{2}{|c|}{ GI (glucose $=100)$} & \multirow{2}{*}{$\begin{array}{l}\text { Serving size }(g) \text { per experimental } \\
\text { portion size }\end{array}$} & \multirow{2}{*}{$\begin{array}{l}\text { Available } \mathrm{CHO} \\
\text { (g) per } \\
\text { experimental } \\
\text { portion }\end{array}$} & \multirow{2}{*}{$\begin{array}{l}\text { Participants } \\
\text { (type and } \\
\text { number) }\end{array}$} & \multirow{2}{*}{$\begin{array}{l}\text { Reference } \\
\text { food and } \\
\text { time period }\end{array}$} \\
\hline & & & & Mean & SEM & & & & \\
\hline 169 & 58 & Indonesia & Suweg oyek & 42 & NA & 64.61 & 50 & $\begin{array}{l}10 \text { Healthy } \\
\text { participants }\end{array}$ & Glucose/2 h \\
\hline 170 & 58 & Indonesia & Cassava oyek & 30 & NA & 61.71 & 50 & $\begin{array}{l}10 \text { Healthy } \\
\text { participants }\end{array}$ & Glucose $/ 2 \mathrm{~h}$ \\
\hline 171 & 58 & Indonesia & Arrowroot tiwul (Garut) & 40 & NA & 68.58 & 50 & $\begin{array}{l}10 \text { Healthy } \\
\text { participants }\end{array}$ & Glucose $/ 2 \mathrm{~h}$ \\
\hline 172 & 58 & Indonesia & Suweg tiwul & 40 & NA & 67.72 & 50 & $\begin{array}{l}10 \text { Healthy } \\
\text { participants }\end{array}$ & Glucose/2 h \\
\hline 173 & 58 & Indonesia & Cassava tiwul (Singkong) & 29 & NA & 60.46 & 50 & $\begin{array}{l}10 \text { Healthy } \\
\text { participants }\end{array}$ & Glucose/2 h \\
\hline 174 & 59 & Indonesia & Standard cookies & 67 & NA & 73 & 50 & $\begin{array}{l}10 \text { Healthy } \\
\text { participants }\end{array}$ & Glucose $/ 2 \mathrm{~h}$ \\
\hline 175 & 59 & Indonesia & Cookies with rice bran & 31 & NA & 87 & 50 & $\begin{array}{l}10 \text { Healthy } \\
\text { participants }\end{array}$ & Glucose/2 h \\
\hline 176 & 59 & Indonesia & Standard donut & 72 & NA & 120 & 50 & $\begin{array}{l}10 \text { Healthy } \\
\text { participants }\end{array}$ & Glucose/2 h \\
\hline 177 & 59 & Indonesia & Donut made with rice bran & 39 & NA & 119 & 50 & $\begin{array}{l}10 \text { Healthy } \\
\text { participants }\end{array}$ & Glucose $/ 2 \mathrm{~h}$ \\
\hline 178 & 60 & Indonesia & Brown rice & 97.28 & NA & 123 & 50 & $\begin{array}{l}21 \text { Healthy } \\
\text { participants }\end{array}$ & $\begin{array}{l}\text { White bread/ } \\
2 \mathrm{~h}\end{array}$ \\
\hline 179 & 60 & Indonesia & White rice (IR 64) & 99.26 & NA & 113 & 50 & $\begin{array}{l}21 \text { Healthy } \\
\text { participants }\end{array}$ & $\begin{array}{l}\text { White bread/ } \\
2 \mathrm{~h}\end{array}$ \\
\hline 180 & 61 & Indonesia & $\begin{array}{l}\text { Bread made from } 400 \mathrm{~g} \text { flour containing } 50 \% \\
\mathrm{w} / \mathrm{w} \text { annealed purple yam flour }\end{array}$ & 93.19 & NA & 95 & 50 & $\begin{array}{l}10 \text { Healthy } \\
\text { participants }\end{array}$ & $\begin{array}{l}\text { White bread/ } \\
2 \mathrm{~h}\end{array}$ \\
\hline 181 & 62 & Indonesia & Boiled GEMBILI (Dioscorea esculenta) & 85.56 & NA & 114.7 & 25 & $\begin{array}{l}10 \text { Healthy } \\
\text { participants }\end{array}$ & Glucose/2 h \\
\hline 182 & 62 & Indonesia & Steamed GEMBILI (Dioscorea esculenta) & 87.56 & NA & 86.2 & 25 & $\begin{array}{l}10 \text { Healthy } \\
\text { participants }\end{array}$ & Glucose $/ 2 \mathrm{~h}$ \\
\hline 183 & 62 & Indonesia & Fried GEMBILI (Dioscorea esculenta) & 83.61 & NA & 76.2 & 25 & $\begin{array}{l}10 \text { Healthy } \\
\text { participants }\end{array}$ & Glucose/2 h \\
\hline 184 & 63 & Indonesia & Snack bar-red sweet potato & 23.56 & NA & 90.91 & 50 & $\begin{array}{l}10 \text { Healthy } \\
\text { participants }\end{array}$ & Glucose $/ 2 \mathrm{~h}$ \\
\hline 185 & 63 & Indonesia & Snack bar-yellow sweet potato & 41.08 & NA & 78.12 & 50 & $\begin{array}{l}10 \text { Healthy } \\
\text { participants }\end{array}$ & Glucose $/ 2 \mathrm{~h}$ \\
\hline 186 & 63 & Indonesia & Snack bar-purple sweet potato & 21.54 & NA & 86.21 & 50 & $\begin{array}{l}10 \text { Healthy } \\
\text { participants }\end{array}$ & Glucose $/ 2 \mathrm{~h}$ \\
\hline 187 & 64 & Indonesia & Wheat flour noodles & 69.49 & 1.37 & NA & 50 & $\begin{array}{l}10 \text { Healthy } \\
\text { participants }\end{array}$ & Glucose $/ 2 \mathrm{~h}$ \\
\hline 188 & 64 & Indonesia & $\begin{array}{l}\text { Wheat flour noodle with } 20 \% \text { of wheat flour } \\
\text { replaced with whole-wheat flour (dewata } \\
\text { variety) }\end{array}$ & 66.23 & 6.14 & NA & 50 & $\begin{array}{l}10 \text { Healthy } \\
\text { participants }\end{array}$ & Glucose $/ 2 \mathrm{~h}$ \\
\hline 189 & 64 & Indonesia & $\begin{array}{l}\text { Wheat flour cookies (with 0\% whole- } \\
\text { wheat flour) }\end{array}$ & 52.11 & 2.07 & NA & 50 & $\begin{array}{l}10 \text { Healthy } \\
\text { participants }\end{array}$ & Glucose $/ 2 \mathrm{~h}$ \\
\hline 190 & 64 & Indonesia & $\begin{array}{l}\text { Wheat flour cookies with } 20 \% \text { of wheat flour } \\
\text { replaced with whole-wheat flour (dewata } \\
\text { variety) }\end{array}$ & 49.94 & 1.90 & NA & 50 & $\begin{array}{l}10 \text { Healthy } \\
\text { participants }\end{array}$ & Glucose $/ 2 \mathrm{~h}$ \\
\hline 191 & 65 & Indonesia & $\begin{array}{l}\text { Standard wheat biscuit (with agar-agar and } \\
\text { Diabetasol sweetener) }\end{array}$ & 52.11 & NA & NA & NA & $\begin{array}{l}10 \text { Healthy } \\
\text { participants }\end{array}$ & Glucose $/ 2 \mathrm{~h}$ \\
\hline 192 & 65 & Indonesia & $\begin{array}{l}\text { Wheat biscuit substituted with } 20 \% \text { whole- } \\
\text { wheat flour }\end{array}$ & 49.94 & NA & NA & NA & $\begin{array}{l}10 \text { Healthy } \\
\text { participants }\end{array}$ & Glucose $/ 2 \mathrm{~h}$ \\
\hline 193 & 66 & Indonesia & Analogue rice ( $80 \%$ mocaf: $20 \%$ corn flour) & 46.06 & 4.95 & 77.34 & 50 & $\begin{array}{l}10 \text { Healthy } \\
\text { participants }\end{array}$ & $\begin{array}{l}\text { White bread/ } \\
2 \mathrm{~h}\end{array}$ \\
\hline 194 & 66 & Indonesia & $\begin{array}{l}\text { Analogue rice ( } 80 \% \text { mocaf:20\% sweet } \\
\text { potato flour) }\end{array}$ & 44.01 & 3.79 & 70.58 & 50 & $\begin{array}{l}10 \text { Healthy } \\
\text { participants }\end{array}$ & $\begin{array}{l}\text { White bread/ } \\
2 \mathrm{~h}\end{array}$ \\
\hline 195 & 66 & Indonesia & Analogue rice ( $80 \%$ mocaf:20\% carrot) & 42.03 & 5.59 & 85.35 & 50 & $\begin{array}{l}10 \text { Healthy } \\
\text { participants }\end{array}$ & $\begin{array}{l}\text { White bread/ } \\
2 \mathrm{~h}\end{array}$ \\
\hline 196 & 67 & Indonesia & Arrowroot snack bar with 30\% kidney beans & 25 & NA & 42 & 50 & $\begin{array}{l}10 \text { Healthy } \\
\text { participants }\end{array}$ & Glucose $/ 2 \mathrm{~h}$ \\
\hline 197 & 68 & Indonesia & $\begin{array}{l}\text { Optimum rice analogue formulation made } \\
\text { from corn, sago, soybean and rice brans }\end{array}$ & 54 & NA & NA & 50 & $\begin{array}{l}10 \text { Healthy } \\
\text { participants }\end{array}$ & Glucose $/ 2 \mathrm{~h}$ \\
\hline 198 & 69 & Indonesia & $\begin{array}{l}\text { Gayam seed (Inocarfus fagifer Forst. Gayam } \\
\text { flour without pre-gelatinisation }\end{array}$ & 74 & NA & 90.40 & 50 & $\begin{array}{l}10 \text { Healthy } \\
\text { participants }\end{array}$ & Glucose $/ 2 \mathrm{~h}$ \\
\hline 199 & 69 & Indonesia & Pre-geletinised Gayam flour boiled for $15 \mathrm{~min}$ & 75 & NA & 79.91 & 50 & $\begin{array}{l}10 \text { Healthy } \\
\text { participants }\end{array}$ & Glucose $/ 2 \mathrm{~h}$ \\
\hline 200 & 69 & Indonesia & Pre-geletinised Gayam flour boiled for $30 \mathrm{~min}$ & 61 & NA & 81.71 & 50 & $\begin{array}{l}10 \text { Healthy } \\
\text { participants }\end{array}$ & Glucose $/ 2 \mathrm{~h}$ \\
\hline 201 & 69 & Indonesia & Pre-geletinised Gayam flour boiled for $45 \mathrm{~min}$ & 57 & NA & 84.43 & 50 & $\begin{array}{l}10 \text { Healthy } \\
\text { participants }\end{array}$ & Glucose $/ 2 \mathrm{~h}$ \\
\hline
\end{tabular}


Table 1 continued

\begin{tabular}{|c|c|c|c|c|c|c|c|c|c|}
\hline & \multirow[t]{2}{*}{ Reference } & \multirow[t]{2}{*}{ Country } & \multirow[t]{2}{*}{ Food item } & \multicolumn{2}{|c|}{ GI (glucose = 100) } & \multirow{2}{*}{$\begin{array}{l}\text { Serving size }(g) \text { per experimental } \\
\text { portion size }\end{array}$} & \multirow{2}{*}{$\begin{array}{l}\text { Available } \mathrm{CHO} \\
\text { (g) per } \\
\text { experimental } \\
\text { portion }\end{array}$} & \multirow{2}{*}{$\begin{array}{l}\text { Participants } \\
\text { (type and } \\
\text { number) }\end{array}$} & \multirow{2}{*}{$\begin{array}{l}\text { Reference } \\
\text { food and } \\
\text { time period }\end{array}$} \\
\hline & & & & Mean & SEM & & & & \\
\hline 202 & 70 & Indonesia & $\begin{array}{l}\text { Corn-based rice analogues with } 20 \% \\
\text { cassava starch }\end{array}$ & 34.79 & $2.11(\mathrm{SD})$ & NA & 50 & $\begin{array}{l}10 \text { Healthy } \\
\text { participants }\end{array}$ & Glucose/2 h \\
\hline 203 & 70 & Indonesia & $\begin{array}{l}\text { Corn-based rice analogues with } 30 \% \\
\text { cassava starch }\end{array}$ & 37.47 & $2.16(S D)$ & NA & 50 & $\begin{array}{l}10 \text { Healthy } \\
\text { participants }\end{array}$ & Glucose $/ 2 \mathrm{~h}$ \\
\hline 204 & 70 & Indonesia & $\begin{array}{l}\text { Corn-based rice analogues with } 40 \% \\
\text { cassava starch }\end{array}$ & 40.77 & $2.12(\mathrm{SD})$ & NA & 50 & $\begin{array}{l}10 \text { Healthy } \\
\text { participants }\end{array}$ & Glucose/2 h \\
\hline 205 & 71 & Indonesia & $\begin{array}{l}\text { Millet and bean cookie bar ( } 15 \% \text { foxtail millet, } \\
15 \% \text { arrowroot flour and } 30 \% \text { of kidney beans) }\end{array}$ & 37.6 & NA & 85 & 25 & $\begin{array}{l}12 \text { Healthy } \\
\text { participants }\end{array}$ & Glucose/2 h \\
\hline 206 & 72 & Indonesia & Arenga (Arenga pinata) starch cake & 77.72 & 9.57 & 53.44 & 50 & $\begin{array}{l}12 \text { Healthy } \\
\text { participants }\end{array}$ & Glucose/2 h \\
\hline 207 & 72 & Indonesia & $\begin{array}{l}\text { Arenga (Arenga pinata) starch cake with } 4 \% \\
\text { guava extract }\end{array}$ & 51.84 & 6.34 & 53.44 & 50 & $\begin{array}{l}12 \text { Healthy } \\
\text { participants }\end{array}$ & Glucose $/ 2 \mathrm{~h}$ \\
\hline 208 & 72 & Indonesia & Arenga (Arenga pinata) starch cookie & 47.31 & 6.22 & 72 & 50 & $\begin{array}{l}12 \text { Healthy } \\
\text { participants }\end{array}$ & Glucose/2 h \\
\hline 209 & 72 & Indonesia & $\begin{array}{l}\text { Arenga (Arenga pinata) starch cookie with } 4 \% \\
\text { guava extract }\end{array}$ & 46.2 & 7.39 & 72 & 50 & $\begin{array}{l}12 \text { Healthy } \\
\text { participants }\end{array}$ & Glucose/2 h \\
\hline 210 & 73 & Indonesia & $\begin{array}{l}\text { Steamed brownies made with wheat and } \\
\text { sweet potato flour (1:1 ratio) }\end{array}$ & 53.76 & NA & 140 & 50 & $\begin{array}{l}10 \text { Healthy } \\
\text { participants }\end{array}$ & $\begin{array}{l}\text { White bread/ } \\
2 \mathrm{~h}\end{array}$ \\
\hline 211 & 74 & Indonesia & $\begin{array}{l}\text { Fried noodle snack made with flour, yellow } \\
\text { sweet potatoes (Ipomoea batatas) and } \\
\text { pumpkin (Cucurbita moschata) flour }\end{array}$ & 30.18 & NA & 35 & 25 & $\begin{array}{l}10 \text { Healthy } \\
\text { participants }\end{array}$ & Glucose/2 h \\
\hline 212 & 75 & Indonesia & Pumpkin flour chips & 51 & NA & 88 & 50 & $\begin{array}{l}10 \text { Healthy } \\
\text { participants }\end{array}$ & Glucose/2 h \\
\hline 213 & 75 & Indonesia & $\begin{array}{l}\text { Pumpkin flour chips with 15\% bran flour } \\
\text { substitution }\end{array}$ & 87 & NA & 88 & 50 & $\begin{array}{l}10 \text { Healthy } \\
\text { participants }\end{array}$ & Glucose/2 h \\
\hline 214 & 76 & Indonesia & SIKKATO (Sinonggi) & 78.42 & NA & 59.32 & 50 & $\begin{array}{l}10 \text { Healthy } \\
\text { participants }\end{array}$ & $\begin{array}{l}\text { White bread/ } \\
2 \mathrm{~h}\end{array}$ \\
\hline 215 & 76 & Indonesia & SIKKATO (Kasuami) & 90.36 & NA & 72.11 & 50 & $\begin{array}{l}10 \text { Healthy } \\
\text { participants }\end{array}$ & $\begin{array}{l}\text { White bread/ } \\
2 \mathrm{~h}\end{array}$ \\
\hline 216 & 76 & Indonesia & SIKKATO (Kambuse) & 72.04 & NA & 71.29 & 50 & $\begin{array}{l}10 \text { Healthy } \\
\text { participants }\end{array}$ & $\begin{array}{l}\text { White bread/ } \\
2 \mathrm{~h}\end{array}$ \\
\hline 217 & 76 & Indonesia & SIKKATO (Kabuto) & 84.54 & NA & 136.84 & 50 & $\begin{array}{l}10 \text { Healthy } \\
\text { participants }\end{array}$ & $\begin{array}{l}\text { White bread/ } \\
2 \mathrm{~h}\end{array}$ \\
\hline 218 & 77 & Indonesia & Pekawai (Durio kutejensis; Durian species) chips & 12 & NA & NA & 50 & $\begin{array}{l}10 \text { Healthy } \\
\text { participants }\end{array}$ & Glucose/2 h \\
\hline 219 & 78 & Indonesia & Coleus tuberosus crackers & 40.88 & 6.42 & NA & 50 & $\begin{array}{l}10 \text { Healthy } \\
\text { participants }\end{array}$ & Glucose/2 h \\
\hline 220 & 78 & Indonesia & Wheat crackers & 78.06 & 5.36 & NA & 50 & $\begin{array}{l}10 \text { Healthy } \\
\text { participants }\end{array}$ & Glucose $/ 2 \mathrm{~h}$ \\
\hline 221 & 79 & Indonesia & $\begin{array}{l}\text { Cookies made with brown rice flour (Oryza } \\
\text { nivara) and winged bean's (Psophocarpus } \\
\text { tetragonolobus L.) seed flour }\end{array}$ & 17.39 & NA & 146 & 50 & $\begin{array}{l}10 \text { Healthy } \\
\text { participants }\end{array}$ & Glucose $/ 2 \mathrm{~h}$ \\
\hline 222 & 79 & Indonesia & Standard cookies & 36.82 & NA & 92 & 50 & $\begin{array}{l}10 \text { Healthy } \\
\text { participants }\end{array}$ & Glucose $/ 2 \mathrm{~h}$ \\
\hline 223 & 80 & Indonesia & $\begin{array}{l}\text { Chromium-fortified parboiled rice (Cr-PR) } \\
\text { coated with cinammon extracts }\end{array}$ & 29 & NA & NA & 50 & $\begin{array}{l}18 \text { Healthy } \\
\text { participants }\end{array}$ & Glucose $/ 2 \mathrm{~h}$ \\
\hline 224 & 81 & Indonesia & $\begin{array}{l}\text { White sweet potato pudding (with agar-agar } \\
\text { and Diabetasol sweetener) }\end{array}$ & 37.75 & NA & 200.24 & 50 & $\begin{array}{l}10 \text { Healthy } \\
\text { participants }\end{array}$ & Glucose $/ 2 \mathrm{~h}$ \\
\hline 225 & 81 & Indonesia & $\begin{array}{l}\text { White sweet potato pudding with addition of } \\
\text { red dragon fruit } 25 \% \text { (with agar-agar and } \\
\text { Diabetasol sweetener) }\end{array}$ & 33.81 & NA & 233.32 & 50 & $\begin{array}{l}10 \text { Healthy } \\
\text { participants }\end{array}$ & Glucose $/ 2 \mathrm{~h}$ \\
\hline 226 & 81 & Indonesia & $\begin{array}{l}\text { White sweet potato pudding with addition of } \\
\text { red dragon fruit } 50 \% \text {, (with agar-agar and } \\
\text { Diabetasol sweetener) }\end{array}$ & 32.81 & NA & 286.20 & 50 & $\begin{array}{l}10 \text { Healthy } \\
\text { participants }\end{array}$ & Glucose $/ 2 \mathrm{~h}$ \\
\hline 227 & 81 & Indonesia & $\begin{array}{l}\text { White sweet potato pudding with addition of } \\
\text { red dragon fruit } 75 \% \text {, }\end{array}$ & 29.54 & NA & 349.90 & 50 & $\begin{array}{l}10 \text { Healthy } \\
\text { participants }\end{array}$ & Glucose $/ 2 \mathrm{~h}$ \\
\hline 228 & 82 & Indonesia & $\begin{array}{l}\text { Mocaf-black rice flakes with black } \\
\text { soybean flour }\end{array}$ & 50.19 & 21.57 & 63.8 & 50 & $\begin{array}{l}10 \text { Healthy } \\
\text { participants }\end{array}$ & Glucose $/ 2 \mathrm{~h}$ \\
\hline 229 & 82 & Indonesia & $\begin{array}{l}\text { Mocaf-black rice flakes added with jack } \\
\text { bean flour }\end{array}$ & 52.59 & 22.93 & 57.4 & 50 & $\begin{array}{l}10 \text { Healthy } \\
\text { participants }\end{array}$ & Glucose $/ 2 \mathrm{~h}$ \\
\hline 230 & 83 & Indonesia & Honey tikung & 35 & NA & 69 & 50 & $\begin{array}{l}10 \text { Healthy } \\
\text { participants }\end{array}$ & Glucose $/ 2 \mathrm{~h}$ \\
\hline 231 & 83 & Indonesia & Honey kelulut & 39 & NA & 73 & 50 & $\begin{array}{l}10 \text { Healthy } \\
\text { participants }\end{array}$ & Glucose/2 h \\
\hline 232 & 84 & Indonesia & $\begin{array}{l}\text { Snack bar made from sagu flour, tempe and } \\
\text { beras hitam }\end{array}$ & 44 & $23.75(S D)$ & 92 (2:1 ratio of sago starch and tempe) & 50 & $\begin{array}{l}10 \text { Healthy } \\
\text { participants }\end{array}$ & Glucose/2 h \\
\hline 233 & 84 & Indonesia & $\begin{array}{l}\text { Snack bar made from sagu flour, tempe and } \\
\text { beras hitam }\end{array}$ & 46 & $18.42(\mathrm{SD})$ & 108 (1.5:1 ratio of sago starch and tempe) & 50 & $\begin{array}{l}10 \text { Healthy } \\
\text { participants }\end{array}$ & Glucose $/ 2 \mathrm{~h}$ \\
\hline
\end{tabular}


Table 1 continued

\begin{tabular}{|c|c|c|c|c|c|c|c|c|c|}
\hline & \multirow[t]{2}{*}{ Reference } & \multirow[t]{2}{*}{ Country } & \multirow[t]{2}{*}{ Food item } & \multicolumn{2}{|c|}{ GI (glucose $=100)$} & \multirow{2}{*}{$\begin{array}{l}\text { Serving size }(g) \text { per experimental } \\
\text { portion size }\end{array}$} & \multirow{2}{*}{$\begin{array}{l}\text { Available } \mathrm{CHO} \\
\text { (g) per } \\
\text { experimental } \\
\text { portion }\end{array}$} & \multirow{2}{*}{$\begin{array}{l}\text { Participants } \\
\text { (type and } \\
\text { number) }\end{array}$} & \multirow{2}{*}{$\begin{array}{l}\text { Reference } \\
\text { food and } \\
\text { time perioc }\end{array}$} \\
\hline & & & & Mean & SEM & & & & \\
\hline 234 & 84 & Indonesia & $\begin{array}{l}\text { Snack bar made from sagu flour, tempe and } \\
\text { beras hitam }\end{array}$ & 40 & $13.62(\mathrm{SD})$ & 129 (1:1 ratio of sago starch and tempe) & 50 & $\begin{array}{l}10 \text { Healthy } \\
\text { participants }\end{array}$ & Glucose $/ 2 \mathrm{~h}$ \\
\hline 235 & 85 & Indonesia & $\begin{array}{l}\text { Tempeh gembus cookies ( } 50 \% \text { flour } \\
\text { replacement) }\end{array}$ & 47.01 & 11.08 & 85.18 & 50 & $\begin{array}{l}28 \text { Healthy } \\
\text { participants }\end{array}$ & Glucose $/ 2 \mathrm{~h}$ \\
\hline 236 & 85 & Indonesia & $\begin{array}{l}\text { Tempeh gembus cookies ( } 50 \% \text { flour } \\
\text { replacement) }\end{array}$ & 53.66 & 16.55 & 89.97 & 50 & $\begin{array}{l}28 \text { Healthy } \\
\text { participants }\end{array}$ & Glucose $/ 2 \mathrm{~h}$ \\
\hline 237 & 85 & Indonesia & Cookies & 68.67 & 12.28 & 95.45 & 50 & $\begin{array}{l}28 \text { Healthy } \\
\text { participants }\end{array}$ & Glucose $/ 2 \mathrm{~h}$ \\
\hline 238 & 86 & Indonesia & Corn flour cake & 85.02 & 11.21 & 54 & 50 & $\begin{array}{l}12 \text { Healthy } \\
\text { participants }\end{array}$ & Glucose $/ 2 \mathrm{~h}$ \\
\hline 239 & 86 & Indonesia & $\begin{array}{l}\text { Cake made from modified corn flour (corn } \\
\text { starch soaked with } 4 \% \text { green tea extract) }\end{array}$ & 74.96 & 10.48 & 54 & 50 & $\begin{array}{l}12 \text { Healthy } \\
\text { participants }\end{array}$ & Glucose $/ 2 \mathrm{~h}$ \\
\hline 240 & 86 & Indonesia & Corn flour cookie & 52.23 & 6.78 & 71 & 50 & $\begin{array}{l}12 \text { Healthy } \\
\text { participants }\end{array}$ & Glucose $/ 2 \mathrm{~h}$ \\
\hline 241 & 86 & Indonesia & $\begin{array}{l}\text { Cookie made from modified corn flour with } \\
\text { green tea extract }\end{array}$ & 58.25 & 8.33 & 71 & 50 & $\begin{array}{l}12 \text { Healthy } \\
\text { participants }\end{array}$ & Glucose $/ 2 \mathrm{~h}$ \\
\hline 242 & 87 & Indonesia & $\begin{array}{l}\text { Sorghum, oatmeal and honey snack bar } \\
\text { coated with caramel syrup made with } \\
\text { sorghum }\end{array}$ & 44.73 & 8.83 & 60.80 & 50 & $\begin{array}{l}12 \text { Healthy } \\
\text { participants }\end{array}$ & Glucose $/ 2 \mathrm{~h}$ \\
\hline 243 & 87 & Indonesia & $\begin{array}{l}\text { Sorghum, oatmeal and honey snack bar } \\
\text { coated with caramel sugarcane syrup }\end{array}$ & 53.72 & 3.63 & 57.87 & 50 & $\begin{array}{l}12 \text { Healthy } \\
\text { participants }\end{array}$ & Glucose $/ 2 \mathrm{~h}$ \\
\hline 244 & 87 & Indonesia & $\begin{array}{l}\text { Sorghum, oatmeal and honey snack bar } \\
\text { coated with glucose syrup }\end{array}$ & 81.41 & 8.17 & 58.20 & 50 & $\begin{array}{l}12 \text { Healthy } \\
\text { participants }\end{array}$ & Glucose $/ 2 \mathrm{~h}$ \\
\hline 245 & 88 & Philippines & Pan de sal + coconut flour & 87.2 & 5.5 & NA & 50 & $\begin{array}{l}10 \text { Healthy } \\
\text { participants }\end{array}$ & Glucose $/ 2 \mathrm{~h}$ \\
\hline 246 & 88 & Philippines & Pan de sal + coconut flour & 96.6 & 6.1 & NA & 50 & $\begin{array}{l}10 \mathrm{~T} 2 \mathrm{DM} \\
\text { participants }\end{array}$ & Glucose $/ 3 \mathrm{~h}$ \\
\hline 247 & 88 & Philippines & Granola bar + coconut flour & 65.1 & 4.9 & NA & 50 & $\begin{array}{l}10 \text { Healthy } \\
\text { participants }\end{array}$ & Glucose $/ 2 \mathrm{~h}$ \\
\hline 248 & 88 & Philippines & Granola bar + coconut flour & 71.6 & 4.7 & NA & 50 & $\begin{array}{l}10 \mathrm{~T} 2 \mathrm{DM} \\
\text { participants }\end{array}$ & Glucose $/ 3 \mathrm{~h}$ \\
\hline 249 & 88 & Philippines & Cinnamon bread + coconut flour & 62.7 & 4.2 & NA & 50 & $\begin{array}{l}10 \text { Healthy } \\
\text { participants }\end{array}$ & Glucose $/ 2 \mathrm{~h}$ \\
\hline 250 & 88 & Philippines & Cinnamon bread + coconut flour & 71.4 & 4.9 & NA & 50 & $\begin{array}{l}10 \text { T2DM } \\
\text { participants }\end{array}$ & Glucose/3 h \\
\hline 251 & 88 & Philippines & Multigrain loaf + coconut flour & 85.2 & 6.8 & NA & 50 & $\begin{array}{l}10 \text { Healthy } \\
\text { participants }\end{array}$ & Glucose $/ 2 \mathrm{~h}$ \\
\hline 252 & 88 & Philippines & Multigrain loaf + coconut flour & 92.5 & 5.9 & NA & 50 & $\begin{array}{l}10 \mathrm{~T} 2 \mathrm{DM} \\
\text { participants }\end{array}$ & Glucose/3h \\
\hline 253 & 88 & Philippines & Choco chip cookies + coconut flour & 61.3 & 4.6 & NA & 50 & $\begin{array}{l}10 \text { Healthy } \\
\text { participants }\end{array}$ & Glucose $/ 2 \mathrm{~h}$ \\
\hline 254 & 88 & Philippines & Choco chip cookies + coconut flour & 71.4 & 7.3 & NA & 50 & $\begin{array}{l}10 \mathrm{~T} 2 \mathrm{DM} \\
\text { participants }\end{array}$ & Glucose $/ 3 \mathrm{~h}$ \\
\hline 255 & 88 & Philippines & Hotcake + coconut flour & 65.0 & 3.3 & NA & 50 & $\begin{array}{l}10 \text { Healthy } \\
\text { participants }\end{array}$ & Glucose $/ 2 \mathrm{~h}$ \\
\hline 256 & 88 & Philippines & Hotcake + coconut flour & 72.3 & 5.8 & NA & 50 & $\begin{array}{l}10 \mathrm{~T} 2 \mathrm{DM} \\
\text { participants }\end{array}$ & Glucose $/ 3 \mathrm{~h}$ \\
\hline 257 & 88 & Philippines & Choco crinkles + coconut flour & 61.3 & 5.4 & NA & 50 & $\begin{array}{l}10 \text { Healthy } \\
\text { participants }\end{array}$ & Glucose $/ 2 \mathrm{~h}$ \\
\hline 258 & 88 & Philippines & Choco crinkles + coconut flour & 77.0 & 4.4 & NA & 50 & $\begin{array}{l}10 \mathrm{~T} 2 \mathrm{DM} \\
\text { participants }\end{array}$ & Glucose $/ 3 \mathrm{~h}$ \\
\hline 259 & 88 & Philippines & European carrot cake + coconut flour & 51.8 & 3.3 & NA & 50 & $\begin{array}{l}10 \text { Healthy } \\
\text { participants }\end{array}$ & Glucose $/ 2 \mathrm{~h}$ \\
\hline 260 & 88 & Philippines & European carrot cake + coconut flour & 55.0 & 3.7 & NA & 50 & $\begin{array}{l}10 \mathrm{~T} 2 \mathrm{DM} \\
\text { participants }\end{array}$ & Glucose $/ 3 \mathrm{~h}$ \\
\hline 261 & 88 & Philippines & Macaroons + coconut flour & 45.7 & 3.0 & NA & 50 & $\begin{array}{l}10 \text { Healthy } \\
\text { participants }\end{array}$ & Glucose $/ 2 \mathrm{~h}$ \\
\hline 262 & 88 & Philippines & Macaroons + coconut flour & 46.6 & 3.7 & NA & 50 & $\begin{array}{l}10 \mathrm{~T} 2 \mathrm{DM} \\
\text { participants }\end{array}$ & Glucose $/ 3 \mathrm{~h}$ \\
\hline 263 & 88 & Philippines & Brownies + coconut flour & 60.1 & 5.4 & NA & 50 & $\begin{array}{l}10 \text { Healthy } \\
\text { participants }\end{array}$ & Glucose $/ 2 \mathrm{~h}$ \\
\hline 264 & 88 & Philippines & Brownies + coconut flour & 61.3 & 5.6 & NA & 50 & $\begin{array}{l}10 \text { T2DM } \\
\text { participants }\end{array}$ & Glucose $/ 3 \mathrm{~h}$ \\
\hline 265 & 89 & Philippines & White bread & 93.3 & 8.9 & NA & 50 & $\begin{array}{l}11 \text { Healthy } \\
\text { participants }\end{array}$ & Glucose $/ 2 \mathrm{~h}$ \\
\hline 266 & 89 & Philippines & Japonica rice & 87.5 & 7.8 & NA & 50 & $\begin{array}{l}11 \text { Healthy } \\
\text { participants }\end{array}$ & Glucose $/ 2 \mathrm{~h}$ \\
\hline
\end{tabular}


Table 1 continued

\begin{tabular}{|c|c|c|c|c|c|c|c|c|c|}
\hline & \multirow[t]{2}{*}{ Reference } & \multirow[t]{2}{*}{ Country } & \multirow[t]{2}{*}{ Food item } & \multicolumn{2}{|c|}{ GI (glucose $=100)$} & \multirow{2}{*}{$\begin{array}{l}\text { Serving size }(g) \text { per experimental } \\
\text { portion size }\end{array}$} & \multirow{2}{*}{$\begin{array}{l}\text { Available } \mathrm{CHO} \\
\text { (g) per } \\
\text { experimental } \\
\text { portion }\end{array}$} & \multirow{2}{*}{$\begin{array}{l}\text { Participants } \\
\text { (type and } \\
\text { number) }\end{array}$} & \multirow{2}{*}{$\begin{array}{l}\text { Reference } \\
\text { food and } \\
\text { time perioo }\end{array}$} \\
\hline & & & & Mean & SEM & & & & \\
\hline 267 & 89 & Philippines & Japonica rice +3 g sunfibre & 67.5 & 6.0 & NA & 50 & $\begin{array}{l}11 \text { Healthy } \\
\text { participants }\end{array}$ & Glucose $/ 2 \mathrm{~h}$ \\
\hline 268 & 89 & Philippines & Japonica rice $+5 \mathrm{~g}$ sunfibre & 65.5 & 5.8 & NA & 50 & $\begin{array}{l}11 \text { Healthy } \\
\text { participants }\end{array}$ & Glucose $/ 2 \mathrm{~h}$ \\
\hline 269 & 89 & Philippines & White bread $+5 \mathrm{~g}$ sunfibre (drink) & 49.0 & 4.4 & NA & 50 & $\begin{array}{l}11 \text { Healthy } \\
\text { participants }\end{array}$ & Glucose $/ 2 \mathrm{~h}$ \\
\hline 270 & 89 & Philippines & White bread $+10 \mathrm{~g}$ sunfibre (drink) & 56.9 & 5.1 & NA & 50 & $\begin{array}{l}11 \text { Healthy } \\
\text { participants }\end{array}$ & Glucose $/ 2 \mathrm{~h}$ \\
\hline 271 & 89 & Philippines & White bread $+10 \mathrm{~g}$ inulin (drink) & 66.7 & 6.0 & NA & 50 & $\begin{array}{l}11 \text { Healthy } \\
\text { participants }\end{array}$ & Glucose $/ 2 \mathrm{~h}$ \\
\hline 272 & 89 & Philippines & White bread + $10 \mathrm{~g}$ Indigestible dextrin (drink) & 66.3 & 5.9 & NA & 50 & $\begin{array}{l}11 \text { Healthy } \\
\text { participants }\end{array}$ & Glucose $/ 2 \mathrm{~h}$ \\
\hline 273 & 90 & Philippines & Biscuit 1 (Marie) & 88 & 7 & 44 & 25 & $\begin{array}{l}10 \text { Healthy } \\
\text { participants }\end{array}$ & Glucose $/ 2 \mathrm{~h}$ \\
\hline 274 & 90 & Philippines & Biscuit 2 (Mik Mik) & 94 & 7 & 45 & 25 & $\begin{array}{l}10 \text { Healthy } \\
\text { participants }\end{array}$ & Glucose $/ 2 \mathrm{~h}$ \\
\hline 275 & 90 & Philippines & Biscuit $2+$ oat fibre & 52 & 4 & 37 & 25 & $\begin{array}{l}10 \text { Healthy } \\
\text { participants }\end{array}$ & Glucose $/ 2 \mathrm{~h}$ \\
\hline 276 & 90 & Philippines & Donut, sugar coated & 70 & 5 & 109 & 50 & $\begin{array}{l}10 \text { Healthy } \\
\text { participants }\end{array}$ & Glucose $/ 2 \mathrm{~h}$ \\
\hline 277 & 90 & Philippines & Mamon, ordinary & 48 & 3 & 60 & 25 & $\begin{array}{l}10 \text { Healthy } \\
\text { participants }\end{array}$ & Glucose $/ 2 \mathrm{~h}$ \\
\hline 278 & 90 & Philippines & Mamon, sugar-free & 48 & 4 & 55 & 25 & $\begin{array}{l}10 \text { Healthy } \\
\text { participants }\end{array}$ & Glucose $/ 2 \mathrm{~h}$ \\
\hline 279 & 90 & Philippines & Kutsinta & 80 & 6 & 65 & 25 & $\begin{array}{l}10 \text { Healthy } \\
\text { participants }\end{array}$ & Glucose $/ 2 \mathrm{~h}$ \\
\hline 280 & 90 & Philippines & Puto, white & 90 & 6 & 50 & 25 & $\begin{array}{l}10 \text { Healthy } \\
\text { participants }\end{array}$ & Glucose $/ 2 \mathrm{~h}$ \\
\hline 281 & 90 & Philippines & Bihon (noodles) & 49 & 3 & 61 & 50 & $\begin{array}{l}10 \text { Healthy } \\
\text { participants }\end{array}$ & Glucose $/ 2 \mathrm{~h}$ \\
\hline 282 & 90 & Philippines & Canton (noodles) & 49 & 2 & 97 & 50 & $\begin{array}{l}10 \text { Healthy } \\
\text { participants }\end{array}$ & Glucose $/ 2 \mathrm{~h}$ \\
\hline 283 & 90 & Philippines & Sotanghon (noodles) & 60 & 3 & 59 & 50 & $\begin{array}{l}10 \text { Healthy } \\
\text { participants }\end{array}$ & Glucose $/ 2 \mathrm{~h}$ \\
\hline 284 & 90 & Philippines & Misua (noodles) & 46 & 4 & 71 & 50 & $\begin{array}{l}10 \text { Healthy } \\
\text { participants }\end{array}$ & Glucose $/ 2 \mathrm{~h}$ \\
\hline 285 & 90 & Philippines & Miki (noodles) & 47 & 3 & 99 & 50 & $\begin{array}{l}10 \text { Healthy } \\
\text { participants }\end{array}$ & Glucose $/ 2 \mathrm{~h}$ \\
\hline 286 & 90 & Philippines & Potato & 43 & 3 & 118 & 50 & $\begin{array}{l}10 \text { Healthy } \\
\text { participants }\end{array}$ & Glucose $/ 2 \mathrm{~h}$ \\
\hline 287 & 90 & Philippines & Yacon (tuber) & 34 & 3 & 244 & 25 & $\begin{array}{l}10 \text { healthy } \\
\text { participants }\end{array}$ & Glucose $/ 2 \mathrm{~h}$ \\
\hline 288 & 90 & Philippines & Yacon juice & 61 & 2 & $250(\mathrm{ml})$ & 30 & $\begin{array}{l}10 \text { Healthy } \\
\text { participants }\end{array}$ & Glucose $/ 2 \mathrm{~h}$ \\
\hline 289 & 90 & Philippines & Cashew nuts & 36 & 4 & 106 & 25 & $\begin{array}{l}10 \text { Healthy } \\
\text { participants }\end{array}$ & Glucose $/ 2 \mathrm{~h}$ \\
\hline 290 & 90 & Philippines & Lima beans & 16 & 2 & 64 & 50 & $\begin{array}{l}10 \text { Healthy } \\
\text { participants }\end{array}$ & Glucose $/ 2 \mathrm{~h}$ \\
\hline 291 & 90 & Philippines & Sitaw (string beans) & 23 & 1 & 200 & 10 & $\begin{array}{l}10 \text { Healthy } \\
\text { participants }\end{array}$ & Glucose $/ 2 \mathrm{~h}$ \\
\hline 292 & 90 & Philippines & Banana, Lakatan & 62 & 5 & 180 & 50 & $\begin{array}{l}10 \text { Healthy } \\
\text { participants }\end{array}$ & Glucose $/ 2 \mathrm{~h}$ \\
\hline 293 & 90 & Philippines & Banana, Saba & 53 & 4 & 161 & 50 & $\begin{array}{l}10 \text { Healthy } \\
\text { participants }\end{array}$ & Glucose $/ 2 \mathrm{~h}$ \\
\hline 294 & 90 & Philippines & Grapes, seedless & 46 & 3 & 267 & 50 & $\begin{array}{l}10 \text { Healthy } \\
\text { participants }\end{array}$ & Glucose $/ 2 \mathrm{~h}$ \\
\hline 295 & 90 & Philippines & Pear, Chinese & 29 & 3 & 243 & 25 & $\begin{array}{l}10 \text { Healthy } \\
\text { participants }\end{array}$ & Glucose $/ 2 \mathrm{~h}$ \\
\hline 296 & 90 & Philippines & Cantalope (melon) & 34 & 3 & 291 & 25 & $\begin{array}{l}10 \text { Healthy } \\
\text { participants }\end{array}$ & Glucose $/ 2 \mathrm{~h}$ \\
\hline 297 & 90 & Philippines & Watermelon & 48 & 4 & 373 & 25 & $\begin{array}{l}10 \text { Healthy } \\
\text { participants }\end{array}$ & Glucose $/ 2 \mathrm{~h}$ \\
\hline 298 & 90 & Philippines & Jackfruit & 41 & 3 & 114 & 25 & $\begin{array}{l}10 \text { Healthy } \\
\text { participants }\end{array}$ & Glucose $/ 2 \mathrm{~h}$ \\
\hline 299 & 90 & Philippines & Mango, carabao, ripe & 46 & 4 & 176 & 25 & $\begin{array}{l}10 \text { Healthy } \\
\text { participants }\end{array}$ & Glucose $/ 2 \mathrm{~h}$ \\
\hline 300 & 90 & Philippines & Papaya & 45 & 3 & 232 & 25 & $\begin{array}{l}10 \text { Healthy } \\
\text { participants }\end{array}$ & Glucose $/ 2 \mathrm{~h}$ \\
\hline
\end{tabular}


Table 1 continued

\begin{tabular}{|c|c|c|c|c|c|c|c|c|c|}
\hline & \multirow[t]{2}{*}{ Reference } & \multirow[t]{2}{*}{ Country } & \multirow[t]{2}{*}{ Food item } & \multicolumn{2}{|c|}{ Gl (glucose $=100)$} & \multirow{2}{*}{$\begin{array}{l}\text { Serving size }(g) \text { per experimental } \\
\text { portion size }\end{array}$} & \multirow{2}{*}{$\begin{array}{l}\text { Available CHO } \\
\text { (g) per } \\
\text { experimental } \\
\text { portion }\end{array}$} & \multirow{2}{*}{$\begin{array}{l}\text { Participants } \\
\text { (type and } \\
\text { number) }\end{array}$} & \multirow{2}{*}{$\begin{array}{l}\text { Reference } \\
\text { food and } \\
\text { time period }\end{array}$} \\
\hline & & & & Mean & SEM & & & & \\
\hline 301 & 90 & Philippines & Apple, red & 42 & 3 & 181 & 25 & $\begin{array}{l}10 \text { Healthy } \\
\text { participants }\end{array}$ & Glucose $/ 2 \mathrm{~h}$ \\
\hline 302 & 90 & Philippines & Pineapple & 56 & 3 & 215 & 25 & $\begin{array}{l}10 \text { Healthy } \\
\text { participants }\end{array}$ & Glucose $/ 2 \mathrm{~h}$ \\
\hline 303 & 90 & Philippines & Guava, white & 19 & 2 & 233 & 25 & $\begin{array}{l}10 \text { Healthy } \\
\text { participants }\end{array}$ & Glucose $/ 2 \mathrm{~h}$ \\
\hline 304 & 90 & Philippines & Raisins & 61 & 5 & 76 & 50 & $\begin{array}{l}10 \text { Healthy } \\
\text { participants }\end{array}$ & Glucose $/ 2 \mathrm{~h}$ \\
\hline 305 & 90 & Philippines & Squash (veg) & 44 & 5 & 234 & 15 & $\begin{array}{l}10 \text { Healthy } \\
\text { participants }\end{array}$ & Glucose $/ 2 \mathrm{~h}$ \\
\hline 306 & 90 & Philippines & Carrot & 35 & 2 & 211 & 15 & $\begin{array}{l}10 \text { Healthy } \\
\text { participants }\end{array}$ & Glucose $/ 2 \mathrm{~h}$ \\
\hline 307 & 90 & Philippines & Sayote (veg) & 27 & 2 & 286 & 10 & $\begin{array}{l}10 \text { Healthy } \\
\text { participants }\end{array}$ & Glucose $/ 2 \mathrm{~h}$ \\
\hline 308 & 90 & Philippines & Togue (veg) & 25 & 2 & 137 & 10 & $\begin{array}{l}10 \text { Healthy } \\
\text { participants }\end{array}$ & Glucose $/ 2 \mathrm{~h}$ \\
\hline 309 & 90 & Philippines & Avocado & 31 & 3 & 114 & 10 & $\begin{array}{l}10 \text { Healthy } \\
\text { participants }\end{array}$ & Glucose $/ 2 \mathrm{~h}$ \\
\hline 310 & 90 & Philippines & Coconut sap sugar (PCA) & 35 & 4 & 54 & 50 & $\begin{array}{l}10 \text { Healthy } \\
\text { participants }\end{array}$ & Glucose $/ 2 \mathrm{~h}$ \\
\hline 311 & 90 & Philippines & Coconut sap sugar (e-Asia) & 42 & 4 & 28 & 25 & $\begin{array}{l}10 \text { Healthy } \\
\text { participants }\end{array}$ & Glucose $/ 2 \mathrm{~h}$ \\
\hline 312 & 90 & Philippines & Coconut sap syrup (e-Asia) & 39 & 4 & 33 & 25 & $\begin{array}{l}10 \text { Healthy } \\
\text { participants }\end{array}$ & Glucose $/ 2 \mathrm{~h}$ \\
\hline 313 & 91 & Japan & $\begin{array}{l}\text { White rice - reference food (beihan) + dried } \\
\text { sea algae }\end{array}$ & 100 & NA & 147 g Rice + 1 g dried sea algae (shiso) & 50.4 & $\begin{array}{l}58 \text { Healthy } \\
\text { participants }\end{array}$ & $\begin{array}{l}\text { White rice/ } \\
2 \mathrm{~h}\end{array}$ \\
\hline 314 & 91 & Japan & Rice gruel (okayu) & 99 & 38 & 659 & 50.2 & $\begin{array}{l}10 \text { Healthy } \\
\text { participants }\end{array}$ & $\begin{array}{l}\text { White rice/ } \\
2 \mathrm{~h}\end{array}$ \\
\hline 315 & 91 & Japan & Rice cracker (osenbe) & 111 & 44 & 25 pieces & 50 & $\begin{array}{l}10 \text { Healthy } \\
\text { participants }\end{array}$ & $\begin{array}{l}\text { White rice/ } \\
2 \mathrm{~h}\end{array}$ \\
\hline 316 & 91 & Japan & Low protein white rice (tei-tanpaku gohan) & 86 & 28 & 125 & 50.4 & $\begin{array}{l}10 \text { Healthy } \\
\text { participants }\end{array}$ & $\begin{array}{l}\text { White rice/ } \\
2 \mathrm{~h}\end{array}$ \\
\hline 317 & 91 & Japan & White rice and sated plum frout (umeboshi) & 98 & 49 & 152 & 49.9 & $\begin{array}{l}10 \text { Healthy } \\
\text { participants }\end{array}$ & $\begin{array}{l}\text { White rice/ } \\
2 \mathrm{~h}\end{array}$ \\
\hline 318 & 91 & Japan & White rice and curry & 82 & 33 & 224 & 50.9 & $\begin{array}{l}10 \text { Healthy } \\
\text { participants }\end{array}$ & $\begin{array}{l}\text { White rice/ } \\
2 \mathrm{~h}\end{array}$ \\
\hline 319 & 91 & Japan & $\begin{array}{l}\text { White rice and pickled food (beihan, } \\
\text { sunomono) (taken before rice) }\end{array}$ & 73 & 29 & 173 & 49.8 & $\begin{array}{l}11 \text { Healthy } \\
\text { participants }\end{array}$ & $\begin{array}{l}\text { White rice/ } \\
2 \mathrm{~h}\end{array}$ \\
\hline 320 & 91 & Japan & Butter rice & 96 & 48 & 157 & 50 & $\begin{array}{l}10 \text { Healthy } \\
\text { participants }\end{array}$ & $\begin{array}{l}\text { White rice/ } \\
2 \mathrm{~h}\end{array}$ \\
\hline 321 & 91 & Japan & White rice and yoghurt (taken before rice) & 72 & 28 & 232 & 50.2 & $\begin{array}{l}10 \text { Healthy } \\
\text { participants }\end{array}$ & $\begin{array}{l}\text { White rice/ } \\
2 \mathrm{~h}\end{array}$ \\
\hline 322 & 91 & Japan & White rice and yoghurt (taken after rice) & 71 & 24 & 232 & 50.2 & $\begin{array}{l}10 \text { Healthy } \\
\text { participants }\end{array}$ & $\begin{array}{l}\text { White rice/ } \\
2 \mathrm{~h}\end{array}$ \\
\hline 323 & 91 & Japan & White rice with curry and cheese & 67 & 34 & 255 & 50.1 & $\begin{array}{l}10 \text { Healthy } \\
\text { participants }\end{array}$ & $\begin{array}{l}\text { White rice/ } \\
2 \mathrm{~h}\end{array}$ \\
\hline 324 & 91 & Japan & White rice and fermented soybean (natto) & 68 & 30 & 174 & 49.9 & $\begin{array}{l}10 \text { Healthy } \\
\text { participants }\end{array}$ & $\begin{array}{l}\text { White rice/ } \\
2 \mathrm{~h}\end{array}$ \\
\hline 325 & 91 & Japan & Soybean paste soup (miso shiru) and rice & 74 & 17 & 160 & 50.1 & $\begin{array}{l}10 \text { Healthy } \\
\text { participants }\end{array}$ & $\begin{array}{l}\text { White rice/ } \\
2 \mathrm{~h}\end{array}$ \\
\hline 326 & 91 & Japan & $\begin{array}{l}\text { Bread (International Standard Reference Food } \\
\text { - white bread) }\end{array}$ & 92 & 38 & 116 & 50.1 & $\begin{array}{l}10 \text { Healthy } \\
\text { participants }\end{array}$ & $\begin{array}{l}\text { White rice/ } \\
2 \mathrm{~h}\end{array}$ \\
\hline 327 & 91 & Japan & Spaghetti & 56 & 37 & 131 & 50.2 & $\begin{array}{l}10 \text { Healthy } \\
\text { participants }\end{array}$ & $\begin{array}{l}\text { White rice/ } \\
2 \mathrm{~h}\end{array}$ \\
\hline 328 & 92 & Japan & White rice & 75.9 & 6.6 & 161 & 49.3 & $\begin{array}{l}19 \text { Healthy } \\
\text { participants }\end{array}$ & Glucose $/ 2 \mathrm{~h}$ \\
\hline 329 & 92 & Japan & Pre-germinated brown rice & 56.9 & 2.9 & 185 & 50.6 & $\begin{array}{l}19 \text { Healthy } \\
\text { participants }\end{array}$ & Glucose $/ 2 \mathrm{~h}$ \\
\hline 330 & 92 & Japan & Brown rice & 61.5 & 4.7 & 178 & 49.4 & $\begin{array}{l}19 \text { Healthy } \\
\text { participants }\end{array}$ & Glucose $/ 2 \mathrm{~h}$ \\
\hline 331 & 92 & Japan & $\begin{array}{l}1 / 3 \text { Pre-germinated brown rice (mixture of pre- } \\
\text { germinated brown rice to white rice) }\end{array}$ & 67.4 & 2.9 & 169 (WR/PGBR ratio is 2:1) & 49.7 & $\begin{array}{l}13 \text { Healthy } \\
\text { participants }\end{array}$ & Glucose $/ 2 \mathrm{~h}$ \\
\hline 332 & 92 & Japan & $\begin{array}{l}2 / 3 \text { Pre-germinated brown rice (mixture of pre- } \\
\text { germinated brown rice to white rice) }\end{array}$ & 63.7 & 5.3 & 177 (WR/PGBR ratio is 1:2) & 50.2 & $\begin{array}{l}13 \text { Healthy } \\
\text { participants }\end{array}$ & Glucose $/ 2 \mathrm{~h}$ \\
\hline 333 & 92 & Japan & White rice & 74.6 & 6.2 & 161 & 49.3 & $\begin{array}{l}13 \text { Healthy } \\
\text { participants }\end{array}$ & Glucose $/ 2 \mathrm{~h}$ \\
\hline 334 & 92 & Japan & Pre-germinated brown rice & 54.4 & 5.1 & 185 & 50.6 & $\begin{array}{l}13 \text { Healthy } \\
\text { participants }\end{array}$ & Glucose/2 h \\
\hline
\end{tabular}


Table 1 continued

\begin{tabular}{|c|c|c|c|c|c|c|c|c|c|}
\hline & \multirow[t]{2}{*}{ Reference } & \multirow[t]{2}{*}{ Country } & \multirow[t]{2}{*}{ Food item } & \multicolumn{2}{|c|}{ GI (glucose $=100)$} & \multirow{2}{*}{$\begin{array}{l}\text { Serving size }(\mathrm{g}) \text { per experimental } \\
\text { portion size }\end{array}$} & \multirow{2}{*}{$\begin{array}{l}\text { Available } \mathrm{CHO} \\
\text { (g) per } \\
\text { experimental } \\
\text { portion }\end{array}$} & \multirow{2}{*}{$\begin{array}{l}\text { Participants } \\
\text { (type and } \\
\text { number) }\end{array}$} & \multirow{2}{*}{$\begin{array}{l}\text { Reference } \\
\text { food and } \\
\text { time period }\end{array}$} \\
\hline & & & & Mean & SEM & & & & \\
\hline 335 & 93 & Japan & Cake made from whole soy & 22 & 6 & 114 & 50.5 & $\begin{array}{l}20 \text { Healthy } \\
\text { participants }\end{array}$ & $\begin{array}{l}\text { Glucose }(50 \mathrm{~g} \\
\mathrm{CHO} / 4 \mathrm{~h}\end{array}$ \\
\hline 336 & 94 & Japan & Rice-1 (Sato-no-gohan) & 71 & $25(S D)$ & 150 & 50 & $\begin{array}{l}12 \text { Healthy } \\
\text { participants }\end{array}$ & Glucose $/ 2 \mathrm{~h}$ \\
\hline 337 & 94 & Japan & Rice-1 (Sato-no-gohan) & 86 & $28(S D)$ & 150 & 50 & $\begin{array}{l}12 \text { Healthy } \\
\text { participants }\end{array}$ & Glucose $/ 3 \mathrm{~h}$ \\
\hline 338 & 94 & Japan & Rice-2 (Nihonbare) & 69 & $28(S D)$ & 135 & 50.1 & $\begin{array}{l}12 \text { Healthy } \\
\text { participants }\end{array}$ & Glucose/2 h \\
\hline 339 & 94 & Japan & Rice-2 (Nihonbare) & 82 & $34(S D)$ & 135 & 50.1 & $\begin{array}{l}12 \text { Healthy } \\
\text { participants }\end{array}$ & Glucose/3 h \\
\hline 340 & 94 & Japan & Rice-3 (Hinohikari) & 74 & $23(S D)$ & 142 & 50.1 & $\begin{array}{l}12 \text { Healthy } \\
\text { participants }\end{array}$ & Glucose $/ 2 \mathrm{~h}$ \\
\hline 341 & 94 & Japan & Rice-3 (Hinohikari) & 82 & $24(S D)$ & 142 & 50.1 & $\begin{array}{l}12 \text { Healthy } \\
\text { participants }\end{array}$ & Glucose $/ 3 \mathrm{~h}$ \\
\hline 342 & 94 & Japan & Rice-4 (Koshihikari) & 75 & 14 (SD) & 142 & 50.1 & $\begin{array}{l}12 \text { Healthy } \\
\text { participants }\end{array}$ & Glucose $/ 2 \mathrm{~h}$ \\
\hline 343 & 94 & Japan & Rice-4 (Koshihikari) & 88 & $17(S D)$ & 142 & 50.1 & $\begin{array}{l}12 \text { Healthy } \\
\text { participants }\end{array}$ & Glucose $/ 3 \mathrm{~h}$ \\
\hline 344 & 94 & Japan & Potato-1 (Nishiyutaka) & 64 & $15(S D)$ & 284 & 50 & $\begin{array}{l}12 \text { Healthy } \\
\text { participants }\end{array}$ & Glucose/2 h \\
\hline 345 & 94 & Japan & Potato-1 (Nishiyutaka) & 65 & $17(S D)$ & 284 & 50 & $\begin{array}{l}12 \text { Healthy } \\
\text { participants }\end{array}$ & Glucose $/ 3 \mathrm{~h}$ \\
\hline 346 & 94 & Japan & Potato-2 (Ainoaka) & 63 & 19 (SD) & 284 & 50 & $\begin{array}{l}12 \text { Healthy } \\
\text { participants }\end{array}$ & Glucose/2 h \\
\hline 347 & 94 & Japan & Potato-2 (Ainoaka) & 63 & 19 (SD) & 284 & 50 & $\begin{array}{l}12 \text { Healthy } \\
\text { participants }\end{array}$ & Glucose $/ 3 \mathrm{~h}$ \\
\hline 348 & 94 & Japan & Potato-3 (Dejima) & 54 & $17(S D)$ & 284 & 50 & $\begin{array}{l}12 \text { Healthy } \\
\text { participants }\end{array}$ & Glucose $/ 2 \mathrm{~h}$ \\
\hline 349 & 94 & Japan & Potato-3 (Dejima) & 52 & $17(\mathrm{SD})$ & 284 & 50 & $\begin{array}{l}12 \text { Healthy } \\
\text { participants }\end{array}$ & Glucose $/ 3 \mathrm{~h}$ \\
\hline 350 & 94 & Japan & Noodle-1 (Simabara-udon) & 62 & $27(S D)$ & 170 & 50 & $\begin{array}{l}12 \text { Healthy } \\
\text { participants }\end{array}$ & Glucose/2 h \\
\hline 351 & 94 & Japan & Noodle-1 (Simabara-udon) & 80 & $36(S D)$ & 170 & 50 & $\begin{array}{l}12 \text { Healthy } \\
\text { participants }\end{array}$ & Glucose $/ 3 \mathrm{~h}$ \\
\hline 352 & 94 & Japan & Noodle-2 (Goto-udon) & 38 & $15(S D)$ & 170 & 50 & $\begin{array}{l}12 \text { Healthy } \\
\text { participants }\end{array}$ & Glucose $/ 2 \mathrm{~h}$ \\
\hline 353 & 94 & Japan & Noodle-2 (Goto-udon) & 49 & $20(S D)$ & 170 & 50 & $\begin{array}{l}12 \text { Healthy } \\
\text { participants }\end{array}$ & Glucose $/ 3 \mathrm{~h}$ \\
\hline 354 & 94 & Japan & Noodle-3 (Katokichi-udon) & 55 & $7(S D)$ & 172 & 49.9 & $\begin{array}{l}12 \text { Healthy } \\
\text { participants }\end{array}$ & Glucose $/ 2 \mathrm{~h}$ \\
\hline 355 & 94 & Japan & Noodle-3 (Katokichi-udon) & 67 & $15(S D)$ & 172 & 49.9 & $\begin{array}{l}12 \text { Healthy } \\
\text { participants }\end{array}$ & Glucose/3 h \\
\hline 356 & 94 & Japan & White bread (Yamazaki) & 58 & $25(\mathrm{SD})$ & 107 & 49.9 & $\begin{array}{l}12 \text { Healthy } \\
\text { participants }\end{array}$ & Glucose/2 h \\
\hline 357 & 94 & Japan & White bread (Yamazaki) & 59 & $15(\mathrm{SD})$ & 107 & 49.9 & $\begin{array}{l}12 \text { Healthy } \\
\text { participants }\end{array}$ & Glucose $/ 3 \mathrm{~h}$ \\
\hline 358 & 94 & Japan & Sponge cake (Castilla) & 64 & $20(S D)$ & 80 & 49.9 & $\begin{array}{l}12 \text { Healthy } \\
\text { participants }\end{array}$ & Glucose $/ 2 \mathrm{~h}$ \\
\hline 359 & 94 & Japan & Sponge cake (Castella) & 65 & 19 (SD) & 80 & 49.9 & $\begin{array}{l}12 \text { Healthy } \\
\text { participants }\end{array}$ & Glucose $/ 3 \mathrm{~h}$ \\
\hline 360 & 95 & Japan & White rice & 89 & NA & NA & 50 & $\begin{array}{l}15 \text { Healthy } \\
\text { participants }\end{array}$ & Glucose $/ 2 \mathrm{~h}$ \\
\hline 361 & 95 & Japan & Long grain rice & 60 & NA & NA & 50 & $\begin{array}{l}15 \text { Healthy } \\
\text { participants }\end{array}$ & Glucose $/ 2 \mathrm{~h}$ \\
\hline 362 & 95 & Japan & Rice vermicelli (a) & 55 & NA & NA & 50 & $\begin{array}{l}15 \text { Healthy } \\
\text { participants }\end{array}$ & Glucose/2 h \\
\hline 363 & 95 & Japan & Rice vermicelli (b) & 50 & NA & NA & 50 & $\begin{array}{l}15 \text { Healthy } \\
\text { participants }\end{array}$ & Glucose/2 h \\
\hline 364 & 95 & Japan & Rice vermicelli (c) & 35 & NA & NA & 50 & $\begin{array}{l}15 \text { Healthy } \\
\text { participants }\end{array}$ & Glucose/2 h \\
\hline 365 & 95 & Japan & Rice vermicelli (d) & 59 & NA & NA & 50 & $\begin{array}{l}15 \text { Healthy } \\
\text { participants }\end{array}$ & Glucose/2 h \\
\hline 366 & 95 & Japan & Rice vermicelli (e) & 60 & NA & NA & 50 & $\begin{array}{l}15 \text { Healthy } \\
\text { participants }\end{array}$ & Glucose/2 h \\
\hline 367 & 95 & Japan & Rice vermicelli (f) & 62 & NA & NA & 50 & $\begin{array}{l}15 \text { Healthy } \\
\text { participants }\end{array}$ & Glucose $/ 2 \mathrm{~h}$ \\
\hline
\end{tabular}


Table 1 continued

\begin{tabular}{|c|c|c|c|c|c|c|c|c|c|}
\hline & \multirow[t]{2}{*}{ Reference } & \multirow[t]{2}{*}{ Country } & \multirow[t]{2}{*}{ Food item } & \multicolumn{2}{|c|}{ GI (glucose $=100)$} & \multirow{2}{*}{$\begin{array}{l}\text { Serving size }(\mathrm{g}) \text { per experimental } \\
\text { portion size }\end{array}$} & \multirow{2}{*}{$\begin{array}{l}\text { Available } \mathrm{CHO} \\
\text { (g) per } \\
\text { experimental } \\
\text { portion }\end{array}$} & \multirow{2}{*}{$\begin{array}{l}\text { Participants } \\
\text { (type and } \\
\text { number) }\end{array}$} & \multirow{2}{*}{$\begin{array}{l}\text { Reference } \\
\text { food and } \\
\text { time period }\end{array}$} \\
\hline & & & & Mean & SEM & & & & \\
\hline 368 & 96 & Japan & Raw herb: corn salad & 97.5 & $18.4(\mathrm{SD})$ & 20 & 50 & $\begin{array}{l}11 \text { Healthy } \\
\text { participants }\end{array}$ & $\begin{array}{l}\text { White rice/ } \\
2 \mathrm{~h}\end{array}$ \\
\hline 369 & 96 & Japan & Herbal tea: lemon balm & 99.6 & $22.2(\mathrm{SD})$ & 1 & 50 & $\begin{array}{l}10 \text { Healthy } \\
\text { participants }\end{array}$ & $\begin{array}{l}\text { White rice/ } \\
2 \mathrm{~h}\end{array}$ \\
\hline 370 & 96 & Japan & Herbal tea: lemongrass & 112.1 & $28.9(\mathrm{SD})$ & 1 & 50 & $\begin{array}{l}10 \text { Healthy } \\
\text { participants }\end{array}$ & $\begin{array}{l}\text { White rice/ } \\
2 \mathrm{~h}\end{array}$ \\
\hline 371 & 96 & Japan & Herbal tea: rosemary & 126.5 & $27.3(\mathrm{SD})$ & 0.6 & 50 & $\begin{array}{l}10 \text { Healthy } \\
\text { participants }\end{array}$ & $\begin{array}{l}\text { White rice/ } \\
2 \mathrm{~h}\end{array}$ \\
\hline 372 & 96 & Japan & Herbal tea: spearmint & 108.8 & $30(S D)$ & 0.5 & 50 & $\begin{array}{l}10 \text { Healthy } \\
\text { participants }\end{array}$ & $\begin{array}{l}\text { White rice/ } \\
2 \mathrm{~h}\end{array}$ \\
\hline 373 & 96 & Japan & Herbal tea: thyme & 106.1 & $22.6(S D)$ & 1 & 50 & $\begin{array}{l}10 \text { Healthy } \\
\text { participants }\end{array}$ & $\begin{array}{l}\text { White rice/ } \\
2 \mathrm{~h}\end{array}$ \\
\hline 374 & 97 & Japan & Boiled Barleymax & 24.3 & 2.5 & 204 & 50 & $\begin{array}{l}11 \text { Healthy } \\
\text { participants }\end{array}$ & Glucose $/ 2 \mathrm{~h}$ \\
\hline 375 & 98 & Japan & Noodles made from dehulled yellow pea & 50.4 & $31.6(S D)$ & NA & NA & 50 & $\begin{array}{l}11 \text { Healthy } \\
\text { participants }\end{array}$ \\
\hline 376 & 98 & Japan & Noodles made from dehulled yellow pea & 40.3 & $25.3(\mathrm{SD})$ & NA & 50 & $\begin{array}{l}11 \text { Healthy } \\
\text { participants }\end{array}$ & Glucose $/ 2 \mathrm{~h}$ \\
\hline 377 & 98 & Japan & Noodles made from unshelled yellow pea & 68.8 & $12.4(\mathrm{SD})$ & NA & 50 & $\begin{array}{l}11 \text { Healthy } \\
\text { participants }\end{array}$ & $\begin{array}{l}\text { White rice/ } \\
2 \mathrm{~h}\end{array}$ \\
\hline 378 & 98 & Japan & Noodles made from dehulled yellow pea & 40.3 & $25.3(\mathrm{SD})$ & NA & 50 & $\begin{array}{l}11 \text { Healthy } \\
\text { participants }\end{array}$ & Glucose $/ 2 \mathrm{~h}$ \\
\hline 379 & 99 & Korea & Apple & 33.5 & 11.92 (SD) & 100 & 50 & $\begin{array}{l}13 \text { Healthy } \\
\text { participants }\end{array}$ & Glucose $/ 2 \mathrm{~h}$ \\
\hline 380 & 99 & Korea & Tangerine & 50.4 & $15.16(S D)$ & 100 & 50 & $\begin{array}{l}13 \text { Healthy } \\
\text { participants }\end{array}$ & Glucose $/ 2 \mathrm{~h}$ \\
\hline 381 & 99 & Korea & Pear & 35.7 & $14.38(\mathrm{SD})$ & 100 & 50 & $\begin{array}{l}13 \text { Healthy } \\
\text { participants }\end{array}$ & Glucose $/ 2 \mathrm{~h}$ \\
\hline 382 & 99 & Korea & Watermelon & 53.5 & $18.07(\mathrm{SD})$ & 100 & 50 & $\begin{array}{l}13 \text { Healthy } \\
\text { participants }\end{array}$ & Glucose $/ 2 \mathrm{~h}$ \\
\hline 383 & 99 & Korea & Persimmon & 42.9 & $18.92(S D)$ & 100 & 50 & $\begin{array}{l}13 \text { Healthy } \\
\text { participants }\end{array}$ & Glucose $/ 2 \mathrm{~h}$ \\
\hline 384 & 99 & Korea & Grapes & 48.1 & $14.05(S D)$ & 100 & 50 & $\begin{array}{l}13 \text { Healthy } \\
\text { participants }\end{array}$ & Glucose $/ 2 \mathrm{~h}$ \\
\hline 385 & 99 & Korea & Oriental melon & 51.2 & $18.14(S D)$ & 100 & 50 & $\begin{array}{l}13 \text { Healthy } \\
\text { participants }\end{array}$ & Glucose $/ 2 \mathrm{~h}$ \\
\hline 386 & 99 & Korea & Peach & 56.5 & 14.17 (SD) & 100 & 50 & $\begin{array}{l}13 \text { Healthy } \\
\text { participants }\end{array}$ & Glucose $/ 2 \mathrm{~h}$ \\
\hline 387 & 100 & Korea & Rice gruel & 92.5 & 8.8 & 447.7 & 50 & $\begin{array}{l}10 \text { Healthy } \\
\text { participants }\end{array}$ & Glucose $/ 2 \mathrm{~h}$ \\
\hline 388 & 100 & Korea & Puffed rice grains & 72.4 & 6.6 & 56.2 & 50 & $\begin{array}{l}10 \text { Healthy } \\
\text { participants }\end{array}$ & Glucose $/ 2 \mathrm{~h}$ \\
\hline 389 & 100 & Korea & Rice cakes & 80.7 & 8.5 & 93.8 & 50 & $\begin{array}{l}10 \text { Healthy } \\
\text { participants }\end{array}$ & Glucose $/ 2 \mathrm{~h}$ \\
\hline 390 & 100 & Korea & Steamed glutinous rice & 75.7 & 10.6 & 111.11 & 50 & $\begin{array}{l}10 \text { Healthy } \\
\text { participants }\end{array}$ & Glucose $/ 2 \mathrm{~h}$ \\
\hline 391 & 100 & Korea & Rice balls & 96.9 & 15.1 & 100 & 50 & $\begin{array}{l}10 \text { Healthy } \\
\text { participants }\end{array}$ & Glucose $/ 2 \mathrm{~h}$ \\
\hline 392 & 100 & Korea & Barley powder & 69.8 & 6.7 & 67.0 & 50 & $\begin{array}{l}11 \text { Healthy } \\
\text { participants }\end{array}$ & Glucose $/ 2 \mathrm{~h}$ \\
\hline 393 & 100 & Korea & Fine noodles & 49.0 & 7.0 & 65.8 & 50 & $\begin{array}{l}13 \text { Healthy } \\
\text { participants }\end{array}$ & Glucose $/ 2 \mathrm{~h}$ \\
\hline 394 & 100 & Korea & Fresh wheat noodles & 48.2 & 4.9 & 91.5 & 50 & $\begin{array}{l}13 \text { Healthy } \\
\text { participants }\end{array}$ & Glucose $/ 2 \mathrm{~h}$ \\
\hline 395 & 100 & Korea & Hand-pulled dough & 50.2 & 5.6 & 91.4 & 50 & $\begin{array}{l}14 \text { Healthy } \\
\text { participants }\end{array}$ & Glucose $/ 2 \mathrm{~h}$ \\
\hline 396 & 100 & Korea & Spaghetti & 55.3 & 6.5 & 72.5 & 50 & $\begin{array}{l}11 \text { Healthy } \\
\text { participants }\end{array}$ & Glucose $/ 2 \mathrm{~h}$ \\
\hline 397 & 100 & Korea & Buckwheat noodles & 59.6 & 13.3 & 70.2 & 50 & $\begin{array}{l}13 \text { Healthy } \\
\text { participants }\end{array}$ & Glucose $/ 2 \mathrm{~h}$ \\
\hline 398 & 100 & Korea & Sweet potato starch vermicelli & 60.0 & 11.6 & 56.8 & 50 & $\begin{array}{l}11 \text { Healthy } \\
\text { participants }\end{array}$ & Glucose $/ 2 \mathrm{~h}$ \\
\hline 399 & 100 & Korea & Plainbread & 70.7 & 11.4 & 116.6 & 50 & $\begin{array}{l}10 \text { Healthy } \\
\text { participants }\end{array}$ & Glucose $/ 2 \mathrm{~h}$ \\
\hline 400 & 100 & Korea & Rye bread & 64.9 & 18.4 & 109.4 & 50 & $\begin{array}{l}10 \text { Healthy } \\
\text { participants }\end{array}$ & Glucose $/ 2 \mathrm{~h}$ \\
\hline 401 & 100 & Korea & Rice bread & 73.4 & 7.6 & 116.6 & 50 & $\begin{array}{l}11 \text { Healthy } \\
\text { participants }\end{array}$ & Glucose $/ 2 \mathrm{~h}$ \\
\hline
\end{tabular}


Table 1 continued

\begin{tabular}{|c|c|c|c|c|c|c|c|c|c|}
\hline & \multirow[t]{2}{*}{ Reference } & \multirow[t]{2}{*}{ Country } & \multirow[t]{2}{*}{ Food item } & \multicolumn{2}{|c|}{ GI (glucose $=100)$} & \multirow{2}{*}{$\begin{array}{l}\text { Serving size }(g) \text { per experimental } \\
\text { portion size }\end{array}$} & \multirow{2}{*}{$\begin{array}{l}\text { Available } \mathrm{CHO} \\
\text { (g) per } \\
\text { experimental } \\
\text { portion }\end{array}$} & \multirow{2}{*}{$\begin{array}{l}\text { Participants } \\
\text { (type and } \\
\text { number) }\end{array}$} & \multirow{2}{*}{$\begin{array}{l}\text { Reference } \\
\text { food and } \\
\text { time perioo }\end{array}$} \\
\hline & & & & Mean & SEM & & & & \\
\hline 402 & 100 & Korea & Castella & 59.9 & 13.3 & 114.2 & 50 & $\begin{array}{l}10 \text { Healthy } \\
\text { participants }\end{array}$ & Glucose $/ 2 \mathrm{~h}$ \\
\hline 403 & 100 & Korea & Soft roll & 56.2 & 11.1 & 103.5 & 50 & $\begin{array}{l}10 \text { Healthy } \\
\text { participants }\end{array}$ & Glucose $/ 2 \mathrm{~h}$ \\
\hline 404 & 100 & Korea & Bagel & 77.4 & 11.5 & 104.1 & 50 & $\begin{array}{l}11 \text { Healthy } \\
\text { participants }\end{array}$ & Glucose $/ 2 \mathrm{~h}$ \\
\hline 405 & 100 & Korea & Wheat pancakes & 57.0 & 9.7 & 102.8 & 50 & $\begin{array}{l}14 \text { Healthy } \\
\text { participants }\end{array}$ & Glucose $/ 2 \mathrm{~h}$ \\
\hline 406 & 100 & Korea & Buckwheat pancakes & 49.9 & 8.9 & 169.4 & 50 & $\begin{array}{l}13 \text { Healthy } \\
\text { participants }\end{array}$ & Glucose $/ 2 \mathrm{~h}$ \\
\hline 407 & 100 & Korea & Cornflakes (Kellogg's Inc., South Korea) & 51.6 & 10.7 & 56.2 & 50 & $\begin{array}{l}14 \text { Healthy } \\
\text { participants }\end{array}$ & Glucose $/ 2 \mathrm{~h}$ \\
\hline 408 & 100 & Korea & All-Bran (Kellogg's Inc., South Korea) & 51.4 & 11.1 & 57.5 & 50 & $\begin{array}{l}11 \text { Healthy } \\
\text { participants }\end{array}$ & Glucose $/ 2 \mathrm{~h}$ \\
\hline 409 & 100 & Korea & Acorn jelly & 71.7 & 16.0 & 361.2 & 50 & $\begin{array}{l}12 \text { Healthy } \\
\text { participants }\end{array}$ & Glucose $/ 2 \mathrm{~h}$ \\
\hline 410 & 100 & Korea & Green bean jelly & 55.1 & 8.9 & 443.2 & 50 & $\begin{array}{l}14 \text { Healthy } \\
\text { participants }\end{array}$ & Glucose $/ 2 \mathrm{~h}$ \\
\hline 411 & 100 & Korea & Buckwheat jelly & 65.7 & 11.8 & 318.5 & 50 & $\begin{array}{l}13 \text { Healthy } \\
\text { participants }\end{array}$ & Glucose $/ 2 \mathrm{~h}$ \\
\hline 412 & 100 & Korea & Potato starch steamed & 53.3 & 17.3 & 109.3 & 50 & $\begin{array}{l}12 \text { Healthy } \\
\text { participants }\end{array}$ & Glucose $/ 2 \mathrm{~h}$ \\
\hline 413 & 100 & Korea & Baked sweet potatoes & 90.9 & 9.6 & 160.3 & 50 & $\begin{array}{l}10 \text { Healthy } \\
\text { participants }\end{array}$ & Glucose $/ 2 \mathrm{~h}$ \\
\hline 414 & 100 & Korea & Steamed chestnuts & 57.8 & 6.3 & 134.8 & 50 & $\begin{array}{l}13 \text { Healthy } \\
\text { participants }\end{array}$ & Glucose $/ 2 \mathrm{~h}$ \\
\hline 415 & 100 & Korea & Baked chestnuts & 54.3 & 5.8 & 134.8 & 50 & $\begin{array}{l}11 \text { Healthy } \\
\text { participants }\end{array}$ & Glucose $/ 2 \mathrm{~h}$ \\
\hline 416 & 100 & Korea & Steamed maize & 73.4 & 9.9 & 170.1 & 50 & $\begin{array}{l}11 \text { Healthy } \\
\text { participants }\end{array}$ & Glucose $/ 2 \mathrm{~h}$ \\
\hline 417 & 100 & Korea & Red bean gruel & 38.5 & 7.3 & 247.9 & 50 & $\begin{array}{l}10 \text { Healthy } \\
\text { participants }\end{array}$ & Glucose $/ 2 \mathrm{~h}$ \\
\hline 418 & 100 & Korea & Steamed sweet pumpkin & 52.1 & 14.0 & 277.8 & 50 & $\begin{array}{l}11 \text { Healthy } \\
\text { participants }\end{array}$ & Glucose $/ 2 \mathrm{~h}$ \\
\hline 419 & 101 & China & Cooked rice & 83.2 & 3.1 & NA & 50 & $\begin{array}{l}12 \text { Healthy } \\
\text { participants }\end{array}$ & Glucose $/ 2 \mathrm{~h}$ \\
\hline 420 & 101 & China & Brown rice (cooked) & 87.0 & 5.0 & NA & 50 & $\begin{array}{l}10 \text { Healthy } \\
\text { participants }\end{array}$ & Glucose $/ 2 \mathrm{~h}$ \\
\hline 421 & 101 & China & Sticky rice (cooked) & 87.0 & 7.0 & NA & 50 & $\begin{array}{l}10 \text { Healthy } \\
\text { participants }\end{array}$ & Glucose $/ 2 \mathrm{~h}$ \\
\hline 422 & 101 & China & Sticky rice (higher amylose) & 50.0 & 6.0 & NA & 50 & $\begin{array}{l}10 \text { Healthy } \\
\text { participants }\end{array}$ & Glucose $/ 2 \mathrm{~h}$ \\
\hline 423 & 101 & China & Rice porridge & 69.4 & 18.5 & NA & 50 & $\begin{array}{l}10 \text { Healthy } \\
\text { participants }\end{array}$ & Glucose $/ 2 \mathrm{~h}$ \\
\hline 424 & 101 & China & Instant rice (in hot water $3 \mathrm{~min}$ ) & 46.0 & 8.5 & NA & 50 & $\begin{array}{l}10 \text { Healthy } \\
\text { participants }\end{array}$ & Glucose $/ 2 \mathrm{~h}$ \\
\hline 425 & 101 & China & Instant rice (cooked 6 min) & 87.0 & 5.5 & NA & 50 & $\begin{array}{l}10 \text { Healthy } \\
\text { participants }\end{array}$ & Glucose $/ 2 \mathrm{~h}$ \\
\hline 426 & 101 & China & Corn powder porridge & 68.0 & 10.6 & NA & 50 & $\begin{array}{l}10 \text { Healthy } \\
\text { participants }\end{array}$ & Glucose $/ 2 \mathrm{~h}$ \\
\hline 427 & 101 & China & Corn granule & 51.8 & 9.2 & NA & 50 & $\begin{array}{l}10 \text { Healthy } \\
\text { participants }\end{array}$ & Glucose $/ 2 \mathrm{~h}$ \\
\hline 428 & 101 & China & Sweet corn (cooked) & 55.0 & 5.0 & NA & 50 & $\begin{array}{l}10 \text { Healthy } \\
\text { participants }\end{array}$ & Glucose $/ 2 \mathrm{~h}$ \\
\hline 429 & 101 & China & Oat biscuit & 55.0 & 2.5 & NA & 50 & $\begin{array}{l}10 \text { Healthy } \\
\text { participants }\end{array}$ & Glucose $/ 2 \mathrm{~h}$ \\
\hline 430 & 101 & China & Wheat pancake & 79.6 & 11.5 & NA & 50 & $\begin{array}{l}10 \text { Healthy } \\
\text { participants }\end{array}$ & Glucose $/ 2 \mathrm{~h}$ \\
\hline 431 & 101 & China & Bread (refined wheat) & 87.9 & 10.2 & NA & 50 & $\begin{array}{l}10 \text { Healthy } \\
\text { participants }\end{array}$ & Glucose $/ 2 \mathrm{~h}$ \\
\hline 432 & 101 & China & Bread (whole wheat) & 69.0 & 10.4 & NA & 50 & $\begin{array}{l}10 \text { Healthy } \\
\text { participants }\end{array}$ & Glucose $/ 2 \mathrm{~h}$ \\
\hline 433 & 101 & China & Bread (whole wheat with dried fruit) & 47.0 & 7.0 & NA & 50 & $\begin{array}{l}10 \text { Healthy } \\
\text { participants }\end{array}$ & Glucose $/ 2 \mathrm{~h}$ \\
\hline 434 & 101 & China & Wheat noodle (dried) & 46.0 & 5.8 & NA & 50 & $\begin{array}{l}10 \text { Healthy } \\
\text { participants }\end{array}$ & Glucose $/ 2 \mathrm{~h}$ \\
\hline 435 & 101 & China & Dumpling (shallot + meat) & 28.0 & 9.9 & NA & 50 & $\begin{array}{l}10 \text { Healthy } \\
\text { participants }\end{array}$ & Glucose $/ 2 \mathrm{~h}$ \\
\hline
\end{tabular}


Table 1 continued

\begin{tabular}{|c|c|c|c|c|c|c|c|c|c|}
\hline & \multirow[t]{2}{*}{ Reference } & \multirow[t]{2}{*}{ Country } & \multirow[t]{2}{*}{ Food item } & \multicolumn{2}{|c|}{ Gl (glucose $=100)$} & \multirow{2}{*}{$\begin{array}{l}\text { Serving size }(g) \text { per experimental } \\
\text { portion size }\end{array}$} & \multirow{2}{*}{$\begin{array}{l}\text { Available } \mathrm{CHO} \\
\text { (g) per } \\
\text { experimental } \\
\text { portion }\end{array}$} & \multirow{2}{*}{$\begin{array}{l}\text { Participants } \\
\text { (type and } \\
\text { number) }\end{array}$} & \multirow{2}{*}{$\begin{array}{l}\text { Reference } \\
\text { food and } \\
\text { time period }\end{array}$} \\
\hline & & & & Mean & SEM & & & & \\
\hline 436 & 101 & China & Steamed stuffed bun (shallot + meat) & 39.1 & 13.0 & NA & 50 & $\begin{array}{l}10 \text { Healthy } \\
\text { participants }\end{array}$ & Glucose/2 h \\
\hline 437 & 101 & China & Cake crisp & 59.0 & 6.0 & NA & 50 & $\begin{array}{l}10 \text { Healthy } \\
\text { participants }\end{array}$ & Glucose/2 h \\
\hline 438 & 101 & China & Whole-wheat pancake & 42.0 & 7.5 & NA & 50 & $\begin{array}{l}10 \text { Healthy } \\
\text { participants }\end{array}$ & Glucose $/ 2 \mathrm{~h}$ \\
\hline 439 & 101 & China & WoTao (corn + wheat) & 64.9 & 16.5 & NA & 50 & $\begin{array}{l}10 \text { Healthy } \\
\text { participants }\end{array}$ & Glucose/2 h \\
\hline 440 & 101 & China & Potato (cooked) & 66.4 & 3.8 & NA & 50 & $\begin{array}{l}10 \text { healthy } \\
\text { participants }\end{array}$ & Glucose/2 h \\
\hline 441 & 101 & China & Potato (steam) & 62.0 & 5.7 & NA & 50 & $\begin{array}{l}10 \text { Healthy } \\
\text { participants }\end{array}$ & Glucose/2 h \\
\hline 442 & 101 & China & Potato crisp (oil fry) & 60.3 & 7.0 & NA & 50 & $\begin{array}{l}10 \text { Healthy } \\
\text { participants }\end{array}$ & Glucose $/ 2 \mathrm{~h}$ \\
\hline 443 & 101 & China & Yam (steam) & 51.0 & 12.0 & NA & 50 & $\begin{array}{l}10 \text { Healthy } \\
\text { participants }\end{array}$ & Glucose $/ 2 \mathrm{~h}$ \\
\hline 444 & 101 & China & Yam (cooked) & 54.0 & 5.5 & NA & 50 & $\begin{array}{l}10 \text { Healthy } \\
\text { participants }\end{array}$ & Glucose $/ 2 \mathrm{~h}$ \\
\hline 445 & 101 & China & Potato mashed & 73.0 & 9.2 & NA & 50 & $\begin{array}{l}10 \text { Healthy } \\
\text { participants }\end{array}$ & Glucose $/ 2 \mathrm{~h}$ \\
\hline 446 & 102 & China & Resistant starch rice & 48.4 & 21.8 & NA & 40 & $\begin{array}{l}16 \text { Healthy } \\
\text { participants }\end{array}$ & Glucose $/ 4 \mathrm{~h}$ \\
\hline 447 & 102 & China & Wild-type rice & 77.4 & 34.9 & NA & 40 & $\begin{array}{l}16 \text { Healthy } \\
\text { participants }\end{array}$ & Glucose $/ 4 \mathrm{~h}$ \\
\hline 448 & 103 & China & MSB, millet steamed bread & 89.6 & 8.8 & 100 & 50 & $\begin{array}{l}10 \text { Healthy } \\
\text { participants }\end{array}$ & Glucose $/ 2 \mathrm{~h}$ \\
\hline 449 & 103 & China & $\begin{array}{l}\text { MP-1, no. } 1 \text { millet pancake ( } 75.0 \% \text { millet flour } \\
\text { and } 25.0 \% \text { extrusion flour) }\end{array}$ & 83.0 & 9.6 & 141 & 50 & $\begin{array}{l}10 \text { Healthy } \\
\text { participants }\end{array}$ & Glucose $/ 2 \mathrm{~h}$ \\
\hline 450 & 103 & China & $\begin{array}{l}\text { MP-2, no. } 2 \text { millet pancake (without } \\
\text { extrusion flour) }\end{array}$ & 76.2 & 10.7 & 121 & 50 & $\begin{array}{l}10 \text { Healthy } \\
\text { participants }\end{array}$ & Glucose $/ 2 \mathrm{~h}$ \\
\hline 451 & 103 & China & Cooked millet & 64.4 & 8.5 & 169 & 50 & $\begin{array}{l}10 \text { Healthy } \\
\text { participants }\end{array}$ & Glucose $/ 2 \mathrm{~h}$ \\
\hline 452 & 103 & China & Millet porridge & 93.6 & 11.3 & 550 & 50 & $\begin{array}{l}10 \text { Healthy } \\
\text { participants }\end{array}$ & Glucose $/ 2 \mathrm{~h}$ \\
\hline 453 & 104 & China & Majia pomelo & 78.34 & 1.88 & $72.09 \pm 1.08 \mathrm{~g}$ (fresh weight) & 50 & $\begin{array}{l}20 \text { Healthy } \\
\text { participants }\end{array}$ & Glucose $/ 2 \mathrm{~h}$ \\
\hline 454 & 104 & China & Majia pomelo & 72.15 & 1.95 & $72.09 \pm 1.08 \mathrm{~g}$ (fresh weight) & 50 & $\begin{array}{l}20 \mathrm{~T} 2 \mathrm{DM} \\
\text { participants }\end{array}$ & Glucose $/ 2 \mathrm{~h}$ \\
\hline 455 & 105 & China & Rice & 81 & 4 & 66.1 & 50 & $\begin{array}{l}11 \text { Healthy } \\
\text { participants }\end{array}$ & $\begin{array}{l}\text { Glucose and } \\
\text { rice/4h }\end{array}$ \\
\hline 456 & 105 & China & Raisins & 56 & 5 & 75.2 & 50 & $\begin{array}{l}11 \text { Healthy } \\
\text { participants }\end{array}$ & $\begin{array}{l}\text { Glucose and } \\
\text { rice } / 4 \mathrm{~h}\end{array}$ \\
\hline 457 & 105 & China & Dried apples & 43 & 4 & 76.8 & 50 & $\begin{array}{l}11 \text { Healthy } \\
\text { participants }\end{array}$ & $\begin{array}{l}\text { Glucose and } \\
\text { rice } / 4 \mathrm{~h}\end{array}$ \\
\hline 458 & 105 & China & Dried jujubes & 55 & 6 & 84.0 & 50 & $\begin{array}{l}11 \text { Healthy } \\
\text { participants }\end{array}$ & $\begin{array}{l}\text { Glucose and } \\
\text { rice } / 4 \mathrm{~h}\end{array}$ \\
\hline 459 & 105 & China & Dried apricots & 56 & 4 & 90.4 & 50 & $\begin{array}{l}11 \text { Healthy } \\
\text { participants }\end{array}$ & $\begin{array}{l}\text { Glucose and } \\
\text { rice } / 4 \mathrm{~h}\end{array}$ \\
\hline 460 & 105 & China & Raisins + rice & 77 & 8 & $\begin{array}{l}37.6 \text { (raisins) } \\
33.1 \text { (rice) }\end{array}$ & 50 & $\begin{array}{l}11 \text { Healthy } \\
\text { participants }\end{array}$ & $\begin{array}{l}\text { Glucose and } \\
\text { rice } / 4 \mathrm{~h}\end{array}$ \\
\hline 461 & 105 & China & Dried apples + rice & 65 & 5 & $\begin{array}{l}38.4 \text { (dried apples) } \\
33.1 \text { (rice) }\end{array}$ & 50 & $\begin{array}{l}11 \text { Healthy } \\
\text { participants }\end{array}$ & $\begin{array}{l}\text { Glucose and } \\
\text { rice } / 4 \mathrm{~h}\end{array}$ \\
\hline 462 & 105 & China & Dried jujubes + rice & 77 & 6 & $\begin{array}{l}42.0 \text { (dried jujubes) } \\
33.1 \text { (rice) }\end{array}$ & 50 & $\begin{array}{l}11 \text { Healthy } \\
\text { participants }\end{array}$ & $\begin{array}{l}\text { Glucose and } \\
\text { rice } / 4 \mathrm{~h}\end{array}$ \\
\hline 463 & 105 & China & Dried apricots + rice & 75 & 7 & $\begin{array}{l}45.2 \text { (dried apricots) } \\
33.1 \text { (rice) }\end{array}$ & 50 & $\begin{array}{l}11 \text { Healthy } \\
\text { participants }\end{array}$ & $\begin{array}{l}\text { Glucose and } \\
\text { rice } / 4 \mathrm{~h}\end{array}$ \\
\hline 464 & 105 & China & Rice + almonds & 70 & 4 & $\begin{array}{l}66.1 \text { (rice) } \\
30 \text { (almonds) }\end{array}$ & 52 & $\begin{array}{l}11 \text { Healthy } \\
\text { participants }\end{array}$ & $\begin{array}{l}\text { Glucose and } \\
\text { rice } / 4 \mathrm{~h}\end{array}$ \\
\hline 465 & 105 & China & Raisins + rice + almonds & 54 & 2 & $\begin{array}{l}37.6 \text { (raisins) } \\
33.1 \text { (rice) } 30 \text { (almonds) }\end{array}$ & 52 & $\begin{array}{l}11 \text { Healthy } \\
\text { participants }\end{array}$ & $\begin{array}{l}\text { Glucose and } \\
\text { rice } / 4 \mathrm{~h}\end{array}$ \\
\hline 466 & 105 & China & Dried apples + rice + almonds & 60 & 4 & $\begin{array}{l}38.4 \text { (dried apples) } \\
33.1 \text { (rice) } \\
30 \text { (almonds) }\end{array}$ & 52 & $\begin{array}{l}11 \text { Healthy } \\
\text { participants }\end{array}$ & $\begin{array}{l}\text { Glucose and } \\
\text { rice } / 4 \mathrm{~h}\end{array}$ \\
\hline 467 & 105 & China & Dried jujubes + rice + almonds & 52 & 4 & $\begin{array}{l}42.0 \text { (dried jujubes) } \\
33.1 \text { (rice) } \\
30 \text { (almonds) }\end{array}$ & 52 & $\begin{array}{l}11 \text { Healthy } \\
\text { participants }\end{array}$ & $\begin{array}{l}\text { Glucose and } \\
\text { rice } / 4 \mathrm{~h}\end{array}$ \\
\hline 468 & 105 & China & Dried apricots + rice + almonds & 64 & 4 & $\begin{array}{l}45.2 \text { (dried apricots) } \\
3.1 \text { (rice) } \\
30 \text { (almonds) }\end{array}$ & 52 & $\begin{array}{l}11 \text { Healthy } \\
\text { participants }\end{array}$ & $\begin{array}{l}\text { Glucose and } \\
\text { rice } / 4 \mathrm{~h}\end{array}$ \\
\hline
\end{tabular}


Table 1 continued

\begin{tabular}{|c|c|c|c|c|c|c|c|c|c|}
\hline & \multirow[t]{2}{*}{ Reference } & \multirow[t]{2}{*}{ Country } & \multirow[t]{2}{*}{ Food item } & \multicolumn{2}{|c|}{ Gl (glucose $=100)$} & \multirow{2}{*}{$\begin{array}{l}\text { Serving size }(g) \text { per experimental } \\
\text { portion size }\end{array}$} & \multirow{2}{*}{$\begin{array}{l}\text { Available CHO } \\
\text { (g) per } \\
\text { experimental } \\
\text { portion }\end{array}$} & \multirow{2}{*}{$\begin{array}{l}\text { Participants } \\
\text { (type and } \\
\text { number) }\end{array}$} & \multirow{2}{*}{$\begin{array}{l}\text { Reference } \\
\text { food and } \\
\text { time period }\end{array}$} \\
\hline & & & & Mean & SEM & & & & \\
\hline 469 & 106 & China & Cooked rice + cooked pak choy & 71 & 7 & $\begin{array}{l}66.1 \text { (raw rice) } \\
300 \text { (vegetables) } \\
2.5 \text { (sesame oil) } \\
1.5 \text { (salt) }\end{array}$ & 52.9 & $\begin{array}{l}16 \text { Healthy } \\
\text { participants }\end{array}$ & $\begin{array}{l}\text { Glucose and } \\
\text { rice } / 4 \mathrm{~h}\end{array}$ \\
\hline 470 & 106 & China & Cooked rice + homogenised raw pak choy & 84 & 9 & $\begin{array}{l}66.1 \text { (raw rice) } \\
300 \text { (vegetables) } \\
2.5 \text { (sesame oil) } \\
1.5 \text { (salt) }\end{array}$ & 52.9 & $\begin{array}{l}16 \text { Healthy } \\
\text { participants }\end{array}$ & $\begin{array}{l}\text { Glucose and } \\
\text { rice } / 4 \mathrm{~h}\end{array}$ \\
\hline 471 & 106 & China & Cooked rice + homogenised cooked pak choy & 91 & 10 & $\begin{array}{l}66.1 \text { (raw rice) } \\
300 \text { (vegetables) } \\
2.5 \text { (sesame oil) } \\
1.5 \text { (salt) }\end{array}$ & 52.9 & $\begin{array}{l}16 \text { Healthy } \\
\text { participants }\end{array}$ & $\begin{array}{l}\text { Glucose and } \\
\text { rice } / 4 \mathrm{~h}\end{array}$ \\
\hline 472 & 106 & China & Cooked rice + cooked cauliflower & 73 & 7 & $\begin{array}{l}66.1 \text { (raw rice) } \\
300 \text { (vegetables) } \\
2.5 \text { (sesame oil) } \\
1.5 \text { (salt) }\end{array}$ & 50.8 & $\begin{array}{l}16 \text { Healthy } \\
\text { participants }\end{array}$ & $\begin{array}{l}\text { Glucose and } \\
\text { rice } / 4 \mathrm{~h}\end{array}$ \\
\hline 473 & 106 & China & Cooked rice + homogenised raw Cauliflower & 83 & 10 & $\begin{array}{l}66.1 \text { (raw rice) } \\
300 \text { (vegetables) } \\
2.5 \text { (sesame oil) } \\
1.5 \text { (salt) }\end{array}$ & 50.8 & $\begin{array}{l}16 \text { Healthy } \\
\text { participants }\end{array}$ & $\begin{array}{l}\text { Glucose and } \\
\text { rice } / 4 \mathrm{~h}\end{array}$ \\
\hline 474 & 106 & China & $\begin{array}{l}\text { Cooked rice }+ \text { homogenised cooked } \\
\text { Cauliflower }\end{array}$ & 85 & 9 & $\begin{array}{l}66.1 \text { (raw rice) } \\
300 \text { (vegetables) } \\
2.5 \text { (sesame oil) } \\
1.5 \text { (salt) }\end{array}$ & 50.8 & $\begin{array}{l}16 \text { Healthy } \\
\text { participants }\end{array}$ & $\begin{array}{l}\text { Glucose and } \\
\text { rice } / 4 \mathrm{~h}\end{array}$ \\
\hline 475 & 106 & China & Cooked rice + cooked eggplant & 67 & 8 & $\begin{array}{l}66.1 \text { (raw rice) } \\
300 \text { (vegetables) } \\
2.5 \text { (sesame oil) } \\
1.5 \text { (salt) }\end{array}$ & 53.5 & $\begin{array}{l}16 \text { Healthy } \\
\text { participants }\end{array}$ & $\begin{array}{l}\text { Glucose and } \\
\text { rice } / 4 \mathrm{~h}\end{array}$ \\
\hline 476 & 106 & China & Cooked rice + homogenised raw eggplant & 93 & 10 & $\begin{array}{l}66.1 \text { (raw rice) } \\
300 \text { (vegetables) } \\
2.5 \text { (sesame oil) } \\
1.5 \text { (salt) }\end{array}$ & 53.5 & $\begin{array}{l}16 \text { Healthy } \\
\text { participants }\end{array}$ & $\begin{array}{l}\text { Glucose and } \\
\text { rice/ } 4 \mathrm{~h}\end{array}$ \\
\hline 477 & 106 & China & Cooked rice + homogenised cooked eggplant & 78 & 8 & $\begin{array}{l}66.1 \text { (raw rice) } \\
300 \text { (vegetables) } \\
2.5 \text { (sesame oil) } 1.5 \text { (salt) }\end{array}$ & 53.5 & $\begin{array}{l}16 \text { Healthy } \\
\text { participants }\end{array}$ & $\begin{array}{l}\text { Glucose and } \\
\text { rice } / 4 \mathrm{~h}\end{array}$ \\
\hline 478 & 107 & China & White rice cooked for $30 \mathrm{~min}$ & 83 & 9 & 230 (66.1 g raw rice) & 50 & $\begin{array}{l}10 \text { Healthy } \\
\text { participants }\end{array}$ & $\begin{array}{l}\text { Glucose and } \\
\text { white rice } / 2 \mathrm{~h}\end{array}$ \\
\hline 479 & 107 & China & Waxy black rice cooked for $30 \mathrm{~min}$ & 100 & 10 & 230 (66.1 g raw rice) & 50 & $\begin{array}{l}10 \text { Healthy } \\
\text { participants }\end{array}$ & $\begin{array}{l}\text { Glucose and } \\
\text { white rice } / 2 \mathrm{~h}\end{array}$ \\
\hline 480 & 107 & China & Waxy black rice cooked for $60 \mathrm{~min}$ & 109 & 12 & 230 (66.1 g raw rice) & 50 & $\begin{array}{l}10 \text { Healthy } \\
\text { participants }\end{array}$ & $\begin{array}{l}\text { Glucose and } \\
\text { white rice } / 2 \mathrm{~h}\end{array}$ \\
\hline 481 & 107 & China & Foxtail millet cooked for $30 \mathrm{~min}$ & 93 & 8 & 230 ( $72.3 \mathrm{~g}$ of millet) & 50 & $\begin{array}{l}10 \text { Healthy } \\
\text { participants }\end{array}$ & $\begin{array}{l}\text { Glucose and } \\
\text { White rice/ } \\
2 \mathrm{~h}\end{array}$ \\
\hline 482 & 107 & China & Foxtail millet cooked for $60 \mathrm{~min}$ & 89 & 6 & 230 (72.3 g of millet) & 50 & $\begin{array}{l}10 \text { Healthy } \\
\text { participants }\end{array}$ & $\begin{array}{l}\text { Glucose and } \\
\text { white rice } / 2 \mathrm{~h}\end{array}$ \\
\hline 483 & 107 & China & Adlay cooked for $30 \mathrm{~min}$ & 91 & 10 & 230 (75.0 g of adlay) & 50 & $\begin{array}{l}10 \text { Healthy } \\
\text { participants }\end{array}$ & $\begin{array}{l}\text { Glucose and } \\
\text { white rice } / 2 \mathrm{~h}\end{array}$ \\
\hline 484 & 107 & China & Adlay cooked for $60 \mathrm{~min}$ & 100 & 11 & 230 (75.0 g of adlay) & 50 & $\begin{array}{l}10 \text { Healthy } \\
\text { participants }\end{array}$ & $\begin{array}{l}\text { Glucose and } \\
\text { white rice } / 2 \mathrm{~h}\end{array}$ \\
\hline 485 & 107 & China & Dried lily bulb cooked for $30 \mathrm{~min}$ & 83 & 9 & $230(74.0 \mathrm{~g}$ of dried lily bulb) & 50 & $\begin{array}{l}10 \text { Healthy } \\
\text { participants }\end{array}$ & $\begin{array}{l}\text { Glucose and } \\
\text { white rice } / 2 \mathrm{~h}\end{array}$ \\
\hline 486 & 107 & China & Dried lily bulb cooked for $60 \mathrm{~min}$ & 85 & 7 & 230 (74.0 g of dried lily bulb) & 50 & $\begin{array}{l}10 \text { Healthy } \\
\text { participants }\end{array}$ & $\begin{array}{l}\text { Glucose and } \\
\text { white rice } / 2 \mathrm{~h}\end{array}$ \\
\hline 487 & 107 & China & Lotus seed cooked for $30 \mathrm{~min}$ & 45 & 5 & $230(77.6 \mathrm{~g}$ of lotus seed $)$ & 50 & $\begin{array}{l}10 \text { Healthy } \\
\text { participants }\end{array}$ & $\begin{array}{l}\text { Glucose and } \\
\text { White rice/ } \\
2 \mathrm{~h}\end{array}$ \\
\hline 488 & 107 & China & Lotus seed cooked for $60 \mathrm{~min}$ & 51 & 7 & 230 (77.6 g of lotus seed) & 50 & $\begin{array}{l}10 \text { Healthy } \\
\text { participants }\end{array}$ & $\begin{array}{l}\text { Glucose and } \\
\text { white rice } / 2 \mathrm{~h}\end{array}$ \\
\hline 489 & 107 & China & Adzuki bean cooked for $40 \mathrm{~min}$ & 21 & 4 & 230 (83.1 g of adzuki bean) & 50 & $\begin{array}{l}10 \text { Healthy } \\
\text { participants }\end{array}$ & $\begin{array}{l}\text { Glucose and } \\
\text { white rice } / 2 \mathrm{~h}\end{array}$ \\
\hline 490 & 107 & China & Adzuki bean cooked for $70 \mathrm{~min}$ & 29 & 4 & 230 (83.1 g of adzuki bean) & 50 & $\begin{array}{l}10 \text { Healthy } \\
\text { participants }\end{array}$ & $\begin{array}{l}\text { Glucose and } \\
\text { white rice } / 2 \mathrm{~h}\end{array}$ \\
\hline 491 & 108 & Taiwan, China & Brown rice & 82 & 0.22 & NA & 50 & $\begin{array}{l}10 \text { Healthy } \\
\text { participants }\end{array}$ & $\begin{array}{l}\text { White bread/ } \\
2 \mathrm{~h}\end{array}$ \\
\hline 492 & 108 & Taiwan, China & Taro & 69 & 0.35 & NA & 50 & $\begin{array}{l}10 \text { Healthy } \\
\text { participants }\end{array}$ & $\begin{array}{l}\text { White bread/ } \\
2 \mathrm{~h}\end{array}$ \\
\hline 493 & 108 & Taiwan, China & Adlay & 55 & 0.4 & NA & 50 & $\begin{array}{l}10 \text { Healthy } \\
\text { participants }\end{array}$ & $\begin{array}{l}\text { White bread/ } \\
2 \mathrm{~h}\end{array}$ \\
\hline 494 & 108 & Taiwan, China & Mung bean noodles & 28 & 0.5 & NA & 50 & $\begin{array}{l}10 \text { Healthy } \\
\text { participants }\end{array}$ & $\begin{array}{l}\text { White bread/ } \\
2 \mathrm{~h}\end{array}$ \\
\hline
\end{tabular}


Table 1 continued

\begin{tabular}{|c|c|c|c|c|c|c|c|c|c|}
\hline & \multirow[t]{2}{*}{ Reference } & \multirow[t]{2}{*}{ Country } & \multirow[t]{2}{*}{ Food item } & \multicolumn{2}{|c|}{ Gl (glucose $=100)$} & \multirow{2}{*}{$\begin{array}{l}\text { Serving size }(g) \text { per experimental } \\
\text { portion size }\end{array}$} & \multirow{2}{*}{$\begin{array}{l}\text { Available } \mathrm{CHO} \\
\text { (g) per } \\
\text { experimental } \\
\text { portion }\end{array}$} & \multirow{2}{*}{$\begin{array}{l}\text { Participants } \\
\text { (type and } \\
\text { number) }\end{array}$} & \multirow{2}{*}{$\begin{array}{l}\text { Reference } \\
\text { food and } \\
\text { time period }\end{array}$} \\
\hline & & & & Mean & SEM & & & & \\
\hline 495 & 108 & Taiwan, China & Yam & 52 & 0.25 & NA & 50 & $\begin{array}{l}10 \text { Healthy } \\
\text { participants }\end{array}$ & $\begin{array}{l}\text { White bread/ } \\
2 \mathrm{~h}\end{array}$ \\
\hline 496 & 109 & Taiwan & Brown rice (Taikeng 9) & 49.8 & 4.3 & NA & 50 & $\begin{array}{l}15 \text { Healthy } \\
\text { participants }\end{array}$ & Glucose $/ 2 \mathrm{~h}$ \\
\hline 497 & 109 & Taiwan & Brown rice (Taikeng 9) & 70.8 & 4.3 & NA & 50 & $\begin{array}{l}15 \text { Healthy } \\
\text { participants }\end{array}$ & $\begin{array}{l}\text { White bread/ } \\
2 \mathrm{~h}\end{array}$ \\
\hline 498 & 109 & Taiwan & Brown rice (Taichung Sen 10) & 51 & 4.9 & NA & 50 & $\begin{array}{l}15 \text { Healthy } \\
\text { participants }\end{array}$ & Glucose $/ 2 \mathrm{~h}$ \\
\hline 499 & 109 & Taiwan & Brown rice (Taichung Sen 10) & 73 & 4.7 & NA & 50 & $\begin{array}{l}15 \text { Healthy } \\
\text { participants }\end{array}$ & $\begin{array}{l}\text { White bread/ } \\
2 \mathrm{~h}\end{array}$ \\
\hline 500 & 109 & Taiwan & White rice (TRGC9152) & 52.2 & 6.3 & NA & 50 & $\begin{array}{l}15 \text { Healthy } \\
\text { participants }\end{array}$ & Glucose $/ 2 \mathrm{~h}$ \\
\hline 501 & 109 & Taiwan & White rice (TRGC9152) & 73.1 & 5.7 & NA & 50 & $\begin{array}{l}15 \text { Healthy } \\
\text { participants }\end{array}$ & $\begin{array}{l}\text { White bread/ } \\
2 \mathrm{~h}\end{array}$ \\
\hline 502 & 109 & Taiwan & White rice (IR50) & 55.6 & 4 & NA & 50 & $\begin{array}{l}15 \text { Healthy } \\
\text { participants }\end{array}$ & Glucose $/ 2 \mathrm{~h}$ \\
\hline 503 & 109 & Taiwan & White rice (IR50) & 77.3 & 4.1 & NA & 50 & $\begin{array}{l}15 \text { Healthy } \\
\text { participants }\end{array}$ & $\begin{array}{l}\text { White bread/ } \\
2 \mathrm{~h}\end{array}$ \\
\hline 504 & 109 & Taiwan & White rice (Taichung Sen 17) & 47.3 & 4.7 & NA & 50 & $\begin{array}{l}15 \text { Healthy } \\
\text { participants }\end{array}$ & Glucose $/ 2 \mathrm{~h}$ \\
\hline 505 & 109 & Taiwan & White rice (Taichung Sen 17) & 71.7 & 4.2 & NA & 50 & $\begin{array}{l}15 \text { Healthy } \\
\text { participants }\end{array}$ & $\begin{array}{l}\text { White bread/ } \\
2 \mathrm{~h}\end{array}$ \\
\hline 506 & 109 & Taiwan & White rice (Taikeng 9) & 60.5 & 5.4 & NA & 50 & $\begin{array}{l}15 \text { Healthy } \\
\text { participants }\end{array}$ & Glucose $/ 2 \mathrm{~h}$ \\
\hline 507 & 109 & Taiwan & White rice (Taikeng 9) & 87.5 & 4.3 & NA & 50 & $\begin{array}{l}15 \text { Healthy } \\
\text { participants }\end{array}$ & $\begin{array}{l}\text { White bread/ } \\
2 \mathrm{~h}\end{array}$ \\
\hline 508 & 109 & Taiwan & White rice (Taiching Sen 10) & 55.6 & 3.2 & NA & 50 & $\begin{array}{l}15 \text { Healthy } \\
\text { participants }\end{array}$ & Glucose $/ 2 \mathrm{~h}$ \\
\hline 509 & 109 & Taiwan & White rice (Taiching Sen 10) & 82.5 & 5.5 & NA & 50 & $\begin{array}{l}15 \text { Healthy } \\
\text { participants }\end{array}$ & $\begin{array}{l}\text { White bread/ } \\
2 \mathrm{~h}\end{array}$ \\
\hline 510 & 109 & Taiwan & White rice (Khazar) & 62.4 & 6.9 & NA & 50 & $\begin{array}{l}15 \text { Healthy } \\
\text { participants }\end{array}$ & Glucose $/ 2 \mathrm{~h}$ \\
\hline 511 & 109 & Taiwan & White rice (Khazar) & 88.9 & 4.1 & NA & 50 & $\begin{array}{l}15 \text { Healthy } \\
\text { participants }\end{array}$ & $\begin{array}{l}\text { White bread/ } \\
2 \mathrm{~h}\end{array}$ \\
\hline 512 & 110 & Taiwan & Steamed white rice & 91.1 & 6.8 & 107 & 50 & $\begin{array}{l}12 \text { Healthy } \\
\text { participants }\end{array}$ & Glucose $/ 2 \mathrm{~h}$ \\
\hline 513 & 110 & Taiwan & Rice porridge & 98.4 & 8.1 & 290 & 50 & $\begin{array}{l}12 \text { Healthy } \\
\text { participants }\end{array}$ & Glucose $/ 2 \mathrm{~h}$ \\
\hline 514 & 110 & Taiwan & Reheated overnight rice & 90.6 & 6.6 & 107 & 50 & $\begin{array}{l}12 \text { Healthy } \\
\text { participants }\end{array}$ & Glucose $/ 2 \mathrm{~h}$ \\
\hline 515 & 111 & Taiwan & Steamed white rice $+10 \mathrm{~g}$ of canola oil & 90.3 & 2.1 & 117 & 50 & $\begin{array}{l}12 \text { healthy } \\
\text { participants }\end{array}$ & $\begin{array}{l}\text { White rice/ } \\
2 \mathrm{~h}\end{array}$ \\
\hline 516 & 111 & Taiwan & Steamed white rice $+5 \mathrm{~g}$ dextrin fibre & 89.3 & 2.6 & 112 & 50 & $\begin{array}{l}12 \text { Healthy } \\
\text { participants }\end{array}$ & $\begin{array}{l}\text { White rice/ } \\
2 \mathrm{~h}\end{array}$ \\
\hline 517 & 111 & Taiwan & Steamed white rice $+10 \mathrm{~g}$ dextrin fibre & 88.1 & 2.1 & 117 & 50 & $\begin{array}{l}12 \text { Healthy } \\
\text { participants }\end{array}$ & $\begin{array}{l}\text { White rice/ } \\
2 \mathrm{~h}\end{array}$ \\
\hline 518 & 111 & Taiwan & Steamed white rice $+5 \mathrm{~g}$ gluten protein & 84.9 & 1.7 & 112 & 50 & $\begin{array}{l}12 \text { Healthy } \\
\text { participants }\end{array}$ & $\begin{array}{l}\text { White rice/ } \\
2 \mathrm{~h}\end{array}$ \\
\hline 519 & 111 & Taiwan & Steamed white rice $+10 \mathrm{~g}$ gluten protein & 83.1 & 1.6 & 117 & 50 & $\begin{array}{l}12 \text { Healthy } \\
\text { participants }\end{array}$ & $\begin{array}{l}\text { White rice/ } \\
2 \mathrm{~h}\end{array}$ \\
\hline 520 & 111 & Taiwan & $\begin{array}{l}\text { Steamed white rice }+5 \mathrm{~g} \text { gluten protein }+5 \mathrm{~g} \\
\text { dextrin fibre }\end{array}$ & 88.5 & 1.9 & 117 & 50 & $\begin{array}{l}12 \text { Healthy } \\
\text { participants }\end{array}$ & $\begin{array}{l}\text { White rice/ } \\
2 \mathrm{~h}\end{array}$ \\
\hline 521 & 111 & Taiwan & $\begin{array}{l}\text { Steamed white rice }+5 \mathrm{~g} \text { gluten protein }+ \\
10 \mathrm{~g} \text { dextrin fibre }\end{array}$ & 88.8 & 1.3 & 122 & 50 & $\begin{array}{l}12 \text { Healthy } \\
\text { participants }\end{array}$ & $\begin{array}{l}\text { White rice/ } \\
2 \mathrm{~h}\end{array}$ \\
\hline 522 & 111 & Taiwan & $\begin{array}{l}\text { Steamed white rice }+10 \mathrm{~g} \text { gluten protein }+ \\
5 \mathrm{~g} \text { dextrin fibre }\end{array}$ & 86.2 & 1.3 & 122 & 50 & $\begin{array}{l}12 \text { Healthy } \\
\text { participants }\end{array}$ & $\begin{array}{l}\text { White rice/ } \\
2 \mathrm{~h}\end{array}$ \\
\hline 523 & 111 & Taiwan & $\begin{array}{l}\text { Steamed white rice }+10 \mathrm{~g} \text { gluten protein } \\
+10 \mathrm{~g} \text { dextrin fibre }\end{array}$ & 86.1 & 1.7 & 127 & 50 & $\begin{array}{l}12 \text { Healthy } \\
\text { participants }\end{array}$ & $\begin{array}{l}\text { White rice/ } \\
2 \mathrm{~h}\end{array}$ \\
\hline 524 & 111 & Taiwan & $\begin{array}{l}\text { Steamed white rice }+5 \mathrm{~g} \text { of canola oil }+5 \mathrm{~g} \\
\text { gluten protein }\end{array}$ & 92 & 2.1 & 117 & 50 & $\begin{array}{l}12 \text { Healthy } \\
\text { participants }\end{array}$ & $\begin{array}{l}\text { White rice/ } \\
2 \mathrm{~h}\end{array}$ \\
\hline 525 & 111 & Taiwan & $\begin{array}{l}\text { Steamed white rice }+5 \mathrm{~g} \text { of canola oil }+10 \mathrm{~g} \\
\text { gluten protein }\end{array}$ & 91.9 & 2.3 & 122 & 50 & $\begin{array}{l}12 \text { Healthy } \\
\text { participants }\end{array}$ & $\begin{array}{l}\text { White rice/ } \\
2 \mathrm{~h}\end{array}$ \\
\hline 526 & 111 & Taiwan & $\begin{array}{l}\text { Steamed white rice }+10 \mathrm{~g} \text { of canola oil }+5 \mathrm{~g} \\
\text { gluten protein }\end{array}$ & 93.1 & 2.2 & 122 & 50 & $\begin{array}{l}12 \text { Healthy } \\
\text { participants }\end{array}$ & $\begin{array}{l}\text { White rice/ } \\
2 \mathrm{~h}\end{array}$ \\
\hline 527 & 111 & Taiwan & $\begin{array}{l}\text { Steamed white rice }+10 \mathrm{~g} \text { of canola oil }+10 \mathrm{~g} \\
\text { gluten protein }\end{array}$ & 91.3 & 1.7 & 127 & 50 & $\begin{array}{l}12 \text { Healthy } \\
\text { participants }\end{array}$ & $\begin{array}{l}\text { White rice/ } \\
2 \mathrm{~h}\end{array}$ \\
\hline 528 & 111 & Taiwan & $\begin{array}{l}\text { Steamed white rice }+5 \mathrm{~g} \text { of canola oil }+5 \mathrm{~g} \\
\text { dextrin fibre }\end{array}$ & 92.4 & 2.2 & 117 & 50 & $\begin{array}{l}12 \text { Healthy } \\
\text { participants }\end{array}$ & $\begin{array}{l}\text { White rice/ } \\
2 \mathrm{~h}\end{array}$ \\
\hline
\end{tabular}


Table 1 continued

\begin{tabular}{|c|c|c|c|c|c|c|c|c|c|}
\hline & \multirow[t]{2}{*}{ Reference } & \multirow[t]{2}{*}{ Country } & \multirow[t]{2}{*}{ Food item } & \multicolumn{2}{|c|}{ GI (glucose $=100)$} & \multirow{2}{*}{$\begin{array}{l}\text { Serving size }(g) \text { per experimental } \\
\text { portion size }\end{array}$} & \multirow{2}{*}{$\begin{array}{l}\text { Available CHO } \\
\text { (g) per } \\
\text { experimental } \\
\text { portion }\end{array}$} & \multirow{2}{*}{$\begin{array}{l}\text { Participants } \\
\text { (type and } \\
\text { number) }\end{array}$} & \multirow{2}{*}{$\begin{array}{l}\text { Reference } \\
\text { food and } \\
\text { time period }\end{array}$} \\
\hline & & & & Mean & SEM & & & & \\
\hline 529 & 111 & Taiwan & $\begin{array}{l}\text { Steamed white rice }+5 \mathrm{~g} \text { of canola oil }+10 \mathrm{~g} \\
\text { dextrin fibre }\end{array}$ & 94 & 2.2 & 122 & 50 & $\begin{array}{l}12 \text { Healthy } \\
\text { participants }\end{array}$ & $\begin{array}{l}\text { White rice/ } \\
2 \mathrm{~h}\end{array}$ \\
\hline 530 & 111 & Taiwan & $\begin{array}{l}\text { Steamed white rice }+10 \mathrm{~g} \text { of canola oil }+5 \mathrm{~g} \\
\text { dextrin fibre }\end{array}$ & 96 & 2 & 122 & 50 & $\begin{array}{l}12 \text { Healthy } \\
\text { participants }\end{array}$ & $\begin{array}{l}\text { White rice/ } \\
2 \mathrm{~h}\end{array}$ \\
\hline 531 & 111 & Taiwan & $\begin{array}{l}\text { Steamed white rice }+10 \mathrm{~g} \text { of canola oil }+10 \mathrm{~g} \\
\text { dextrin fibre }\end{array}$ & 96.3 & 2.2 & 127 & 50 & $\begin{array}{l}12 \text { Healthy } \\
\text { participants }\end{array}$ & $\begin{array}{l}\text { White rice/ } \\
2 \mathrm{~h}\end{array}$ \\
\hline 532 & 111 & Taiwan & $\begin{array}{l}\text { Steamed white rice }+5 \mathrm{~g} \text { gluten protein }+5 \mathrm{~g} \\
\text { dextrin fibre }+5 \mathrm{~g} \text { canola oil }\end{array}$ & 92 & 2.6 & 122 & 50 & $\begin{array}{l}12 \text { Healthy } \\
\text { participants }\end{array}$ & $\begin{array}{l}\text { White rice/ } \\
2 \mathrm{~h}\end{array}$ \\
\hline 533 & 111 & Taiwan & $\begin{array}{l}\text { Steamed white rice }+5 \mathrm{~g} \text { gluten protein }+ \\
10 \mathrm{~g} \text { dextrin fibre }+5 \mathrm{~g} \text { canola oil }\end{array}$ & 92.4 & 1.6 & 127 & 50 & $\begin{array}{l}12 \text { Healthy } \\
\text { participants }\end{array}$ & $\begin{array}{l}\text { White rice/ } \\
2 \mathrm{~h}\end{array}$ \\
\hline 534 & 111 & Taiwan & $\begin{array}{l}\text { Steamed white rice }+10 \mathrm{~g} \text { gluten protein }+ \\
5 \mathrm{~g} \text { dextrin fibre }+5 \mathrm{~g} \text { canola oil }\end{array}$ & 91.5 & 1.9 & 127 & 50 & $\begin{array}{l}12 \text { Healthy } \\
\text { participants }\end{array}$ & $\begin{array}{l}\text { White rice/ } \\
2 \mathrm{~h}\end{array}$ \\
\hline 535 & 111 & Taiwan & $\begin{array}{l}\text { Steamed white rice }+10 \mathrm{~g} \text { gluten protein }+ \\
10 \mathrm{~g} \text { dextrin fibre }+5 \mathrm{~g} \text { canola oil }\end{array}$ & 89 & 2.2 & 132 & 50 & $\begin{array}{l}12 \text { Healthy } \\
\text { participants }\end{array}$ & $\begin{array}{l}\text { White rice/ } \\
2 \mathrm{~h}\end{array}$ \\
\hline 536 & 111 & Taiwan & $\begin{array}{l}\text { Steamed white rice }+5 \mathrm{~g} \text { gluten protein }+5 \mathrm{~g} \\
\text { dextrin fibre }+10 \mathrm{~g} \text { canola oil }\end{array}$ & 94.2 & 2.3 & 127 & 50 & $\begin{array}{l}12 \text { Healthy } \\
\text { participants }\end{array}$ & $\begin{array}{l}\text { White rice/ } \\
2 \mathrm{~h}\end{array}$ \\
\hline 537 & 111 & Taiwan & $\begin{array}{l}\text { Steamed white rice }+5 \mathrm{~g} \text { gluten protein }+ \\
10 \mathrm{~g} \text { dextrin fibre }+10 \mathrm{~g} \text { canola oil }\end{array}$ & 93.1 & 1.6 & 132 & 50 & $\begin{array}{l}12 \text { Healthy } \\
\text { participants }\end{array}$ & $\begin{array}{l}\text { White rice/ } \\
2 \mathrm{~h}\end{array}$ \\
\hline 538 & 111 & Taiwan & $\begin{array}{l}\text { Steamed white rice }+10 \mathrm{~g} \text { gluten protein }+ \\
5 \mathrm{~g} \text { dextrin fibre }+0 \mathrm{~g} \text { canola oil }\end{array}$ & 95.8 & 1.4 & 132 & 50 & $\begin{array}{l}12 \text { Healthy } \\
\text { participants }\end{array}$ & $\begin{array}{l}\text { White rice/ } \\
2 \mathrm{~h}\end{array}$ \\
\hline 539 & 111 & Taiwan & $\begin{array}{l}\text { Steamed white rice }+10 \mathrm{~g} \text { gluten protein }+ \\
10 \mathrm{~g} \text { dextrin fibre }+10 \mathrm{~g} \text { canola oil }\end{array}$ & 88.6 & 1.9 & 137 & 50 & $\begin{array}{l}12 \text { Healthy } \\
\text { participants }\end{array}$ & $\begin{array}{l}\text { White rice/ } \\
2 \mathrm{~h}\end{array}$ \\
\hline 540 & 112 & $\begin{array}{l}\text { Hong } \\
\text { Kong, China }\end{array}$ & Baked barbecued pork puff & 55 & 8 & 161 & 50 & $\begin{array}{l}15 \text { Healthy } \\
\text { participants }\end{array}$ & Glucose $/ 2 \mathrm{~h}$ \\
\hline 541 & 112 & $\begin{array}{l}\text { Hong } \\
\text { Kong, China }\end{array}$ & Fried rice in Yangzhou style & 80 & 6 & 217 & 50 & $\begin{array}{l}15 \text { Healthy } \\
\text { participants }\end{array}$ & Glucose $/ 2 \mathrm{~h}$ \\
\hline 542 & 112 & $\begin{array}{l}\text { Hong } \\
\text { Kong, China }\end{array}$ & Fried fritter & 69 & 9 & 139 & 50 & $\begin{array}{l}15 \text { Healthy } \\
\text { participants }\end{array}$ & Glucose $/ 2 \mathrm{~h}$ \\
\hline 543 & 112 & $\begin{array}{l}\text { Hong } \\
\text { Kong, China }\end{array}$ & 'Mai-Lai' cake & 61 & 8 & 114 & 50 & $\begin{array}{l}15 \text { Healthy } \\
\text { participants }\end{array}$ & Glucose $/ 2 \mathrm{~h}$ \\
\hline 544 & 112 & $\begin{array}{l}\text { Hong } \\
\text { Kong, China }\end{array}$ & Tuna fish bun & 46 & 4 & 139 & 50 & $\begin{array}{l}15 \text { Healthy } \\
\text { participants }\end{array}$ & Glucose $/ 2 \mathrm{~h}$ \\
\hline 545 & 112 & $\begin{array}{l}\text { Hong } \\
\text { Kong, China }\end{array}$ & Sticky rice wrapped in lotus leaf & 83 & 5 & 167 & 50 & $\begin{array}{l}15 \text { Healthy } \\
\text { participants }\end{array}$ & Glucose $/ 2 \mathrm{~h}$ \\
\hline 546 & 112 & $\begin{array}{l}\text { Hong } \\
\text { Kong, China }\end{array}$ & Steamed glutinous rice roll & 89 & 8 & 109 & 50 & $\begin{array}{l}15 \text { Healthy } \\
\text { participants }\end{array}$ & Glucose $/ 2 \mathrm{~h}$ \\
\hline 547 & 112 & $\begin{array}{l}\text { Hong } \\
\text { Kong, China }\end{array}$ & 'Pineapple' bun & 65 & 8 & 91 & 50 & $\begin{array}{l}15 \text { Healthy } \\
\text { participants }\end{array}$ & Glucose $/ 2 \mathrm{~h}$ \\
\hline 548 & 112 & $\begin{array}{l}\text { Hong } \\
\text { Kong, China }\end{array}$ & Jam and peanut butter toast & 72 & 8 & 106 & 50 & $\begin{array}{l}15 \text { Healthy } \\
\text { participants }\end{array}$ & Glucose $/ 2 \mathrm{~h}$ \\
\hline 549 & 112 & $\begin{array}{l}\text { Hong } \\
\text { Kong, China }\end{array}$ & Fried rice noodles with sliced beef & 66 & 7 & 250 & 50 & $\begin{array}{l}15 \text { Healthy } \\
\text { participants }\end{array}$ & Glucose $/ 2 \mathrm{~h}$ \\
\hline 550 & 112 & $\begin{array}{l}\text { Hong } \\
\text { Kong, China }\end{array}$ & Egg tart & 45 & 3 & 143 & 50 & $\begin{array}{l}15 \text { Healthy } \\
\text { participants }\end{array}$ & Glucose $/ 2 \mathrm{~h}$ \\
\hline 551 & 112 & $\begin{array}{l}\text { Hong } \\
\text { Kong, China }\end{array}$ & Plain steamed vermicelli roll & 90 & 8 & 238 & 50 & $\begin{array}{l}15 \text { Healthy } \\
\text { participants }\end{array}$ & Glucose $/ 2 \mathrm{~h}$ \\
\hline 552 & 112 & $\begin{array}{l}\text { Hong } \\
\text { Kong, China }\end{array}$ & Green bean dessert & 54 & 6 & 333 & 50 & $\begin{array}{l}15 \text { Healthy } \\
\text { participants }\end{array}$ & Glucose $/ 2 \mathrm{~h}$ \\
\hline 553 & 112 & $\begin{array}{l}\text { Hong } \\
\text { Kong, China }\end{array}$ & Barbecue pork bun & 69 & 9 & 119 & 50 & $\begin{array}{l}15 \text { Healthy } \\
\text { participants }\end{array}$ & Glucose $/ 2 \mathrm{~h}$ \\
\hline 554 & 112 & $\begin{array}{l}\text { Hong } \\
\text { Kong, China }\end{array}$ & Red bean dessert & 75 & 8 & 263 & 50 & $\begin{array}{l}15 \text { Healthy } \\
\text { participants }\end{array}$ & Glucose $/ 2 \mathrm{~h}$ \\
\hline 555 & 112 & $\begin{array}{l}\text { Hong } \\
\text { Kong, China }\end{array}$ & Moon cakes & 56 & 7 & 80 & 50 & $\begin{array}{l}15 \text { Healthy } \\
\text { participants }\end{array}$ & Glucose $/ 2 \mathrm{~h}$ \\
\hline 556 & 112 & $\begin{array}{l}\text { Hong } \\
\text { Kong, China }\end{array}$ & Glutinous rice ball & 61 & 10 & 115 & 50 & $\begin{array}{l}15 \text { Healthy } \\
\text { participants }\end{array}$ & Glucose $/ 2 \mathrm{~h}$ \\
\hline 557 & 112 & $\begin{array}{l}\text { Hong } \\
\text { Kong, China }\end{array}$ & Chinese herbal jelly & 47 & 3 & 333 & 50 & $\begin{array}{l}15 \text { Healthy } \\
\text { participants }\end{array}$ & Glucose $/ 2 \mathrm{~h}$ \\
\hline 558 & 112 & $\begin{array}{l}\text { Hong } \\
\text { Kong, China }\end{array}$ & Instant sweet milky bun & 67 & 5 & 114 & 50 & $\begin{array}{l}15 \text { Healthy } \\
\text { participants }\end{array}$ & Glucose $/ 2 \mathrm{~h}$ \\
\hline 559 & 112 & $\begin{array}{l}\text { Hong } \\
\text { Kong, China }\end{array}$ & Frozen sweet milky bun & 72 & 8 & 114 & 50 & $\begin{array}{l}15 \text { Healthy } \\
\text { participants }\end{array}$ & Glucose $/ 2 \mathrm{~h}$ \\
\hline 560 & 112 & $\begin{array}{l}\text { Hong } \\
\text { Kong, China }\end{array}$ & Fried rice vermicelli in Singapore style & 54 & 6 & 333 & 50 & $\begin{array}{l}15 \text { Healthy } \\
\text { participants }\end{array}$ & Glucose $/ 2 \mathrm{~h}$ \\
\hline 561 & $\begin{array}{l}\text { Chen } \\
\text { et al., 2010) }\end{array}$ & $\begin{array}{l}\text { Hong } \\
\text { Kong, China }\end{array}$ & Fried rice vermicelli in Singapore style & 69 & 8 & 167 & 50 & $\begin{array}{l}15 \text { Healthy } \\
\text { participants }\end{array}$ & Glucose $/ 2 \mathrm{~h}$ \\
\hline 562 & 112 & $\begin{array}{l}\text { Hong } \\
\text { Kong, China }\end{array}$ & Salted meat rice dumpling & 58 & 9 & 200 & 50 & $\begin{array}{l}15 \text { Healthy } \\
\text { participants }\end{array}$ & Glucose $/ 2 \mathrm{~h}$ \\
\hline
\end{tabular}


Table 1 continued

\begin{tabular}{|c|c|c|c|c|c|c|c|c|c|}
\hline & \multirow[t]{2}{*}{ Reference } & \multirow[t]{2}{*}{ Country } & \multirow[t]{2}{*}{ Food item } & \multicolumn{2}{|c|}{ GI (glucose $=100)$} & \multirow{2}{*}{$\begin{array}{l}\text { Serving size }(g) \text { per experimental } \\
\text { portion size }\end{array}$} & \multirow{2}{*}{$\begin{array}{l}\text { Available } \mathrm{CHO} \\
\text { (g) per } \\
\text { experimental } \\
\text { portion }\end{array}$} & \multirow{2}{*}{$\begin{array}{l}\text { Participants } \\
\text { (type and } \\
\text { number) }\end{array}$} & \multirow{2}{*}{$\begin{array}{l}\text { Reference } \\
\text { food and } \\
\text { time perioo }\end{array}$} \\
\hline & & & & Mean & SEM & & & & \\
\hline 563 & 112 & $\begin{array}{l}\text { Hong } \\
\text { Kong, China }\end{array}$ & Salted meat rice dumpling & 81 & 7 & 100 & 50 & $\begin{array}{l}15 \text { Healthy } \\
\text { participants }\end{array}$ & Glucose $/ 2 \mathrm{~h}$ \\
\hline 564 & 112 & $\begin{array}{l}\text { Hong } \\
\text { Kong, China }\end{array}$ & Spring roll & 50 & 5 & 114 & 50 & $\begin{array}{l}15 \text { Healthy } \\
\text { participants }\end{array}$ & Glucose $/ 2 \mathrm{~h}$ \\
\hline 565 & 113 & Hong Kong & Jianxi rice vermicelli & 56 & 7 & 63.3 & 50 & $\begin{array}{l}23 \text { Healthy } \\
\text { participants }\end{array}$ & Glucose $/ 2 \mathrm{~h}$ \\
\hline 566 & 113 & Hong Kong & Sau tao Bejing noodles & 61 & 5 & 69.2 & 50 & $\begin{array}{l}23 \text { Healthy } \\
\text { participants }\end{array}$ & Glucose $/ 2 \mathrm{~h}$ \\
\hline 567 & 113 & Hong Kong & Taiwan vermicelli & 68 & 12 & 54.4 & 50 & $\begin{array}{l}23 \text { Healthy } \\
\text { participants }\end{array}$ & Glucose $/ 2 \mathrm{~h}$ \\
\hline 568 & 113 & Hong Kong & $\begin{array}{l}\text { Sau tao chicken-flavoured Sichuan spicy } \\
\text { noodles }\end{array}$ & 65 & 4 & 75.4 & 50 & $\begin{array}{l}23 \text { Healthy } \\
\text { participants }\end{array}$ & Glucose $/ 2 \mathrm{~h}$ \\
\hline 569 & 113 & Hong Kong & Doll fried noodles & 88 & 8 & 105.2 & 50 & $\begin{array}{l}23 \text { Healthy } \\
\text { participants }\end{array}$ & Glucose $/ 2 \mathrm{~h}$ \\
\hline 570 & 113 & Hong Kong & Garden milk bar bun & 73 & 8 & 105 & 50 & $\begin{array}{l}23 \text { Healthy } \\
\text { participants }\end{array}$ & Glucose $/ 2 \mathrm{~h}$ \\
\hline 571 & 113 & Hong Kong & Linola seed bread & 90 & 11 & 116.8 & 50 & $\begin{array}{l}23 \text { Healthy } \\
\text { participants }\end{array}$ & Glucose $/ 2 \mathrm{~h}$ \\
\hline 572 & 114 & West India & Round leaf yellow yam, boiled & 68 & 3 & 223.02 & 50 & $\begin{array}{l}10 \text { Healthy } \\
\text { participants }\end{array}$ & Glucose $/ 2 \mathrm{~h}$ \\
\hline 573 & 114 & West India & Round leaf yellow yam, roasted & 80 & 7 & 186.43 & 50 & $\begin{array}{l}10 \text { Healthy } \\
\text { participants }\end{array}$ & Glucose $/ 2 \mathrm{~h}$ \\
\hline 574 & 114 & West India & Negro yam, boiled & 73 & 4 & 235.07 & 50 & $\begin{array}{l}10 \text { Healthy } \\
\text { participants }\end{array}$ & Glucose $/ 2 \mathrm{~h}$ \\
\hline 575 & 114 & West India & Negro yam, roasted & 73 & 6 & 194.25 & 50 & $\begin{array}{l}10 \text { Healthy } \\
\text { participants }\end{array}$ & Glucose $/ 2 \mathrm{~h}$ \\
\hline 576 & 114 & West India & Lucea yam, boiled & 74 & 7 & 274.42 & 50 & $\begin{array}{l}10 \text { Healthy } \\
\text { participants }\end{array}$ & Glucose $/ 2 \mathrm{~h}$ \\
\hline 577 & 114 & West India & Lucea yam, roasted & 77 & 5 & 198.18 & 50 & $\begin{array}{l}10 \text { Healthy } \\
\text { participants }\end{array}$ & Glucose $/ 2 \mathrm{~h}$ \\
\hline 578 & 114 & West India & White yam, boiled & 75 & 6 & 239.00 & 50 & $\begin{array}{l}10 \text { Healthy } \\
\text { participants }\end{array}$ & Glucose $/ 2 \mathrm{~h}$ \\
\hline 579 & 114 & West India & White yam, roasted & 80 & 6 & 214.13 & 50 & $\begin{array}{l}10 \text { Healthy } \\
\text { participants }\end{array}$ & Glucose $/ 2 \mathrm{~h}$ \\
\hline 580 & 114 & West India & Sweet yam, boiled & 79 & 4 & 297.97 & 50 & $\begin{array}{l}10 \text { Healthy } \\
\text { participants }\end{array}$ & Glucose $/ 2 \mathrm{~h}$ \\
\hline 581 & 114 & West India & Sweet yam, roasted & 82 & 7 & 192.53 & 50 & $\begin{array}{l}10 \text { Healthy } \\
\text { participants }\end{array}$ & Glucose $/ 2 \mathrm{~h}$ \\
\hline 582 & 114 & West India & Sweet potato, boiled & 46 & 5 & 234.63 & 50 & $\begin{array}{l}10 \text { Healthy } \\
\text { participants }\end{array}$ & Glucose $/ 2 \mathrm{~h}$ \\
\hline 583 & 114 & West India & Sweet potato, roasted & 82 & 5 & 167.79 & 50 & $\begin{array}{l}10 \text { Healthy } \\
\text { participants }\end{array}$ & Glucose $/ 2 \mathrm{~h}$ \\
\hline 584 & 114 & West India & Sweet potato, baked & 94 & 8 & 167.79 & 50 & $\begin{array}{l}10 \text { Healthy } \\
\text { participants }\end{array}$ & Glucose $/ 2 \mathrm{~h}$ \\
\hline 585 & 114 & West India & Sweet potato, fried & 76 & 7 & 167.79 & 50 & $\begin{array}{l}10 \text { Healthy } \\
\text { participants }\end{array}$ & Glucose $/ 2 \mathrm{~h}$ \\
\hline 586 & 114 & West India & Irish potato, boiled & 59 & 4 & 230.95 & 50 & $\begin{array}{l}10 \text { Healthy } \\
\text { participants }\end{array}$ & Glucose $/ 2 \mathrm{~h}$ \\
\hline 587 & 114 & West India & Irish potato, baked & 83 & 6 & 249.63 & 50 & $\begin{array}{l}10 \text { Healthy } \\
\text { participants }\end{array}$ & Glucose $/ 2 \mathrm{~h}$ \\
\hline 588 & 114 & West India & Irish potato, fried & 70 & 6 & 249.63 & 50 & $\begin{array}{l}10 \text { Healthy } \\
\text { participants }\end{array}$ & Glucose $/ 2 \mathrm{~h}$ \\
\hline 589 & 114 & West India & Dasheen, boiled & 72 & 5 & 279.30 & 50 & $\begin{array}{l}10 \text { Healthy } \\
\text { participants }\end{array}$ & Glucose $/ 2 \mathrm{~h}$ \\
\hline 590 & 114 & West India & Coco yam, boiled & 61 & 5 & 482.63 & 50 & $\begin{array}{l}10 \text { Healthy } \\
\text { participants }\end{array}$ & Glucose $/ 2 \mathrm{~h}$ \\
\hline 591 & 114 & West India & Pumpkin, boiled & 66 & 4 & 223.81 & 50 & $\begin{array}{l}10 \text { Healthy } \\
\text { participants }\end{array}$ & Glucose $/ 2 \mathrm{~h}$ \\
\hline 592 & 114 & West India & Breadfruit, boiled & 47 & 5 & 276.55 & 50 & $\begin{array}{l}10 \text { Healthy } \\
\text { participants }\end{array}$ & Glucose $/ 2 \mathrm{~h}$ \\
\hline 593 & 114 & West India & Breadfruit, roasted & 72 & 8 & 221.34 & 50 & $\begin{array}{l}10 \text { Healthy } \\
\text { participants }\end{array}$ & Glucose $/ 2 \mathrm{~h}$ \\
\hline 594 & 114 & West India & Green banana, boiled & 37 & 5 & 225.23 & 50 & $\begin{array}{l}10 \text { Healthy } \\
\text { participants }\end{array}$ & Glucose $/ 2 \mathrm{~h}$ \\
\hline 595 & 114 & West India & Green banana, fried & 35 & 3 & 195.31 & 50 & $\begin{array}{l}10 \text { Healthy } \\
\text { participants }\end{array}$ & Glucose $/ 2 \mathrm{~h}$ \\
\hline 596 & 114 & West India & Green plantain, boiled & 39 & 4 & 259.20 & 50 & $\begin{array}{l}10 \text { Healthy } \\
\text { participants }\end{array}$ & Glucose $/ 2 \mathrm{~h}$ \\
\hline
\end{tabular}


Table 1 continued

\begin{tabular}{|c|c|c|c|c|c|c|c|c|c|}
\hline & \multirow[t]{2}{*}{ Reference } & \multirow[t]{2}{*}{ Country } & \multirow[t]{2}{*}{ Food item } & \multicolumn{2}{|c|}{ GI (glucose $=100)$} & \multirow{2}{*}{$\begin{array}{l}\text { Serving size }(g) \text { per experimental } \\
\text { portion size }\end{array}$} & \multirow{2}{*}{$\begin{array}{l}\text { Available } \mathrm{CHO} \\
\text { (g) per } \\
\text { experimental } \\
\text { portion }\end{array}$} & \multirow{2}{*}{$\begin{array}{l}\text { Participants } \\
\text { (type and } \\
\text { number) }\end{array}$} & \multirow{2}{*}{$\begin{array}{l}\text { Reference } \\
\text { food and } \\
\text { time period }\end{array}$} \\
\hline & & & & Mean & SEM & & & & \\
\hline 597 & 114 & West India & Green plantain, fried & 40 & 3 & 175.93 & 50 & $\begin{array}{l}10 \text { Healthy } \\
\text { participants }\end{array}$ & Glucose $/ 2 \mathrm{~h}$ \\
\hline 598 & 114 & West India & Ripe plantain, boiled & 66 & 2 & 308.64 & 50 & $\begin{array}{l}10 \text { Healthy } \\
\text { participants }\end{array}$ & Glucose $/ 2 \mathrm{~h}$ \\
\hline 599 & 114 & West India & Ripe plantain, fried & 90 & 6 & 211.60 & 50 & $\begin{array}{l}10 \text { Healthy } \\
\text { participants }\end{array}$ & Glucose $/ 2 \mathrm{~h}$ \\
\hline 600 & 115 & India & $\begin{array}{l}\text { Biscuits ( } 45 \% \text { foxtail millet }+55 \% \text { refined } \\
\text { wheat flour) }\end{array}$ & 50.8 & $27.9(S D)$ & 90 & 50 & $\begin{array}{l}13 \text { Healthy } \\
\text { participants }\end{array}$ & Glucose $/ 2.5 \mathrm{~h}$ \\
\hline 601 & 115 & India & $\begin{array}{l}\text { Biscuits ( } 45 \% \text { barnyard millet }+55 \% \text { refined } \\
\text { wheat flour) }\end{array}$ & 68 & $60.3(S D)$ & 96 & 50 & $\begin{array}{l}13 \text { Healthy } \\
\text { participants }\end{array}$ & Glucose $/ 2.5 \mathrm{~h}$ \\
\hline 602 & 115 & India & Biscuits (crude refined wheat flour) & 68 & $52.8(S D)$ & 90 & 50 & $\begin{array}{l}13 \text { Healthy } \\
\text { participants }\end{array}$ & Glucose $/ 2.5 \mathrm{~h}$ \\
\hline 603 & 116 & India & Papaya bar (control) & 65 & NA & 64 & 50 & $\begin{array}{l}15 \text { Healthy } \\
\text { participants }\end{array}$ & Glucose $/ 2 \mathrm{~h}$ \\
\hline 604 & 116 & India & $\begin{array}{l}\text { Papaya bar (treated with inulin and } \\
\text { fructooligosaccharides) }\end{array}$ & 54 & NA & 65 & 50 & $\begin{array}{l}15 \text { Healthy } \\
\text { participants }\end{array}$ & Glucose $/ 2 \mathrm{~h}$ \\
\hline 605 & 117 & India & Banana (yallakki) & 43 & NA & 120 & 25 & $\begin{array}{l}10 \text { Healthy } \\
\text { participants }\end{array}$ & Glucose $/ 2 \mathrm{~h}$ \\
\hline 606 & 117 & India & Mango (Raspuri) & 35 & NA & 120 & 25 & $\begin{array}{l}10 \text { Healthy } \\
\text { participants }\end{array}$ & Glucose $/ 2 \mathrm{~h}$ \\
\hline 607 & 117 & India & Papaya & 19 & NA & 120 & 29 & $\begin{array}{l}10 \text { Healthy } \\
\text { participants }\end{array}$ & Glucose $/ 2 \mathrm{~h}$ \\
\hline 608 & 117 & India & Orange & 52 & NA & 120 & 10 & $\begin{array}{l}10 \text { Healthy } \\
\text { participants }\end{array}$ & Glucose $/ 2 \mathrm{~h}$ \\
\hline 609 & 117 & India & Guava & 78 & NA & 120 & 11.5 & $\begin{array}{l}10 \text { Healthy } \\
\text { participants }\end{array}$ & Glucose $/ 2 \mathrm{~h}$ \\
\hline 610 & 117 & India & Chikku & 73 & NA & 120 & 29 & $\begin{array}{l}10 \text { Healthy } \\
\text { participants }\end{array}$ & Glucose $/ 2 \mathrm{~h}$ \\
\hline 611 & 117 & India & Jackfruit & 63 & NA & 120 & 28.8 & $\begin{array}{l}10 \text { Healthy } \\
\text { participants }\end{array}$ & Glucose $/ 2 \mathrm{~h}$ \\
\hline 612 & 117 & India & Watermelon & 37 & NA & 120 & 6 & $\begin{array}{l}10 \text { Healthy } \\
\text { participants }\end{array}$ & Glucose $/ 2 \mathrm{~h}$ \\
\hline 613 & 117 & India & Pineapple & 19 & NA & 120 & 10 & $\begin{array}{l}10 \text { Healthy } \\
\text { participants }\end{array}$ & Glucose $/ 2 \mathrm{~h}$ \\
\hline 614 & 117 & India & Apple & 45 & NA & 120 & 16 & $\begin{array}{l}10 \text { Healthy } \\
\text { participants }\end{array}$ & Glucose $/ 2 \mathrm{~h}$ \\
\hline 615 & 118 & India & $\begin{array}{l}\text { Roasted Amaranth } \\
\text { Grains flour chapatti }\end{array}$ & 84.83 & 50 & 117.5 & 50 & $\begin{array}{l}50 \text { NIDDM } \\
\text { participants }\end{array}$ & Glucose $/ 2 \mathrm{~h}$ \\
\hline 616 & 118 & India & $\begin{array}{l}\text { Boiled Amaranth } \\
\text { Grains flour chapatti }\end{array}$ & 111.83 & 75 & 118 & 50 & $\begin{array}{l}50 \mathrm{NIDDM} \\
\text { participants }\end{array}$ & Glucose/2 h \\
\hline 617 & 118 & India & $\begin{array}{l}\text { Popped Amaranth } \\
\text { Grains flour chapatti }\end{array}$ & 44 & 25.08 & 116.34 & 50 & $\begin{array}{l}50 \mathrm{NIDDM} \\
\text { participants }\end{array}$ & Glucose $/ 2 \mathrm{~h}$ \\
\hline 618 & 118 & India & $\begin{array}{l}\text { Raw Amaranth } \\
\text { Grains flour chapatti }\end{array}$ & 102.3 & 76.4 & 121.39 & 50 & $\begin{array}{l}50 \mathrm{NIDDM} \\
\text { participants }\end{array}$ & Glucose $/ 2 \mathrm{~h}$ \\
\hline 619 & 119 & India & Sona Masuri (parboiled rice) & 72 & 4.5 & 235 & 50 & $\begin{array}{l}30 \text { Healthy } \\
\text { participants }\end{array}$ & Glucose $/ 2 \mathrm{~h}$ \\
\hline 620 & 119 & India & Ponni (parboiled rice) & 70.2 & 3.6 & 236 & 50 & $\begin{array}{l}30 \text { Healthy } \\
\text { participants }\end{array}$ & Glucose $/ 2 \mathrm{~h}$ \\
\hline 621 & 119 & India & Surti Kolam (parboiled rice) & 77 & 4.0 & 259 & 50 & $\begin{array}{l}30 \text { Healthy } \\
\text { participants }\end{array}$ & Glucose $/ 2 \mathrm{~h}$ \\
\hline 622 & 120 & India & $\begin{array}{l}\text { Burfi (made with } 43 \% \text { foxtail millet, } 57 \% \text { bengal } \\
\text { gram flour) }\end{array}$ & 37.5 & $18.5(\mathrm{SD})$ & NA & 50 & $\begin{array}{l}10 \text { Healthy } \\
\text { participants }\end{array}$ & Glucose $/ 2.5 \mathrm{~h}$ \\
\hline 623 & 120 & India & $\begin{array}{l}\text { Burfi (made with } 43 \% \text { barnyard millet, 57\% } \\
\text { bengal gram flour) }\end{array}$ & 45.0 & 14.5 (SD) & NA & 50 & $\begin{array}{l}10 \text { Healthy } \\
\text { participants }\end{array}$ & Glucose $/ 2.5 \mathrm{~h}$ \\
\hline 624 & 120 & India & Burfi (made with 100\% bengal gram flour) & 43.0 & 14.9 & NA & 50 & $\begin{array}{l}10 \text { Healthy } \\
\text { participants }\end{array}$ & Glucose $/ 2.5 \mathrm{~h}$ \\
\hline 625 & 121 & India & $\begin{array}{l}\text { Namkeen sev (without dried bottle gourd pulp } \\
\text { powder) [bengal gram flour + kidney bean } \\
\text { flour (50:50)] }\end{array}$ & 32.82 & NA & NA & 50 & $\begin{array}{l}10 \text { Healthy } \\
\text { participants }\end{array}$ & Glucose $/ 2 \mathrm{~h}$ \\
\hline 626 & 121 & India & $\begin{array}{l}\text { Namkeen sev (with dried bottle gourd pulp } \\
\text { powder) [bengal gram flour + kidney bean } \\
\text { flour + DBPP (40:40:20)] }\end{array}$ & 21.83 & NA & NA & 50 & $\begin{array}{l}10 \text { Healthy } \\
\text { participants }\end{array}$ & Glucose $/ 2 \mathrm{~h}$ \\
\hline 627 & 122 & India & Idli & 67.11 & 3.25 & 70 & 50 & $\begin{array}{l}10 \text { Healthy } \\
\text { participants }\end{array}$ & Glucose $/ 2 \mathrm{~h}$ \\
\hline 628 & 122 & India & Sewai upma & 69.1 & 1.74 & 147 & 50 & $\begin{array}{l}10 \text { Healthy } \\
\text { participants }\end{array}$ & Glucose $/ 2 \mathrm{~h}$ \\
\hline 629 & 122 & India & Idli (60\% Kodo millet) & 58.53 & 1.48 & 76 & 50 & $\begin{array}{l}10 \text { Healthy } \\
\text { participants }\end{array}$ & Glucose/2 h \\
\hline
\end{tabular}


Table 1 continued

\begin{tabular}{|c|c|c|c|c|c|c|c|c|c|}
\hline & \multirow[t]{2}{*}{ Reference } & \multirow[t]{2}{*}{ Country } & \multirow[t]{2}{*}{ Food item } & \multicolumn{2}{|c|}{ GI (glucose $=100$ ) } & \multirow{2}{*}{$\begin{array}{l}\text { Serving size (g) per experimental } \\
\text { portion size }\end{array}$} & \multirow{2}{*}{$\begin{array}{l}\text { Available CHO } \\
\text { (g) per } \\
\text { experimental } \\
\text { portion }\end{array}$} & \multirow{2}{*}{$\begin{array}{l}\text { Participants } \\
\text { (type and } \\
\text { number) }\end{array}$} & \multirow{2}{*}{$\begin{array}{l}\text { Reference } \\
\text { food and } \\
\text { time period }\end{array}$} \\
\hline & & & & Mean & SEM & & & & \\
\hline 630 & 122 & India & Sewai upma ( $60 \%$ Kodo millet) & 65.49 & 1.01 & 150 & 50 & $\begin{array}{l}10 \text { Healthy } \\
\text { participants }\end{array}$ & Glucose $/ 2 \mathrm{~h}$ \\
\hline 631 & 123 & India & Chapatti (whole wheat) & 83.92 & $9.63(\mathrm{SD})$ & NA & 50 & $\begin{array}{l}20 \mathrm{NIDDM} \\
\text { participants }\end{array}$ & Glucose $/ 2 \mathrm{~h}$ \\
\hline 632 & 123 & India & Chapatti (whole wheat + rice bran-based) & 68.34 & $11.49(\mathrm{SD})$ & NA & 50 & $\begin{array}{l}20 \mathrm{NIDDM} \\
\text { participants }\end{array}$ & Glucose $/ 2 \mathrm{~h}$ \\
\hline 633 & 124 & India & Indian branded basmati rice & 54.93 & 1.07 & NA & 50 & $\begin{array}{l}70 \text { Healthy } \\
\text { participants }\end{array}$ & Glucose $/ 2 \mathrm{hr}$ \\
\hline 634 & 125 & India & Misi parantha & 40.41 & NA & NA & 50 & $\begin{array}{l}10 \text { healthy } \\
\text { participants }\end{array}$ & Glucose $/ 2.5 \mathrm{~h}$ \\
\hline 635 & 125 & India & Misi parantha ( $15 \%$ green gram husk) & 32.54 & NA & NA & 50 & $\begin{array}{l}10 \text { Healthy } \\
\text { participants }\end{array}$ & Glucose $/ 2.5 \mathrm{~h}$ \\
\hline 636 & 126 & India & Dal samosa (added 10\% Ficus religiosa leaves) & 35 & NA & NA & 50 & $\begin{array}{l}25 \text { Healthy } \\
\text { participants }\end{array}$ & Glucose $/ 2 \mathrm{~h}$ \\
\hline 637 & 126 & India & Bati (added 5\% Ficus religiosa bark) & 53 & NA & NA & 50 & $\begin{array}{l}25 \text { Healthy } \\
\text { participants }\end{array}$ & Glucose $/ 2 \mathrm{~h}$ \\
\hline 638 & 127 & India & $\begin{array}{l}\text { Noodles ( } 30 \% \text { finger millet flour }+ \text { refined } \\
\text { wheat flour) }\end{array}$ & 45.1 & NA & 64.97 & 50 & $\begin{array}{l}10 \text { Healthy } \\
\text { participants }\end{array}$ & Glucose $/ 2.5 \mathrm{~h}$ \\
\hline 639 & 127 & India & Noodles (refined wheat flour) & 62.6 & NA & 65.66 & 50 & $\begin{array}{l}10 \text { Healthy } \\
\text { participants }\end{array}$ & Glucose $/ 2.5 \mathrm{~h}$ \\
\hline 640 & 128 & India & Refined wheat noodles & 66.43 & NA & NA & 50 & $\begin{array}{l}10 \text { Healthy } \\
\text { participants }\end{array}$ & Glucose $/ 2 \mathrm{~h}$ \\
\hline 641 & 128 & India & $\begin{array}{l}\text { Refined wheat noodles (added bengal gram } \\
\text { seed coat + broken rice) }\end{array}$ & 56.13 & NA & NA & 50 & $\begin{array}{l}10 \text { Healthy } \\
\text { participants }\end{array}$ & Glucose $/ 2 \mathrm{~h}$ \\
\hline 642 & 128 & India & $\begin{array}{l}\text { Refined wheat noodles (added bengal gram } \\
\text { broken + broken rice) }\end{array}$ & 45.78 & NA & NA & 50 & $\begin{array}{l}10 \text { Healthy } \\
\text { participants }\end{array}$ & Glucose $/ 2 \mathrm{~h}$ \\
\hline 643 & 129 & India & Biscuit (refined wheat flour) & 68.70 & NA & NA & 50 & $\begin{array}{l}10 \text { Healthy } \\
\text { participants }\end{array}$ & Glucose/2.5 h \\
\hline 644 & 129 & India & $\begin{array}{l}\text { Biscuit (refined wheat flour with } 12 \% \text { green } \\
\text { gram husk) }\end{array}$ & 46.26 & NA & NA & 50 & $\begin{array}{l}10 \text { Healthy } \\
\text { participants }\end{array}$ & Glucose $/ 2.5 \mathrm{~h}$ \\
\hline 645 & 130 & India & Banana (Nendran) & 87.29 & NA & NA & 50 & $\begin{array}{l}20 \text { Healthy } \\
\text { participants }\end{array}$ & Glucose $/ 2 \mathrm{~h}$ \\
\hline 646 & 130 & India & Banana (Robusta) & 81.55 & NA & NA & 50 & $\begin{array}{l}20 \text { Healthy } \\
\text { participants }\end{array}$ & Glucose $/ 2 \mathrm{~h}$ \\
\hline 647 & 130 & India & Banana (Poovan) & 83.36 & NA & NA & 50 & $\begin{array}{l}20 \text { Healthy } \\
\text { participants }\end{array}$ & Glucose $/ 2 \mathrm{~h}$ \\
\hline 648 & 130 & India & Banana (Chenkadali) & 82.23 & NA & NA & 50 & $\begin{array}{l}20 \text { Healthy } \\
\text { participants }\end{array}$ & Glucose $/ 2 \mathrm{~h}$ \\
\hline 649 & 130 & India & Banana (Njalipoovan) & 95.98 & NA & NA & 50 & $\begin{array}{l}20 \text { Healthy } \\
\text { participants }\end{array}$ & Glucose $/ 2 \mathrm{~h}$ \\
\hline 650 & 131 & India & Little millet flakes (ready to cook) & 52.11 & NA & 84 & 50 & $\begin{array}{l}10 \text { Healthy } \\
\text { participants }\end{array}$ & Glucose $/ 2.5 \mathrm{~h}$ \\
\hline 651 & 132 & India & Sorghum multigrain roti & 68 & 8.63 & 119 & 50 & $\begin{array}{l}10 \text { Healthy } \\
\text { participants }\end{array}$ & Glucose $/ 2 \mathrm{~h}$ \\
\hline 652 & 132 & India & Sorghum coarse semolina upma & 53 & 2.84 & 232 & 50 & $\begin{array}{l}10 \text { Healthy } \\
\text { participants }\end{array}$ & Glucose $/ 2 \mathrm{~h}$ \\
\hline 653 & 132 & India & Sorghum fine semolina upma & 56 & 9.83 & 252 & 50 & $\begin{array}{l}10 \text { Healthy } \\
\text { participants }\end{array}$ & Glucose $/ 2 \mathrm{~h}$ \\
\hline 654 & 132 & India & Sorghum flakes poha & 45 & 5.27 & 277 & 50 & $\begin{array}{l}10 \text { Healthy } \\
\text { participants }\end{array}$ & Glucose $/ 2 \mathrm{~h}$ \\
\hline 655 & 132 & India & Sorghum pasta & 46 & 6.47 & 330 & 50 & $\begin{array}{l}10 \text { Healthy } \\
\text { participants }\end{array}$ & Glucose $/ 2 \mathrm{~h}$ \\
\hline 656 & 132 & India & Sorghum biscuits & 54 & 6.3 & 75 & 50 & $\begin{array}{l}10 \text { Healthy } \\
\text { participants }\end{array}$ & Glucose $/ 2 \mathrm{~h}$ \\
\hline 657 & 132 & India & Wheat roti & 64 & 9.24 & 119 & 50 & $\begin{array}{l}10 \text { Healthy } \\
\text { participants }\end{array}$ & Glucose $/ 2 \mathrm{~h}$ \\
\hline 658 & 132 & India & Wheat coarse semolina upma & 58 & 6.85 & 232 & 50 & $\begin{array}{l}10 \text { Healthy } \\
\text { participants }\end{array}$ & Glucose $/ 2 \mathrm{~h}$ \\
\hline 659 & 132 & India & Wheat fine semolina upma & 67 & 10.8 & 252 & 50 & $\begin{array}{l}10 \text { Healthy } \\
\text { participants }\end{array}$ & Glucose $/ 2 \mathrm{~h}$ \\
\hline 660 & 132 & India & Rice flakes poha & 74 & 4.87 & 277 & 50 & $\begin{array}{l}10 \text { Healthy } \\
\text { participants }\end{array}$ & Glucose $/ 2 \mathrm{~h}$ \\
\hline 661 & 132 & India & Wheat pasta & 72 & 6.51 & 330 & 50 & $\begin{array}{l}10 \text { Healthy } \\
\text { participants }\end{array}$ & Glucose $/ 2 \mathrm{~h}$ \\
\hline 662 & 132 & India & Wheat biscuits & 57 & 11.4 & 75 & 50 & $\begin{array}{l}10 \text { Healthy } \\
\text { participants }\end{array}$ & Glucose $/ 2 \mathrm{~h}$ \\
\hline 663 & 133 & India & Khichdi (barnyard millet) & 34.96 & $1.22(\mathrm{SD})$ & NA & 50 & $\begin{array}{l}10 \text { Healthy } \\
\text { participants }\end{array}$ & Glucose $/ 2.5 \mathrm{~h}$ \\
\hline
\end{tabular}


Table 1 continued

\begin{tabular}{|c|c|c|c|c|c|c|c|c|c|}
\hline & \multirow[t]{2}{*}{ Reference } & \multirow[t]{2}{*}{ Country } & \multirow[t]{2}{*}{ Food item } & \multicolumn{2}{|c|}{$\mathrm{Gl}($ glucose $=100)$} & \multirow{2}{*}{$\begin{array}{l}\text { Serving size }(g) \text { per experimental } \\
\text { portion size }\end{array}$} & \multirow{2}{*}{$\begin{array}{l}\text { Available CHO } \\
\text { (g) per } \\
\text { experimental } \\
\text { portion }\end{array}$} & \multirow{2}{*}{$\begin{array}{l}\text { Participants } \\
\text { (type and } \\
\text { number) }\end{array}$} & \multirow{2}{*}{$\begin{array}{l}\text { Reference } \\
\text { food and } \\
\text { time period }\end{array}$} \\
\hline & & & & Mean & SEM & & & & \\
\hline 664 & 133 & India & Rice khichdi & 62.5 & 1.38 (SD) & NA & 50 & $\begin{array}{l}10 \text { Healthy } \\
\text { participants }\end{array}$ & Glucose $/ 2.5 \mathrm{~h}$ \\
\hline 665 & 134 & India & High fibre white rice & 61.3 & 2.8 & $\begin{array}{l}67 \mathrm{~g} \text { (raw) } \\
1: 2 \text { water }\end{array}$ & 50 & $\begin{array}{l}39 \text { Healthy } \\
\text { participants }\end{array}$ & Glucose $/ 2 \mathrm{~h}$ \\
\hline 666 & 134 & India & White rice & 79.2 & 4.8 & $\begin{array}{l}65 \mathrm{~g} \text { (raw) } \\
1: 2 \text { water }\end{array}$ & 50 & $\begin{array}{l}40 \text { Healthy } \\
\text { participants }\end{array}$ & Glucose $/ 2 \mathrm{~h}$ \\
\hline 667 & 135 & India & Dosa (rice-based) & 77.86 & NA & 140 & 50 & $\begin{array}{l}10 \text { Healthy } \\
\text { participants }\end{array}$ & $\begin{array}{l}\text { White bread/ } \\
2 \mathrm{~h}\end{array}$ \\
\hline 668 & 135 & India & Dosa (foxtail millet-based) & 59.25 & NA & 290 & 50 & $\begin{array}{l}10 \text { Healthy } \\
\text { participants }\end{array}$ & $\begin{array}{l}\text { White bread/ } \\
2 \mathrm{~h}\end{array}$ \\
\hline 669 & 136 & India & Brown ragi roti & 61.0 & 5.77 & 69.44 & 50 & $\begin{array}{l}10 \text { Healthy } \\
\text { participants }\end{array}$ & Glucose $/ 2 \mathrm{~h}$ \\
\hline 670 & 136 & India & White ragi roti & 67.3 & 2.78 & 69.44 & 50 & $\begin{array}{l}10 \text { Healthy } \\
\text { participants }\end{array}$ & Glucose $/ 2 \mathrm{~h}$ \\
\hline 671 & 136 & India & Brown ragi roti + curry leaf powder (CLP) & 56.2 & 5.56 & 64.58 (flour) 5 (CLP) & 50 & $\begin{array}{l}10 \text { Healthy } \\
\text { participants }\end{array}$ & Glucose $/ 2 \mathrm{~h}$ \\
\hline 672 & 136 & India & White ragi flour roti + curry leaf powder (CLP) & 62.5 & 4.23 & 64.58 (flour) 5 (CLP) & 50 & $\begin{array}{l}10 \text { Healthy } \\
\text { participants }\end{array}$ & Glucose $/ 2 \mathrm{~h}$ \\
\hline 673 & 137 & India & Wheat chapatti & 48.37 & 20.59 (SD) & 72.05 wheat flour & 50 & $\begin{array}{l}10 \text { Healthy } \\
\text { participants }\end{array}$ & Glucose $/ 2 \mathrm{~h}$ \\
\hline 674 & 137 & India & Wheat chapatti enriched with carrot powder & 53.48 & $16.91(S D)$ & $\begin{array}{l}72.22 \text { wheat flour } \\
15 \% \text { carrot powder }\end{array}$ & 50 & $\begin{array}{l}10 \text { Healthy } \\
\text { participants }\end{array}$ & Glucose $/ 2 \mathrm{~h}$ \\
\hline 675 & 137 & India & Dalia & 38.05 & $27.04(S D)$ & $\begin{array}{l}10 \mathrm{~g} \text { dalia } \\
10 \mathrm{~g} \text { moong dal } \\
280 \mathrm{ml} \text { water }\end{array}$ & 50 & $\begin{array}{l}10 \text { Healthy } \\
\text { participants }\end{array}$ & Glucose $/ 2 \mathrm{~h}$ \\
\hline 676 & 137 & India & Salty enriched dalia (with carrot grits) & 49.81 & $25.69(S D)$ & $\begin{array}{l}13.34 \mathrm{~g} \text { daliav } \\
6.66 \mathrm{~g} \text { moong dal } \\
10.73 \mathrm{~g} \text { carrot grits } \\
279 \mathrm{ml} \text { water }\end{array}$ & 50 & $\begin{array}{l}10 \text { Healthy } \\
\text { participants }\end{array}$ & Glucose $/ 2 \mathrm{~h}$ \\
\hline 677 & 138 & India & Chakli (added 5\% kale powder) & 48.86 & NA & NA & 50 & $\begin{array}{l}30 \text { Healthy } \\
\text { participants }\end{array}$ & Glucose $/ 2 \mathrm{~h}$ \\
\hline 678 & 138 & India & Twisters (added 10\% kale powder) & 46.44 & NA & NA & 50 & $\begin{array}{l}30 \text { Healthy } \\
\text { participants }\end{array}$ & Glucose $/ 2 \mathrm{~h}$ \\
\hline 679 & 139 & India & $\begin{array}{l}\text { Biscuits [(refined wheat flour, barley flour and } \\
\text { soy flour }(25: 50: 25)]\end{array}$ & 38.68 & NA & 108.5 & 50 & $\begin{array}{l}10 \text { Healthy } \\
\text { participants }\end{array}$ & Glucose $/ 2 \mathrm{~h}$ \\
\hline 680 & 139 & India & Biscuits (100\% refined wheat flour) & 83.99 & NA & 94 & 50 & $\begin{array}{l}10 \text { Healthy } \\
\text { participants }\end{array}$ & $\begin{array}{l}\text { White bread/ } \\
2 \mathrm{~h}\end{array}$ \\
\hline 681 & 140 & India & $\begin{array}{l}\text { Extruded snack (whole-wheat flour, barley and } \\
\text { chickpea, 50:25:25) }\end{array}$ & 48.77 & NA & 67.5 & 50 & $\begin{array}{l}10 \text { Healthy } \\
\text { participants }\end{array}$ & Glucose $/ 2 \mathrm{~h}$ \\
\hline 682 & 140 & India & Extruded snack (100\% whole-wheat flour) & 69.68 & NA & 64 & 50 & $\begin{array}{l}10 \text { Healthy } \\
\text { participants }\end{array}$ & Glucose $/ 2 \mathrm{~h}$ \\
\hline 683 & 141 & India & Brown rice & 57.6 & 6.8 & NA & 50 & $\begin{array}{l}12 \text { Healthy } \\
\text { participants }\end{array}$ & Glucose $/ 2 \mathrm{~h}$ \\
\hline 684 & 141 & India & $\begin{array}{l}\text { Minimally polished/under milled rice with } 2.3 \% \\
\text { degree of polish ( } \approx \text { hand pounded rice) }\end{array}$ & 73 & 5.4 & NA & 50 & $\begin{array}{l}12 \text { Healthy } \\
\text { participants }\end{array}$ & Glucose $/ 2 \mathrm{~h}$ \\
\hline 685 & 141 & India & $\begin{array}{l}\text { Fully polished white rice (WR) with } 9.7 \% \\
\text { degree of polish }\end{array}$ & 79.6 & 6.8 & NA & 50 & $\begin{array}{l}12 \text { Healthy } \\
\text { participants }\end{array}$ & Glucose $/ 2 \mathrm{~h}$ \\
\hline 686 & 142 & India & Uzhunnu vada & 21.54 & NA & 172 & 50 & $\begin{array}{l}11 \text { Healthy } \\
\text { participants }\end{array}$ & Glucose $/ 2 \mathrm{~h}$ \\
\hline 687 & 142 & India & Tapioca & 83.57 & NA & 135 & 50 & $\begin{array}{l}11 \text { healthy } \\
\text { participants }\end{array}$ & Glucose $/ 2 \mathrm{~h}$ \\
\hline 688 & 142 & India & Dosa & 55.80 & NA & 120 & 50 & $\begin{array}{l}11 \text { Healthy } \\
\text { participants }\end{array}$ & Glucose $/ 2 \mathrm{~h}$ \\
\hline 689 & 142 & India & Puttu & 62.68 & NA & 141 & 50 & $\begin{array}{l}11 \text { Healthy } \\
\text { participants }\end{array}$ & Glucose/2h \\
\hline 690 & 142 & India & Plaintain (unripe) & 73.9 & NA & 422 & 50 & $\begin{array}{l}11 \text { Healthy } \\
\text { participants }\end{array}$ & Glucose $/ 2 \mathrm{~h}$ \\
\hline 691 & 142 & India & Chapathi & 54.43 & NA & 110 & 50 & $\begin{array}{l}11 \text { Healthy } \\
\text { participants }\end{array}$ & Glucose $/ 2 \mathrm{~h}$ \\
\hline 692 & 142 & India & Poori & 58.53 & NA & 121 & 50 & $\begin{array}{l}11 \text { Healthy } \\
\text { participants }\end{array}$ & Glucose $/ 2 \mathrm{~h}$ \\
\hline 693 & 142 & India & Idiyappam & 59.41 & NA & 131 & 50 & $\begin{array}{l}11 \text { Healthy } \\
\text { participants }\end{array}$ & Glucose $/ 2 \mathrm{~h}$ \\
\hline 694 & 142 & India & Appam & 59.94 & NA & 122 & 50 & $\begin{array}{l}11 \text { Healthy } \\
\text { participants }\end{array}$ & Glucose $/ 2 \mathrm{~h}$ \\
\hline 695 & 142 & India & Yam & 55.53 & NA & 282 & 50 & $\begin{array}{l}11 \text { Healthy } \\
\text { participants }\end{array}$ & Glucose $/ 2 \mathrm{~h}$ \\
\hline
\end{tabular}


Table 1 continued

\begin{tabular}{|c|c|c|c|c|c|c|c|c|c|}
\hline & \multirow[t]{2}{*}{ Reference } & \multirow[t]{2}{*}{ Country } & \multirow[t]{2}{*}{ Food item } & \multicolumn{2}{|c|}{ GI (glucose $=100)$} & \multirow{2}{*}{$\begin{array}{l}\text { Serving size (g) per experimental } \\
\text { portion size }\end{array}$} & \multirow{2}{*}{$\begin{array}{l}\text { Available CHO } \\
\text { (g) per } \\
\text { experimental } \\
\text { portion }\end{array}$} & \multirow{2}{*}{$\begin{array}{l}\text { Participants } \\
\text { (type and } \\
\text { number) }\end{array}$} & \multirow{2}{*}{$\begin{array}{l}\text { Reference } \\
\text { food and } \\
\text { time period }\end{array}$} \\
\hline & & & & Mean & SEM & & & & \\
\hline 696 & 142 & India & Porotta & 37.98 & NA & 121 & 50 & $\begin{array}{l}11 \text { Healthy } \\
\text { participants }\end{array}$ & Glucose $/ 2 \mathrm{~h}$ \\
\hline 697 & 142 & India & Semolina upma & 62.37 & NA & 142 & 50 & $\begin{array}{l}11 \text { Healthy } \\
\text { participants }\end{array}$ & Glucose/2 $\mathrm{h}$ \\
\hline 698 & 142 & India & Idli & 62.45 & NA & 149 & 50 & $\begin{array}{l}11 \text { Healthy } \\
\text { participants }\end{array}$ & Glucose $/ 2 \mathrm{~h}$ \\
\hline 699 & 143 & India & Thepla & 57.77 & NA & NA & 50 & $\begin{array}{l}30 \text { Healthy } \\
\text { participants }\end{array}$ & Glucose $/ 2 \mathrm{~h}$ \\
\hline 700 & 143 & India & Thepla ( $2 \%$ ashwagandha root powder) & 37.30 & NA & NA & 50 & $\begin{array}{l}30 \text { Healthy } \\
\text { participants }\end{array}$ & Glucose $/ 2 \mathrm{~h}$ \\
\hline 701 & 144 & India & Maize & 75.15 & $0.60(\mathrm{SD})$ & NA & 50 & $\begin{array}{l}10 \text { Healthy } \\
\text { participants }\end{array}$ & Glucose $/ 2 \mathrm{~h}$ \\
\hline 702 & 144 & India & Boiled maize (with whole bengal gram) & 68.72 & $0.86(\mathrm{SD})$ & NA & 50 & $\begin{array}{l}10 \text { Healthy } \\
\text { participants }\end{array}$ & Glucose $/ 2 \mathrm{~h}$ \\
\hline 703 & 144 & India & Alkali-treated maize (with whole bengal gram) & 69.01 & $0.66(S D)$ & NA & 50 & $\begin{array}{l}10 \text { Healthy } \\
\text { participants }\end{array}$ & Glucose $/ 2 \mathrm{~h}$ \\
\hline 704 & 144 & India & Roasted maize (with whole bengal gram) & 72.15 & $0.60(S D)$ & NA & 50 & $\begin{array}{l}10 \text { Healthy } \\
\text { participants }\end{array}$ & Glucose $/ 2 \mathrm{~h}$ \\
\hline 705 & 145 & India & DiaBliss herbal sugar (DHS) & 46.5 & NA & 50 & 50 & $\begin{array}{l}16 \text { Healthy } \\
\text { participants }\end{array}$ & Glucose $/ 2 \mathrm{~h}$ \\
\hline 706 & 146 & India & $\begin{array}{l}\text { Mixed mini meal: wheat, pearl barley and } \\
\text { Bengal gram flour (besan) mix with chana } \\
\text { whole (unhusked chana + curd) }\end{array}$ & 71.9 & 7.4 & NA & 50 & $\begin{array}{l}12 \text { Healthy } \\
\text { participants }\end{array}$ & Glucose $/ 2 \mathrm{~h}$ \\
\hline 707 & 147 & India & $\begin{array}{l}\text { Upma (added decorticated finger millet with } \\
\text { lower degree of polish) }\end{array}$ & 84.7 & 8.2 & NA & 50 & $\begin{array}{l}16 \text { Healthy } \\
\text { participants }\end{array}$ & Glucose $/ 2 \mathrm{~h}$ \\
\hline 708 & 147 & India & Upma (added finger millet flakes) & 82.3 & 6.8 & NA & 50 & $\begin{array}{l}16 \text { Healthy } \\
\text { participants }\end{array}$ & Glucose $/ 2 \mathrm{~h}$ \\
\hline 709 & 147 & India & Upma (added finger millet vermicelli) & 65.5 & 5.5 & NA & 50 & $\begin{array}{l}16 \text { Healthy } \\
\text { participants }\end{array}$ & Glucose $/ 2 \mathrm{~h}$ \\
\hline 710 & 147 & India & Finger millet extruded snack & 65 & 6.6 & NA & 50 & $\begin{array}{l}12 \text { Healthy } \\
\text { participants }\end{array}$ & Glucose $/ 2 \mathrm{~h}$ \\
\hline 711 & 148 & India & Roti (whole-wheat flour) & 44.6 & NA & 55 & 50 & $\begin{array}{l}30 \text { Healthy } \\
\text { participants }\end{array}$ & Dextrose $/ 2 \mathrm{~h}$ \\
\hline 712 & 148 & India & Chappati (multigrain flour) & 28.4 & NA & 84 & 50 & $\begin{array}{l}30 \text { Healthy } \\
\text { participants }\end{array}$ & Dextrose $/ 2 \mathrm{~h}$ \\
\hline 713 & 149 & India & Green jackfruit (freeze-dried) porridge & 65 & 5 & NA & 25 or 50 & $\begin{array}{l}10 \text { Healthy } \\
\text { participants }\end{array}$ & Glucodin $/ 2 \mathrm{~h}$ \\
\hline 714 & 150 & India & Kashi 7 whole-grain 'pilaf' & 58.9 & 5.1 & 160 & 50 & $\begin{array}{l}14 \text { Healthy } \\
\text { participants }\end{array}$ & Glucose $/ 2 \mathrm{~h}$ \\
\hline 715 & 150 & India & $\begin{array}{l}\text { Uncle Ben's whole-grain fast and natural } \\
\text { instant brown rice }\end{array}$ & 87.8 & 6.8 & 193 & 50 & $\begin{array}{l}14 \text { Healthy } \\
\text { participants }\end{array}$ & Glucose $/ 2 \mathrm{~h}$ \\
\hline 716 & 150 & India & Refined maize ugali flour & 71.4 & 5.1 & 161 & 50 & $\begin{array}{l}14 \text { Healthy } \\
\text { participants }\end{array}$ & Glucose $/ 2 \mathrm{~h}$ \\
\hline 717 & 150 & India & Whole maize ugali flour & 74.7 & 6.5 & 164 & 50 & $\begin{array}{l}14 \text { Healthy } \\
\text { participants }\end{array}$ & Glucose $/ 2 \mathrm{~h}$ \\
\hline 718 & 151 & India & Millet-based roti & 53 & NA & NA & 50 & $\begin{array}{l}10 \text { Healthy } \\
\text { participants }\end{array}$ & Glucose $/ 2 \mathrm{~h}$ \\
\hline 719 & 151 & India & Millet-based dosa & 37 & NA & NA & 50 & $\begin{array}{l}10 \text { Healthy } \\
\text { participants }\end{array}$ & Glucose $/ 2 \mathrm{~h}$ \\
\hline 720 & 151 & India & Millet-based dumpling & 48 & NA & NA & 50 & $\begin{array}{l}10 \text { Healthy } \\
\text { participants }\end{array}$ & Glucose $/ 2 \mathrm{~h}$ \\
\hline 721 & 152 & India & Preserved coconut sugar & 52.47 & NA & 62.5 & 50 & $\begin{array}{l}15 \text { Healthy } \\
\text { participants }\end{array}$ & Glucose $/ 2 \mathrm{~h}$ \\
\hline 722 & 153 & Sri Lanka & White sliced bread & 77 & 6 & 114 & 50 & $\begin{array}{l}10 \text { Healthy } \\
\text { participants }\end{array}$ & Glucose $/ 2 \mathrm{~h}$ \\
\hline 723 & 153 & Sri Lanka & Wholemeal bread & 77 & 6 & 128 & 50 & $\begin{array}{l}10 \text { Healthy } \\
\text { participants }\end{array}$ & Glucose $/ 2 \mathrm{~h}$ \\
\hline 724 & 153 & Sri Lanka & Ordinary white bread & 80 & 4 & 121 & 50 & $\begin{array}{l}10 \text { Healthy } \\
\text { participants }\end{array}$ & Glucose $/ 2 \mathrm{~h}$ \\
\hline 725 & 153 & Sri Lanka & Wholemeal bread and lentil curry & 61 & 6 & $\begin{array}{l}\text { Bread: } 83 \\
\text { Curry: } 150\end{array}$ & 50 & $\begin{array}{l}10 \text { Healthy } \\
\text { participants }\end{array}$ & Glucose/2 h \\
\hline 726 & 153 & Sri Lanka & White sliced bread & 100 & NA & 114 & 50 & $\begin{array}{l}10 \text { Healthy } \\
\text { participants }\end{array}$ & $\begin{array}{l}\text { White bread/ } \\
2 \mathrm{~h}\end{array}$ \\
\hline 727 & 153 & Sri Lanka & Wholemeal bread & 103 & 10 & 128 & 50 & $\begin{array}{l}10 \text { Healthy } \\
\text { participants }\end{array}$ & $\begin{array}{l}\text { White bread/ } \\
2 \mathrm{~h}\end{array}$ \\
\hline 728 & 153 & Sri Lanka & Ordinary white bread & 114 & 11 & 121 & 50 & $\begin{array}{l}10 \text { Healthy } \\
\text { participants }\end{array}$ & $\begin{array}{l}\text { White bread/ } \\
2 \mathrm{~h}\end{array}$ \\
\hline
\end{tabular}


Table 1 continued

\begin{tabular}{|c|c|c|c|c|c|c|c|c|c|}
\hline & \multirow[t]{2}{*}{ Reference } & \multirow[t]{2}{*}{ Country } & \multirow[t]{2}{*}{ Food item } & \multicolumn{2}{|c|}{$\mathrm{Gl}($ glucose $=100)$} & \multirow{2}{*}{$\begin{array}{l}\text { Serving size }(g) \text { per experimental } \\
\text { portion size }\end{array}$} & \multirow{2}{*}{$\begin{array}{l}\text { Available } \mathrm{CHO} \\
\text { (g) per } \\
\text { experimental } \\
\text { portion }\end{array}$} & \multirow{2}{*}{$\begin{array}{l}\text { Participants } \\
\text { (type and } \\
\text { number) }\end{array}$} & \multirow{2}{*}{$\begin{array}{l}\text { Reference } \\
\text { food and } \\
\text { time period }\end{array}$} \\
\hline & & & & Mean & SEM & & & & \\
\hline 729 & 153 & Sri Lanka & Wholemeal bread and lentil curry & 87 & 6 & $\begin{array}{l}\text { Bread: } 83 \\
\text { Curry: } 150\end{array}$ & 50 & $\begin{array}{l}10 \text { Healthy } \\
\text { participants }\end{array}$ & $\begin{array}{l}\text { White bread/ } \\
2 \mathrm{~h}\end{array}$ \\
\hline 730 & 154 & Sri Lanka & Wheat flour roti & 72 & 6 & NA & 50 & $\begin{array}{l}10 \text { Healthy } \\
\text { participants }\end{array}$ & $\begin{array}{l}\text { White bread/ } \\
2 \mathrm{~h}\end{array}$ \\
\hline 731 & 154 & Sri Lanka & Rice flour roti & 69 & 7 & NA & 50 & $\begin{array}{l}10 \text { Healthy } \\
\text { participants }\end{array}$ & $\begin{array}{l}\text { White bread/ } \\
2 \mathrm{~h}\end{array}$ \\
\hline 732 & 154 & Sri Lanka & Kurakkan flour roti & 70 & 8 & NA & 50 & $\begin{array}{l}10 \text { Healthy } \\
\text { participants }\end{array}$ & $\begin{array}{l}\text { White bread/ } \\
2 \mathrm{~h}\end{array}$ \\
\hline 733 & 154 & Sri Lanka & Atta flour roti & 67 & 9 & NA & 25 & $\begin{array}{l}10 \text { Healthy } \\
\text { participants }\end{array}$ & $\begin{array}{l}\text { White bread/ } \\
2 \mathrm{~h}\end{array}$ \\
\hline 734 & 154 & Sri Lanka & Wheat flour pittu & 101 & 8 & NA & 25 & $\begin{array}{l}10 \text { Healthy } \\
\text { participants }\end{array}$ & $\begin{array}{l}\text { White bread/ } \\
2 \mathrm{~h}\end{array}$ \\
\hline 735 & 154 & Sri Lanka & Rice flour pittu & 103 & 7 & NA & 25 & $\begin{array}{l}10 \text { Healthy } \\
\text { participants }\end{array}$ & $\begin{array}{l}\text { White bread/ } \\
2 \mathrm{~h}\end{array}$ \\
\hline 736 & 154 & Sri Lanka & Kurakkan flour pittu & 85 & 6 & NA & 25 & $\begin{array}{l}10 \text { Healthy } \\
\text { participants }\end{array}$ & $\begin{array}{l}\text { White bread/ } \\
2 \mathrm{~h}\end{array}$ \\
\hline 737 & 154 & Sri Lanka & Boiled chickpea & 29 & 5 & NA & 25 & $\begin{array}{l}10 \text { Healthy } \\
\text { participants }\end{array}$ & $\begin{array}{l}\text { White bread/ } \\
2 \mathrm{~h}\end{array}$ \\
\hline 738 & 154 & Sri Lanka & Boiled mung bean & 57 & 6 & NA & 25 & $\begin{array}{l}10 \text { Healthy } \\
\text { participants }\end{array}$ & $\begin{array}{l}\text { White bread/ } \\
2 \mathrm{~h}\end{array}$ \\
\hline 739 & 154 & Sri Lanka & Boiled cowpea & 49 & 8 & NA & 25 & $\begin{array}{l}10 \text { Healthy } \\
\text { participants }\end{array}$ & $\begin{array}{l}\text { White bread/ } \\
2 \mathrm{~h}\end{array}$ \\
\hline 740 & 154 & Sri Lanka & Olu-milk rice & 91 & 8 & NA & 25 & $\begin{array}{l}10 \text { Healthy } \\
\text { participants }\end{array}$ & $\begin{array}{l}\text { White bread/ } \\
2 \mathrm{~h}\end{array}$ \\
\hline 741 & 154 & Sri Lanka & Breadfruit & 65 & 7 & NA & 25 & $\begin{array}{l}10 \text { Healthy } \\
\text { participants }\end{array}$ & $\begin{array}{l}\text { White bread/ } \\
2 \mathrm{~h}\end{array}$ \\
\hline 742 & 154 & Sri Lanka & Hopperss & 120 & 8 & NA & 25 & $\begin{array}{l}10 \text { Healthy } \\
\text { participants }\end{array}$ & $\begin{array}{l}\text { White bread/ } \\
2 \mathrm{~h}\end{array}$ \\
\hline 743 & 155 & Sri Lanka & Parboiled rice with green curry & 47.47 & 11.20 & 375 & 75 & $\begin{array}{l}20 \text { Healthy } \\
\text { participants }\end{array}$ & Glucose $/ 2 \mathrm{~h}$ \\
\hline 744 & 155 & Sri Lanka & Parboiled rice with gravy & 56.30 & 9.31 & 355 & 75 & $\begin{array}{l}20 \text { Healthy } \\
\text { participants }\end{array}$ & Glucose $/ 2 \mathrm{~h}$ \\
\hline 745 & 155 & Sri Lanka & Parboiled rice with green curry and gravy & 54.67 & 10.03 & 405 & 75 & $\begin{array}{l}20 \text { Healthy } \\
\text { participants }\end{array}$ & Glucose $/ 2 \mathrm{~h}$ \\
\hline 746 & 155 & Sri Lanka & 'Kurakkan pittu' with green curry & 57.51 & 5.52 & 262 & 75 & $\begin{array}{l}20 \text { Healthy } \\
\text { participants }\end{array}$ & Glucose $/ 2 \mathrm{~h}$ \\
\hline 747 & 155 & Sri Lanka & 'Kurakkan pittu' with gravy & 63.25 & 8.86 & 242 & 75 & $\begin{array}{l}20 \text { Healthy } \\
\text { participants }\end{array}$ & Glucose $/ 2 \mathrm{~h}$ \\
\hline 748 & 155 & Sri Lanka & 'Kurakkan pittu' with green curry and gravy & 59.25 & 5.49 & 292 & 75 & $\begin{array}{l}20 \text { Healthy } \\
\text { participants }\end{array}$ & Glucose $/ 2 \mathrm{~h}$ \\
\hline 749 & 155 & Sri Lanka & 'Atta pittu' with green curry & 44.40 & 14.27 & 327 & 75 & $\begin{array}{l}20 \text { Healthy } \\
\text { participants }\end{array}$ & Glucose $/ 2 \mathrm{~h}$ \\
\hline 750 & 155 & Sri Lanka & 'Atta pittu' with gravy & 50.80 & 9.35 & 307 & 75 & $\begin{array}{l}20 \text { Healthy } \\
\text { participants }\end{array}$ & Glucose $/ 2 \mathrm{~h}$ \\
\hline 751 & 155 & Sri Lanka & 'Atta pittu' with green curry and gravy & 46.29 & 8.90 & 357 & 75 & $\begin{array}{l}20 \text { Healthy } \\
\text { participants }\end{array}$ & Glucose $/ 2 \mathrm{~h}$ \\
\hline 752 & 156 & Sri Lanka & Chickpea meal & 40 & 7 & 186 & 25 & $\begin{array}{l}11 \mathrm{~T} 2 \mathrm{DM} \\
\text { participants }\end{array}$ & $\begin{array}{l}\text { White bread/ } \\
3 \mathrm{~h}\end{array}$ \\
\hline 753 & 156 & Sri Lanka & Red rice meal + accompaniments & 64 & 11 & 149 & 25 & $\begin{array}{l}11 \mathrm{~T} 2 \mathrm{DM} \\
\text { participants }\end{array}$ & $\begin{array}{l}\text { White bread/ } \\
3 \mathrm{~h}\end{array}$ \\
\hline 754 & 156 & Sri Lanka & Atta roti meal + accompaniments & 88 & 9 & 85 & 25 & $\begin{array}{l}11 \text { T2DM } \\
\text { participants }\end{array}$ & $\begin{array}{l}\text { White bread/ } \\
3 \mathrm{~h}\end{array}$ \\
\hline 755 & 157 & Sri Lanka & $\begin{array}{l}\text { Rice with lentil curry, boiled egg, coconut } \\
\text { gravy and Trichosanthes cucumerina (snake } \\
\text { gourd) salad }\end{array}$ & 61 & 5 & $285+30 \mathrm{ml}$ coconut gravy & 50 & $\begin{array}{l}10 \text { Healthy } \\
\text { participants }\end{array}$ & Bread/2h \\
\hline 756 & 156 & Sri Lanka & Chickpea meal & 40 & 7 & 186 & 25 & $\begin{array}{l}11 \mathrm{~T} 2 \mathrm{DM} \\
\text { participants }\end{array}$ & $\begin{array}{l}\text { White bread/ } \\
3 \mathrm{~h}\end{array}$ \\
\hline 757 & 156 & Sri Lanka & Red rice meal + accompaniments & 64 & 11 & 85 & 25 & $\begin{array}{l}11 \mathrm{~T} 2 \mathrm{DM} \\
\text { participants }\end{array}$ & $\begin{array}{l}\text { White bread/ } \\
3 \mathrm{~h}\end{array}$ \\
\hline 758 & 156 & Sri Lanka & Atta roti meal + accompaniments & 88 & 9 & 149 & 25 & $\begin{array}{l}11 \mathrm{~T} 2 \mathrm{DM} \\
\text { participants }\end{array}$ & $\begin{array}{l}\text { White bread/ } \\
3 \mathrm{~h}\end{array}$ \\
\hline 759 & 158 & Sri Lanka & Banana (Silk) & 61 & 5 & 190 & 50 & $\begin{array}{l}10 \text { Healthy } \\
\text { participants }\end{array}$ & Glucose $/ 2 \mathrm{~h}$ \\
\hline 760 & 158 & Sri Lanka & Banana (Mysore) & 61 & 6 & 220 & 50 & $\begin{array}{l}10 \text { Healthy } \\
\text { participants }\end{array}$ & Glucose $/ 2 \mathrm{~h}$ \\
\hline 761 & 158 & Sri Lanka & Banana (Gros Michel) & 67 & 7 & 270 & 50 & $\begin{array}{l}10 \text { Healthy } \\
\text { participants }\end{array}$ & Glucose $/ 2 \mathrm{~h}$ \\
\hline
\end{tabular}


Table 1 continued

\begin{tabular}{|c|c|c|c|c|c|c|c|c|c|}
\hline & \multirow[t]{2}{*}{ Reference } & \multirow[t]{2}{*}{ Country } & \multirow[t]{2}{*}{ Food item } & \multicolumn{2}{|c|}{ Gl (glucose $=100)$} & \multirow{2}{*}{$\begin{array}{l}\text { Serving size }(g) \text { per experimental } \\
\text { portion size }\end{array}$} & \multirow{2}{*}{$\begin{array}{l}\text { Available CHO } \\
\text { (g) per } \\
\text { experimental } \\
\text { portion }\end{array}$} & \multirow{2}{*}{$\begin{array}{l}\text { Participants } \\
\text { (type and } \\
\text { number) }\end{array}$} & \multirow{2}{*}{$\begin{array}{l}\text { Reference } \\
\text { food and } \\
\text { time period }\end{array}$} \\
\hline & & & & Mean & SEM & & & & \\
\hline 762 & 158 & Sri Lanka & Banana (Pisang Awak) & 69 & 9 & 220 & 50 & $\begin{array}{l}10 \text { Healthy } \\
\text { participants }\end{array}$ & Glucose $/ 2 \mathrm{~h}$ \\
\hline 763 & 159 & Sri Lanka & White rice & 66.61 & $9.86(\mathrm{SD})$ & 286.04 & 75 & $\begin{array}{l}22 \text { Healthy } \\
\text { participants }\end{array}$ & Glucose $/ 2.5 \mathrm{~h}$ \\
\hline 764 & 159 & Sri Lanka & Brown rice & 60.24 & 8.16 (SD) & 338 & 75 & $\begin{array}{l}22 \text { Healthy } \\
\text { participants }\end{array}$ & Glucose $/ 2.5 \mathrm{~h}$ \\
\hline 765 & 159 & Sri Lanka & Parboiled rice & 55.97 & $6.01(\mathrm{SD})$ & 324.67 & 75 & $\begin{array}{l}22 \text { Healthy } \\
\text { participants }\end{array}$ & Glucose $/ 2.5 \mathrm{~h}$ \\
\hline 766 & 159 & Sri Lanka & Pittu (from cereal flour) & 43.74 & 9.09 (SD) & 166.55 & 75 & $\begin{array}{l}22 \text { Healthy } \\
\text { participants }\end{array}$ & Glucose $/ 2.5 \mathrm{~h}$ \\
\hline 767 & 159 & Sri Lanka & 'String hopper' (from cereal flour) & 50.01 & $7.06(S D)$ & 200 & 75 & $\begin{array}{l}22 \text { Healthy } \\
\text { participants }\end{array}$ & Glucose $/ 2.5 \mathrm{~h}$ \\
\hline 768 & 159 & Sri Lanka & Cassava (tuber) & 78.67 & 7.30 (SD) & 232.56 & 75 & $\begin{array}{l}22 \text { Healthy } \\
\text { participants }\end{array}$ & Glucose $/ 2.5 \mathrm{~h}$ \\
\hline 769 & 159 & Sri Lanka & Green gram (legume) & 31.43 & $6.96(\mathrm{SD})$ & 294.92 & 75 & $\begin{array}{l}22 \text { Healthy } \\
\text { participants }\end{array}$ & Glucose $/ 2.5 \mathrm{~h}$ \\
\hline 770 & 159 & Sri Lanka & Chickpea (legume) & 33.27 & $6.23(\mathrm{SD})$ & 253.2 & 75 & $\begin{array}{l}22 \text { Healthy } \\
\text { participants }\end{array}$ & Glucose $/ 2.5 \mathrm{~h}$ \\
\hline 771 & 160 & Sri Lanka & Kathali & 54.45 & 9.26 (SD) & 325.95 & 75 & $\begin{array}{l}20 \text { Healthy } \\
\text { participants }\end{array}$ & Glucose $/ 2 \mathrm{~h}$ \\
\hline 772 & 160 & Sri Lanka & Kappal & 50.43 & 5.79 (SD) & 314.33 & 75 & $\begin{array}{l}20 \text { Healthy } \\
\text { participants }\end{array}$ & Glucose $/ 2 \mathrm{~h}$ \\
\hline 773 & 160 & Sri Lanka & Itharai & 48.47 & $10.13(\mathrm{SD})$ & 277.16 & 75 & $\begin{array}{l}20 \text { Healthy } \\
\text { participants }\end{array}$ & Glucose $/ 2 \mathrm{~h}$ \\
\hline 774 & 160 & Sri Lanka & Jackfruit & 65.36 & $8.00(\mathrm{SD})$ & 578.70 & 75 & $\begin{array}{l}20 \text { Healthy } \\
\text { participants }\end{array}$ & Glucose $/ 2 \mathrm{~h}$ \\
\hline 775 & 160 & Sri Lanka & Papaya & 34.90 & 12.78 (SD) & 903.60 & 75 & $\begin{array}{l}20 \text { Healthy } \\
\text { participants }\end{array}$ & Glucose $/ 2 \mathrm{~h}$ \\
\hline 776 & 161 & Sri Lanka & Coconut milk porridge (Cocos nucifera) & 31 & 5 & $\begin{array}{l}\text { Coconut milk porridge was made with rice } \\
\text { and coconut milk in 25:90 ratio }\end{array}$ & 25 & $\begin{array}{l}10 \text { Healthy } \\
\text { participants }\end{array}$ & Glucose $/ 2 \mathrm{~h}$ \\
\hline 777 & 161 & Sri Lanka & Rice porridge & 46 & 17 & $\begin{array}{l}\text { Rice porridge was prepared with rice and } \\
\text { water }(25: 90)\end{array}$ & 25 & $\begin{array}{l}10 \text { Healthy } \\
\text { participants }\end{array}$ & Glucose $/ 2 \mathrm{~h}$ \\
\hline 778 & 161 & Sri Lanka & Murraya koenigii Spreng (Karapincha) & 44 & 8 & $\begin{array}{l}\text { All porridges were cooked until final } \\
\text { volume of } 300 \mathrm{ml} \text { (in the porridge, leaves: } \\
\text { coconut milk:rice = 13:90:25) }\end{array}$ & 25 & $\begin{array}{l}10 \text { Healthy } \\
\text { participants }\end{array}$ & Glucose $/ 2 \mathrm{~h}$ \\
\hline 779 & 161 & Sri Lanka & Hemidesmus indicus (Iramusu) & 40 & 8 & NA & 25 & $\begin{array}{l}10 \text { Healthy } \\
\text { participants }\end{array}$ & Glucose $/ 2 \mathrm{~h}$ \\
\hline 780 & 161 & Sri Lanka & Aegle marmelos (Beli) & 50 & 8 & NA & 25 & $\begin{array}{l}10 \text { Healthy } \\
\text { participants }\end{array}$ & Glucose $/ 2 \mathrm{~h}$ \\
\hline 781 & 161 & Sri Lanka & Coreopsis auriculata Linn. (Ranawara) & 77 & 12 & NA & 25 & $\begin{array}{l}10 \text { Healthy } \\
\text { participants }\end{array}$ & Glucose $/ 2 \mathrm{~h}$ \\
\hline 782 & 161 & Sri Lanka & Clitoria ternatea Linn. (Ela katarolu) & 53 & 10 & NA & 25 & $\begin{array}{l}10 \text { Healthy } \\
\text { participants }\end{array}$ & Glucose $/ 2 \mathrm{~h}$ \\
\hline 783 & 161 & Sri Lanka & Cardiospermum halicacabum (Wel Penela) & 46 & 8 & NA & 25 & $\begin{array}{l}10 \text { Healthy } \\
\text { participants }\end{array}$ & Glucose $/ 2 \mathrm{~h}$ \\
\hline 784 & 161 & Sri Lanka & Alphonsea zeylanica Linn. (Yaki narang) & 52 & 13 & NA & 25 & $\begin{array}{l}10 \text { Healthy } \\
\text { participants }\end{array}$ & Glucose $/ 2 \mathrm{~h}$ \\
\hline 785 & 161 & Sri Lanka & Cannabis indica (Kowakka) & 49 & 8 & NA & 25 & $\begin{array}{l}10 \text { Healthy } \\
\text { participants }\end{array}$ & Glucose $/ 2 \mathrm{~h}$ \\
\hline 786 & 161 & Sri Lanka & Osbeckia octandra (Heen bovitiya) & 55 & 7 & NA & 25 & $\begin{array}{l}10 \text { Healthy } \\
\text { participants }\end{array}$ & Glucose $/ 2 \mathrm{~h}$ \\
\hline 787 & 161 & Sri Lanka & Aerva lanata (Polpala) & 32 & 5 & NA & 25 & $\begin{array}{l}10 \text { Healthy } \\
\text { participants }\end{array}$ & Glucose $/ 2 \mathrm{~h}$ \\
\hline 788 & 161 & Sri Lanka & Asparagus racemosus (haathawaariya) & 37 & 4 & NA & 25 & $\begin{array}{l}10 \text { Healthy } \\
\text { participants }\end{array}$ & Glucose $/ 2 \mathrm{~h}$ \\
\hline 789 & 161 & Sri Lanka & Scoparia dulcis (Wal koththamalli) & 39 & 8 & NA & 25 & $\begin{array}{l}10 \text { Healthy } \\
\text { participants }\end{array}$ & Glucose $/ 2 \mathrm{~h}$ \\
\hline 790 & 161 & Sri Lanka & $\begin{array}{l}\text { Rice with lentil curry, boiled egg, coconut } \\
\text { gravy and Centella asiatica (gotukola) } \\
\text { leaves salad }\end{array}$ & 63 & 6 & $285+30 \mathrm{ml}$ coconut gravy & 50 & $\begin{array}{l}10 \text { Healthy } \\
\text { participants }\end{array}$ & Bread $/ 2 \mathrm{~h}$ \\
\hline 791 & 161 & Sri Lanka & $\begin{array}{l}\text { Rice with lentil curry, boiled egg, coconut } \\
\text { gravy and Lasia spinosa (kohila) salad }\end{array}$ & 57 & 5 & $285+30 \mathrm{ml}$ coconut gravy & 50 & $\begin{array}{l}10 \text { Healthy } \\
\text { participants }\end{array}$ & Bread/2 h \\
\hline 792 & 162 & Sri Lanka & Brown rice flour string hoppers + beans curry & 39.93 & 8.14 & NA & 50 & $\begin{array}{l}30 \text { Healthy } \\
\text { participants }\end{array}$ & Glucose $/ 2 \mathrm{~h}$ \\
\hline 793 & 162 & Sri Lanka & White rice flour string hoppers + beans curry & 41.96 & 9.86 & NA & 50 & $\begin{array}{l}30 \text { Healthy } \\
\text { participants }\end{array}$ & Glucose $/ 2 \mathrm{~h}$ \\
\hline 794 & 162 & Sri Lanka & Brown rice flour string hoppers + lentil curry & 44.30 & 9.25 & NA & 50 & $\begin{array}{l}30 \text { Healthy } \\
\text { participants }\end{array}$ & Glucose $/ 2 \mathrm{~h}$ \\
\hline
\end{tabular}


Table 1 continued

\begin{tabular}{|c|c|c|c|c|c|c|c|c|c|}
\hline & \multirow[t]{2}{*}{ Reference } & \multirow[t]{2}{*}{ Country } & \multirow[t]{2}{*}{ Food item } & \multicolumn{2}{|c|}{ GI (glucose $=100)$} & \multirow{2}{*}{$\begin{array}{l}\text { Serving size }(\mathrm{g}) \text { per experimental } \\
\text { portion size }\end{array}$} & \multirow{2}{*}{$\begin{array}{l}\text { Available } \mathrm{CHO} \\
\text { (g) per } \\
\text { experimental } \\
\text { portion }\end{array}$} & \multirow{2}{*}{$\begin{array}{l}\text { Participants } \\
\text { (type and } \\
\text { number) }\end{array}$} & \multirow{2}{*}{$\begin{array}{l}\text { Reference } \\
\text { food and } \\
\text { time perioc }\end{array}$} \\
\hline & & & & Mean & SEM & & & & \\
\hline 795 & 162 & Sri Lanka & White rice flour string hoppers + lentil curry & 53.46 & 9.57 & NA & 50 & $\begin{array}{l}30 \text { Healthy } \\
\text { participants }\end{array}$ & Glucose/2 h \\
\hline 796 & 162 & Sri Lanka & Brown rice flour string hoppers + fish curry & 45.26 & 9.25 & NA & 50 & $\begin{array}{l}30 \text { Healthy } \\
\text { participants }\end{array}$ & Glucose $/ 2 \mathrm{~h}$ \\
\hline 797 & 162 & Sri Lanka & White rice flour string hoppers + fish curry & 56.13 & 9.94 & NA & 50 & $\begin{array}{l}30 \text { Healthy } \\
\text { participants }\end{array}$ & Glucose $/ 2 \mathrm{~h}$ \\
\hline 798 & 162 & Sri Lanka & $\begin{array}{l}\text { Brown rice flour string hoppers }+ \text { coconut } \\
\text { gravy }+ \text { polsambol }\end{array}$ & 50.46 & 9.74 & NA & 50 & $\begin{array}{l}30 \text { Healthy } \\
\text { participants }\end{array}$ & Glucose $/ 2 \mathrm{~h}$ \\
\hline 799 & 162 & Sri Lanka & $\begin{array}{l}\text { White rice flour string hoppers }+ \text { coconut } \\
\text { gravy }+ \text { polsambol }\end{array}$ & 69.20 & 9.47 & NA & 50 & $\begin{array}{l}30 \text { Healthy } \\
\text { participants }\end{array}$ & Glucose $/ 2 \mathrm{~h}$ \\
\hline 800 & 163 & Sri Lanka & $\begin{array}{l}\text { Pittu (made with 25\% soy flour and } 75 \% \\
\text { rice flour) }\end{array}$ & 35.5 & 9.8 & 330 (4 medium size) & 50 & $\begin{array}{l}13 \text { Healthy } \\
\text { participants }\end{array}$ & Glucose $/ 2 \mathrm{~h}$ \\
\hline 801 & 163 & Sri Lanka & Pittu with vegetable curry & 30.2 & $6.5(S D)$ & 386.2 & 50 & $\begin{array}{l}13 \text { Healthy } \\
\text { participants }\end{array}$ & Glucose $/ 2 \mathrm{~h}$ \\
\hline 802 & 163 & Sri Lanka & $\begin{array}{l}\text { Rotti (made with 25\% soy flour and } 75 \% \\
\text { rice flour) }\end{array}$ & 36.04 & $8.1(S D)$ & 244.1 (4 medium size) & 50 & $\begin{array}{l}13 \text { Healthy } \\
\text { participants }\end{array}$ & Glucose $/ 2 \mathrm{~h}$ \\
\hline 803 & 163 & Sri Lanka & Rotti with vegetable curry & 31.15 & $4.6(S D)$ & 311.7 & 50 & $\begin{array}{l}13 \text { Healthy } \\
\text { participants }\end{array}$ & Glucose/2 h \\
\hline 804 & 163 & Sri Lanka & $\begin{array}{l}\text { Wandu (made with 25\% soy flour and } 75 \% \\
\text { rice flour) }\end{array}$ & 42.97 & $8.9(S D)$ & 400 (8 pcs) & 50 & $\begin{array}{l}13 \text { Healthy } \\
\text { participants }\end{array}$ & Glucose $/ 2 \mathrm{~h}$ \\
\hline 805 & 163 & Sri Lanka & Wandu with vegetable curry & 36.46 & $5.4(S D)$ & 446.9 & 50 & $\begin{array}{l}13 \text { Healthy } \\
\text { participants }\end{array}$ & Glucose $/ 2 \mathrm{~h}$ \\
\hline 806 & 163 & Sri Lanka & $\begin{array}{l}\text { Hopper (made with 25\% soy flour and } 75 \% \\
\text { rice flour) }\end{array}$ & 45.18 & $8.6(S D)$ & 340 (8 pcs) & 50 & $\begin{array}{l}13 \text { Healthy } \\
\text { participants }\end{array}$ & Glucose/2 h \\
\hline 807 & 163 & Sri Lanka & Hopper with vegetable curry & 38.3 & $5.6(S D)$ & 394.9 & 50 & $\begin{array}{l}13 \text { Healthy } \\
\text { participants }\end{array}$ & Glucose $/ 2 \mathrm{~h}$ \\
\hline 808 & 163 & Sri Lanka & $\begin{array}{l}\text { Thosai (made with 25\% soy flour and 75\% } \\
\text { rice flour) }\end{array}$ & 47.34 & $5.3(S D)$ & $353(7 \mathrm{pcs})$ & 50 & $\begin{array}{l}13 \text { Healthy } \\
\text { participants }\end{array}$ & Glucose $/ 2 \mathrm{~h}$ \\
\hline 809 & 164 & Sri Lanka & Thosai and sambol & 63.93 & 7.62 & NA & 75 & $\begin{array}{l}20 \text { Healthy } \\
\text { participants }\end{array}$ & Glucose $/ 2 \mathrm{~h}$ \\
\hline 810 & 164 & Sri Lanka & Thosai, sambol and plantain & 60.17 & 3.58 & NA & 75 & $\begin{array}{l}20 \text { Healthy } \\
\text { participants }\end{array}$ & Glucose $/ 2 \mathrm{~h}$ \\
\hline 811 & 164 & Sri Lanka & Thosai and Sampar & 71.90 & 4.73 & NA & 75 & $\begin{array}{l}20 \text { Healthy } \\
\text { participants }\end{array}$ & Glucose $/ 2 \mathrm{~h}$ \\
\hline 812 & 164 & Sri Lanka & Thosai, sampar and plantain & 68.57 & 4.18 & NA & 75 & $\begin{array}{l}20 \text { healthy } \\
\text { participants }\end{array}$ & Glucose $/ 2 \mathrm{~h}$ \\
\hline 813 & 164 & Sri Lanka & Thosai, sambol and sampar & 65.63 & 3.46 & NA & 75 & $\begin{array}{l}20 \text { Healthy } \\
\text { participants }\end{array}$ & Glucose $/ 2 \mathrm{~h}$ \\
\hline 814 & 164 & Sri Lanka & Thosai, sambol, sampar and plantain & 63.04 & 5.05 & NA & 75 & $\begin{array}{l}20 \text { Healthy } \\
\text { participants }\end{array}$ & Glucose $/ 2 \mathrm{~h}$ \\
\hline 815 & 165 & Sri Lanka & $\begin{array}{l}\text { Pakistani Basmati rice (rice cooker) }+20 \mathrm{~g} \\
\text { coconut sambol }\end{array}$ & 64 & 12 & $147 \mathrm{~g}$ (cooked) & 50 & $\begin{array}{l}10 \text { Healthy } \\
\text { participants }\end{array}$ & Glucose/2 h \\
\hline 816 & 165 & Sri Lanka & $\begin{array}{l}\text { Indian Basmati rice (rice cooker) }+20 \mathrm{~g} \\
\text { coconut sambol }\end{array}$ & 54 & $8(\mathrm{SD})$ & $151 \mathrm{~g}$ (cooked) & 50 & $\begin{array}{l}10 \text { Healthy } \\
\text { participants }\end{array}$ & Glucose $/ 2 \mathrm{~h}$ \\
\hline 817 & 165 & Sri Lanka & $\begin{array}{l}\text { Pakistani Basmati rice (microwave) }+120 \mathrm{~g} \\
\text { coconut sambol }\end{array}$ & 56 & 14 (SD) & $147 \mathrm{~g}$ (cooked) & 50 & $\begin{array}{l}10 \text { Healthy } \\
\text { participants }\end{array}$ & Glucose $/ 2 \mathrm{~h}$ \\
\hline 818 & 165 & Sri Lanka & $\begin{array}{l}\text { Indian Basmati rice (microwave) }+0 \mathrm{~g} \\
\text { coconut sambol }\end{array}$ & 43 & $6(S D)$ & $151 \mathrm{~g}$ (cooked) & 50 & $\begin{array}{l}10 \text { Healthy } \\
\text { participants }\end{array}$ & Glucose $/ 2 \mathrm{~h}$ \\
\hline 819 & 166 & Sri Lanka & Parboiled rice & 55.97 & 6.01 & NA & 75 & $\begin{array}{l}20 \text { Healthy } \\
\text { participants }\end{array}$ & Glucose/2 h \\
\hline 820 & 166 & Sri Lanka & White rice (Sampa) & 66.61 & 9.86 & NA & 75 & $\begin{array}{l}20 \text { Healthy } \\
\text { participants }\end{array}$ & Glucose $/ 2 \mathrm{~h}$ \\
\hline 821 & 166 & Sri Lanka & Brown rice & 60.24 & 8.16 & NA & 75 & $\begin{array}{l}20 \text { Healthy } \\
\text { participants }\end{array}$ & Glucose $/ 2 \mathrm{~h}$ \\
\hline 822 & 166 & Sri Lanka & String hoppers & 50.01 & 7.06 & NA & 75 & $\begin{array}{l}20 \text { Healthy } \\
\text { participants }\end{array}$ & Glucose $/ 2 \mathrm{~h}$ \\
\hline 823 & 166 & Sri Lanka & Pittu & 43.74 & 9.09 & NA & 75 & $\begin{array}{l}20 \text { Healthy } \\
\text { participants }\end{array}$ & Glucose $/ 2 \mathrm{~h}$ \\
\hline 824 & 166 & Sri Lanka & Parboiled rice + green leafy curry & 47.5 & NA & NA & 75 & $\begin{array}{l}20 \text { Healthy } \\
\text { participants }\end{array}$ & Glucose $/ 2 \mathrm{~h}$ \\
\hline 825 & 166 & Sri Lanka & Parboiled rice + gravy & 56.3 & NA & NA & 75 & $\begin{array}{l}20 \text { Healthy } \\
\text { participants }\end{array}$ & Glucose $/ 2 \mathrm{~h}$ \\
\hline 826 & 166 & Sri Lanka & Parboiled rice + green leafy curry and gravy & 54.7 & NA & NA & 75 & $\begin{array}{l}20 \text { Healthy } \\
\text { participants }\end{array}$ & Glucose $/ 2 \mathrm{~h}$ \\
\hline 827 & 166 & Sri Lanka & Pittu (kurakan flour) + green leafy curry & 57.5 & NA & NA & 75 & $\begin{array}{l}20 \text { Healthy } \\
\text { participants }\end{array}$ & Glucose/2 h \\
\hline 828 & 166 & Sri Lanka & Pittu (kurakan flour) + gravy & 63.3 & NA & NA & 75 & $\begin{array}{l}20 \text { Healthy } \\
\text { participants }\end{array}$ & Glucose/2 h \\
\hline
\end{tabular}


Table 1 continued

\begin{tabular}{|c|c|c|c|c|c|c|c|c|c|}
\hline & \multirow[t]{2}{*}{ Reference } & \multirow[t]{2}{*}{ Country } & \multirow[t]{2}{*}{ Food item } & \multicolumn{2}{|c|}{ GI (glucose $=100)$} & \multirow{2}{*}{$\begin{array}{l}\text { Serving size }(g) \text { per experimental } \\
\text { portion size }\end{array}$} & \multirow{2}{*}{$\begin{array}{l}\text { Available CHO } \\
\text { (g) per } \\
\text { experimental } \\
\text { portion }\end{array}$} & \multirow{2}{*}{$\begin{array}{l}\text { Participants } \\
\text { (type and } \\
\text { number) }\end{array}$} & \multirow{2}{*}{$\begin{array}{l}\text { Reference } \\
\text { food and } \\
\text { time period }\end{array}$} \\
\hline & & & & Mean & SEM & & & & \\
\hline 829 & 166 & Sri Lanka & $\begin{array}{l}\text { Pittu (kurakan flour) + green leafy curry + } \\
\text { gravy }\end{array}$ & 59.3 & NA & NA & 75 & $\begin{array}{l}20 \text { Healthy } \\
\text { participants }\end{array}$ & Glucose $/ 2 \mathrm{~h}$ \\
\hline 830 & 166 & Sri Lanka & Pittu (atta flour) + green leafy curry & 44.4 & NA & NA & 75 & $\begin{array}{l}20 \text { Healthy } \\
\text { participants }\end{array}$ & Glucose $/ 2 \mathrm{~h}$ \\
\hline 831 & 166 & Sri Lanka & Pittu (atta flour) + gravy & 50.8 & NA & NA & 75 & $\begin{array}{l}20 \text { Healthy } \\
\text { participants }\end{array}$ & Glucose $/ 2 \mathrm{~h}$ \\
\hline 832 & 166 & Sri Lanka & Pittu (atta flour) + green leafy curry + gravy & 46.3 & NA & NA & 75 & $\begin{array}{l}20 \text { Healthy } \\
\text { participants }\end{array}$ & Glucose $/ 2 \mathrm{~h}$ \\
\hline 833 & 166 & Sri Lanka & Boiled potato & 65.2 & 6.56 & NA & 75 & $\begin{array}{l}20 \text { Healthy } \\
\text { participants }\end{array}$ & Glucose $/ 2 \mathrm{~h}$ \\
\hline 834 & 166 & Sri Lanka & Boiled cassava & 78.7 & 7.3 & NA & 75 & $\begin{array}{l}20 \text { Healthy } \\
\text { participants }\end{array}$ & Glucose $/ 2 \mathrm{~h}$ \\
\hline 835 & 166 & Sri Lanka & Boiled chickpea & 33.3 & 6.23 & NA & 75 & $\begin{array}{l}20 \text { Healthy } \\
\text { participants }\end{array}$ & Glucose $/ 2 \mathrm{~h}$ \\
\hline 836 & 166 & Sri Lanka & Boiled green gram & 31.4 & 6.96 & NA & 75 & $\begin{array}{l}20 \text { Healthy } \\
\text { participants }\end{array}$ & Glucose/2 h \\
\hline 837 & 166 & Sri Lanka & Wheat flour bread & 68.59 & NA & NA & 75 & $\begin{array}{l}20 \text { Healthy } \\
\text { participants }\end{array}$ & Glucose $/ 2 \mathrm{~h}$ \\
\hline 838 & 166 & Sri Lanka & Normal bun & 67.3 & NA & NA & 75 & $\begin{array}{l}20 \text { Healthy } \\
\text { participants }\end{array}$ & Glucose $/ 2 \mathrm{~h}$ \\
\hline 839 & 166 & Sri Lanka & Hard bun & 52.78 & NA & NA & 75 & $\begin{array}{l}20 \text { Healthy } \\
\text { participants }\end{array}$ & Glucose $/ 2 \mathrm{~h}$ \\
\hline 840 & 166 & Sri Lanka & Butter cake & 64.72 & NA & NA & 75 & $\begin{array}{l}20 \text { Healthy } \\
\text { participants }\end{array}$ & Glucose $/ 2 \mathrm{~h}$ \\
\hline 841 & 166 & Sri Lanka & Rusk & 50.30 & NA & NA & 75 & $\begin{array}{l}20 \text { Healthy } \\
\text { participants }\end{array}$ & Glucose/2 h \\
\hline 842 & 166 & Sri Lanka & Idli and sambol & 56.85 & 6.26 & NA & 75 & $\begin{array}{l}20 \text { Healthy } \\
\text { participants }\end{array}$ & Glucose/2 h \\
\hline 843 & 166 & Sri Lanka & Idli, sambol and plantain & 51.10 & 6.57 & NA & 75 & $\begin{array}{l}20 \text { Healthy } \\
\text { participants }\end{array}$ & Glucose $/ 2 \mathrm{~h}$ \\
\hline 844 & 166 & Sri Lanka & Idli and sampar & 70.32 & 8.22 & NA & 75 & $\begin{array}{l}20 \text { Healthy } \\
\text { participants }\end{array}$ & Glucose $/ 2 \mathrm{~h}$ \\
\hline 845 & 166 & Sri Lanka & Idli, sampar and plantain & 67.45 & 7.87 & NA & 75 & $\begin{array}{l}20 \text { Healthy } \\
\text { participants }\end{array}$ & Glucose $/ 2 \mathrm{~h}$ \\
\hline 846 & 166 & Sri Lanka & Idli, sambol and sampar & 63.09 & 3.29 & NA & 75 & $\begin{array}{l}20 \text { Healthy } \\
\text { participants }\end{array}$ & Glucose/2 h \\
\hline 847 & 166 & Sri Lanka & Idli, sambol, sampar and plantain & 61.30 & 3.09 & NA & 75 & $\begin{array}{l}20 \text { Healthy } \\
\text { participants }\end{array}$ & Glucose/2 h \\
\hline 848 & 167 & Sri Lanka & Roti (Caryote urens) & 57 & 4 & 114 & 50 & $\begin{array}{l}10 \text { Healthy } \\
\text { participants }\end{array}$ & $\begin{array}{l}\text { White bread/ } \\
2 \mathrm{~h}\end{array}$ \\
\hline 849 & 167 & Sri Lanka & Porridge (Caryote urens) & 128 & 11 & 530 & 50 & $\begin{array}{l}10 \text { Healthy } \\
\text { participants }\end{array}$ & $\begin{array}{l}\text { White bread/ } \\
2 \mathrm{~h}\end{array}$ \\
\hline 850 & 167 & Sri Lanka & Muffin (Caryote urens) & 92 & 9 & 126 & 50 & $\begin{array}{l}10 \text { Healthy } \\
\text { participants }\end{array}$ & $\begin{array}{l}\text { White bread/ } \\
2 \mathrm{~h}\end{array}$ \\
\hline 851 & 167 & Sri Lanka & Roti (Cycas circanlis) & 66 & 6 & 135 & 50 & $\begin{array}{l}10 \text { Healthy } \\
\text { participants }\end{array}$ & $\begin{array}{l}\text { White bread/ } \\
2 \mathrm{~h}\end{array}$ \\
\hline 852 & 167 & Sri Lanka & Pittu (Cycas circanlis) & 72 & 4 & 145 & 50 & $\begin{array}{l}10 \text { Healthy } \\
\text { participants }\end{array}$ & $\begin{array}{l}\text { White bread/ } \\
2 \mathrm{~h}\end{array}$ \\
\hline 853 & 167 & Sri Lanka & Pittu (Vateria copalifera) & 67 & 7 & 215 & 50 & $\begin{array}{l}10 \text { Healthy } \\
\text { participants }\end{array}$ & $\begin{array}{l}\text { White bread/ } \\
2 \mathrm{~h}\end{array}$ \\
\hline 854 & 168 & Sri Lanka & $\begin{array}{l}\text { Skimmed milk powder with powdered oats } \\
\text { and whey }\end{array}$ & 12 & 2 & NA & 50 & $\begin{array}{l}11 \text { Healthy } \\
\text { participants }\end{array}$ & Glucose $/ 2 \mathrm{~h}$ \\
\hline 855 & 169 & Sri Lanka & Red pigmented rice (Kaluheenati) & 56.3 & 2.5 & NA & 50 & $\begin{array}{l}12 \text { Healthy } \\
\text { participants }\end{array}$ & Glucose $/ 2 \mathrm{~h}$ \\
\hline 856 & 169 & Sri Lanka & Red pigmented rice (Wedaheenati) & 52.5 & 1.5 & NA & 50 & $\begin{array}{l}12 \text { Healthy } \\
\text { participants }\end{array}$ & Glucose $/ 2 \mathrm{~h}$ \\
\hline 857 & 169 & Sri Lanka & Red pigmented rice (Rathkaral) & 62.0 & 3.1 & NA & 50 & $\begin{array}{l}12 \text { Healthy } \\
\text { participants }\end{array}$ & Glucose $/ 2 \mathrm{~h}$ \\
\hline 858 & 169 & Sri Lanka & Red pigmented rice (Madathawalu) & 64.0 & 2.5 & NA & 50 & $\begin{array}{l}12 \text { Healthy } \\
\text { participants }\end{array}$ & Glucose $/ 2 \mathrm{~h}$ \\
\hline 859 & 170 & $\begin{array}{l}\text { United Arab } \\
\text { Emirates (UAE) }\end{array}$ & Rutab (dates) & 47.2 & 17.4 & 101.8 & 50 & $\begin{array}{l}11 \text { Healthy } \\
\text { participants }\end{array}$ & Glucose $/ 2 \mathrm{~h}$ \\
\hline 860 & 170 & $\begin{array}{l}\text { United Arab } \\
\text { Emirates (UAE) }\end{array}$ & Commercial tamer (dates) & 35.5 & 9.7 & 66.7 & 50 & $\begin{array}{l}11 \text { Healthy } \\
\text { participants }\end{array}$ & Glucose $/ 2 \mathrm{~h}$ \\
\hline 861 & 170 & $\begin{array}{l}\text { United Arab } \\
\text { Emirates (UAE) }\end{array}$ & Traditional dates & 45.3 & 25.6 & 66.8 & 50 & $\begin{array}{l}11 \text { Healthy } \\
\text { participants }\end{array}$ & Glucose $/ 2 \mathrm{~h}$ \\
\hline 862 & 171 & $\begin{array}{l}\text { United Arab } \\
\text { Emirates (UAE) }\end{array}$ & Fara'd (dates) & 54.0 & 6.1 & 72.5 & 50 & $\begin{array}{l}13 \text { Healthy } \\
\text { participants }\end{array}$ & Glucose/2 h \\
\hline
\end{tabular}


Table 1 continued

\begin{tabular}{|c|c|c|c|c|c|c|c|c|c|}
\hline & \multirow[t]{2}{*}{ Reference } & \multirow[t]{2}{*}{ Country } & \multirow[t]{2}{*}{ Food item } & \multicolumn{2}{|c|}{ GI (glucose $=100)$} & \multirow{2}{*}{$\begin{array}{l}\text { Serving size }(g) \text { per experimental } \\
\text { portion size }\end{array}$} & \multirow{2}{*}{$\begin{array}{l}\text { Available } \mathrm{CHO} \\
\text { (g) per } \\
\text { experimental } \\
\text { portion }\end{array}$} & \multirow{2}{*}{$\begin{array}{l}\text { Participants } \\
\text { (type and } \\
\text { number) }\end{array}$} & \multirow{2}{*}{$\begin{array}{l}\text { Reference } \\
\text { food and } \\
\text { time perioo }\end{array}$} \\
\hline & & & & Mean & SEM & & & & \\
\hline 863 & 171 & $\begin{array}{l}\text { United Arab } \\
\text { Emirates (UAE) }\end{array}$ & Fara'd (dates) & 46.1 & 6.2 & 72.5 & 50 & $\begin{array}{l}10 \mathrm{~T} 2 \mathrm{DM} \\
\text { participants }\end{array}$ & Glucose $/ 3 \mathrm{~h}$ \\
\hline 864 & 171 & $\begin{array}{l}\text { United Arab } \\
\text { Emirates (UAE) }\end{array}$ & Lulu (dates) & 53.5 & 8.6 & 73.6 & 50 & $\begin{array}{l}13 \text { Healthy } \\
\text { participants }\end{array}$ & Glucose $/ 2 \mathrm{~h}$ \\
\hline 865 & 171 & $\begin{array}{l}\text { United Arab } \\
\text { Emirates (UAE) }\end{array}$ & Lulu (dates) & 43.8 & 7.7 & 73.6 & 50 & $\begin{array}{l}10 \mathrm{~T} 2 \mathrm{DM} \\
\text { participants }\end{array}$ & Glucose $/ 3 \mathrm{~h}$ \\
\hline 866 & 171 & $\begin{array}{l}\text { United Arab } \\
\text { Emirates (UAE) }\end{array}$ & Bo ma'an (dates) & 46.3 & 7.1 & 72.7 & 50 & $\begin{array}{l}13 \text { Healthy } \\
\text { participants }\end{array}$ & Glucose $/ 2 \mathrm{~h}$ \\
\hline 867 & 171 & $\begin{array}{l}\text { United Arab } \\
\text { Emirates (UAE) }\end{array}$ & Bo ma'an (dates) & 51.8 & 6.9 & 72.7 & 50 & $\begin{array}{l}10 \mathrm{~T} 2 \mathrm{DM} \\
\text { participants }\end{array}$ & Glucose $/ 3 \mathrm{~h}$ \\
\hline 868 & 171 & $\begin{array}{l}\text { United Arab } \\
\text { Emirates (UAE) }\end{array}$ & Dabbas (dates) & 49.1 & 3.6 & 76.2 & 50 & $\begin{array}{l}13 \text { Healthy } \\
\text { participants }\end{array}$ & Glucose $/ 2 \mathrm{~h}$ \\
\hline 869 & 171 & $\begin{array}{l}\text { United Arab } \\
\text { Emirates (UAE) }\end{array}$ & Dabbas (dates) & 50.2 & 3.9 & 76.2 & 50 & $\begin{array}{l}10 \mathrm{~T} 2 \mathrm{DM} \\
\text { participants }\end{array}$ & Glucose $/ 3 \mathrm{~h}$ \\
\hline 870 & 171 & $\begin{array}{l}\text { United Arab } \\
\text { Emirates (UAE) }\end{array}$ & Khalas (dates) & 55.1 & 7.7 & 72.6 & 50 & $\begin{array}{l}13 \text { Healthy } \\
\text { participants }\end{array}$ & Glucose $/ 2 \mathrm{~h}$ \\
\hline 871 & 171 & $\begin{array}{l}\text { United Arab } \\
\text { Emirates (UAE) }\end{array}$ & Khalas (dates) & 53.0 & 6.0 & 72.6 & 50 & $\begin{array}{l}10 \text { T2DM } \\
\text { participants }\end{array}$ & Glucose $/ 3 \mathrm{~h}$ \\
\hline 872 & 172 & $\begin{array}{l}\text { United Arab } \\
\text { Emirates (UAE) }\end{array}$ & Khalas (dates) & 55.1 & 7.7 & NA & 50 & $\begin{array}{l}13 \text { Healthy } \\
\text { participants }\end{array}$ & Glucose $/ 2 \mathrm{~h}$ \\
\hline 873 & 172 & $\begin{array}{l}\text { United Arab } \\
\text { Emirates (UAE) }\end{array}$ & Khalas (dates) & 53.0 & 6.0 & NA & 50 & $\begin{array}{l}10 \text { T2DM } \\
\text { participants }\end{array}$ & Glucose $/ 3 \mathrm{~h}$ \\
\hline 874 & 172 & $\begin{array}{l}\text { United Arab } \\
\text { Emirates (UAE) }\end{array}$ & Khalas with Arabic coffee & 52.7 & 6.2 & NA & 50 & $\begin{array}{l}13 \text { Healthy } \\
\text { participants }\end{array}$ & Glucose $/ 2 \mathrm{~h}$ \\
\hline 875 & 172 & $\begin{array}{l}\text { United Arab } \\
\text { Emirates (UAE) }\end{array}$ & Khalas with Arabic coffee & 41.5 & 5.4 & NA & 50 & $\begin{array}{l}10 \text { T2DM } \\
\text { participants }\end{array}$ & Glucose $/ 3 \mathrm{~h}$ \\
\hline 876 & 173 & $\begin{array}{l}\text { United Arab } \\
\text { Emirates (UAE) }\end{array}$ & Arabic bread & 67 & 5 & 78.8 & 50 & $\begin{array}{l}25 \text { Healthy } \\
\text { participants }\end{array}$ & Glucose $/ 2 \mathrm{~h}$ \\
\hline 877 & 173 & $\begin{array}{l}\text { United Arab } \\
\text { Emirates (UAE) }\end{array}$ & Regag bread & 76 & 7 & 112.7 & 50 & $\begin{array}{l}25 \text { Healthy } \\
\text { participants }\end{array}$ & Glucose $/ 2 \mathrm{~h}$ \\
\hline 878 & 173 & $\begin{array}{l}\text { United Arab } \\
\text { Emirates (UAE) }\end{array}$ & Chebab bread & 54 & 8 & 109 & 50 & $\begin{array}{l}15 \text { Healthy } \\
\text { participants }\end{array}$ & Glucose $/ 2 \mathrm{~h}$ \\
\hline 879 & 173 & $\begin{array}{l}\text { United Arab } \\
\text { Emirates (UAE) }\end{array}$ & Muhalla bread & 77 & 2 & 73.9 & 50 & $\begin{array}{l}15 \text { Healthy } \\
\text { participants }\end{array}$ & Glucose $/ 2 \mathrm{~h}$ \\
\hline 880 & 173 & $\begin{array}{l}\text { United Arab } \\
\text { Emirates (UAE) }\end{array}$ & Khameer bread & 47 & 3 & 91.0 & 50 & $\begin{array}{l}15 \text { Healthy } \\
\text { participants }\end{array}$ & Glucose $/ 2 \mathrm{~h}$ \\
\hline 881 & 173 & $\begin{array}{l}\text { United Arab } \\
\text { Emirates (UAE) }\end{array}$ & Fendal & 74 & 7 & 158 & 50 & $\begin{array}{l}20 \text { Healthy } \\
\text { participants }\end{array}$ & Glucose $/ 2 \mathrm{~h}$ \\
\hline 882 & 173 & $\begin{array}{l}\text { United Arab } \\
\text { Emirates (UAE) }\end{array}$ & Chami (cottage cheese) & 60 & 9 & 470.0 & 25 & $\begin{array}{l}16 \text { Healthy } \\
\text { participants }\end{array}$ & Glucose $/ 2 \mathrm{~h}$ \\
\hline 883 & 173 & $\begin{array}{l}\text { United Arab } \\
\text { Emirates (UAE) }\end{array}$ & Habba Hamra & 47 & 3 & 313.3 & 50 & $\begin{array}{l}15 \text { Healthy } \\
\text { participants }\end{array}$ & Glucose $/ 2 \mathrm{~h}$ \\
\hline 884 & 173 & $\begin{array}{l}\text { United Arab } \\
\text { Emirates (UAE) }\end{array}$ & Harees & 42 & 2 & 323.0 & 50 & $\begin{array}{l}15 \text { Healthy } \\
\text { participants }\end{array}$ & Glucose $/ 2 \mathrm{~h}$ \\
\hline 885 & 173 & $\begin{array}{l}\text { United Arab } \\
\text { Emirates (UAE) }\end{array}$ & Thareed (beef) & 74 & 3 & 460.0 & 50 & $\begin{array}{l}15 \text { Healthy } \\
\text { participants }\end{array}$ & Glucose $/ 2 \mathrm{~h}$ \\
\hline 886 & 173 & $\begin{array}{l}\text { United Arab } \\
\text { Emirates (UAE) }\end{array}$ & Biryani (chicken) & 52 & 4 & 253.9 & 50 & $\begin{array}{l}15 \text { Healthy } \\
\text { participants }\end{array}$ & Glucose $/ 2 \mathrm{~h}$ \\
\hline 887 & 173 & $\begin{array}{l}\text { United Arab } \\
\text { Emirates (UAE) }\end{array}$ & Machbous (fish) & 60 & 3 & 277.0 & 50 & $\begin{array}{l}20 \text { Healthy } \\
\text { participants }\end{array}$ & Glucose $/ 2 \mathrm{~h}$ \\
\hline 888 & 173 & $\begin{array}{l}\text { United Arab } \\
\text { Emirates (UAE) }\end{array}$ & Arseyah & 72 & 4 & 507.6 & 50 & $\begin{array}{l}15 \text { Healthy } \\
\text { participants }\end{array}$ & Glucose $/ 2 \mathrm{~h}$ \\
\hline 889 & 173 & $\begin{array}{l}\text { United Arab } \\
\text { Emirates (UAE) }\end{array}$ & Khabisa & 67 & 4 & 89.1 & 50 & $\begin{array}{l}15 \text { Healthy } \\
\text { participants }\end{array}$ & Glucose $/ 2 \mathrm{~h}$ \\
\hline 890 & 173 & $\begin{array}{l}\text { United Arab } \\
\text { Emirates (UAE) }\end{array}$ & Leqemat & 44 & 4 & 113.1 & 50 & $\begin{array}{l}15 \text { Healthy } \\
\text { participants }\end{array}$ & Glucose $/ 2 \mathrm{~h}$ \\
\hline 891 & 173 & $\begin{array}{l}\text { United Arab } \\
\text { Emirates (UAE) }\end{array}$ & Batheetha & 59 & 4 & 130.8 & 50 & $\begin{array}{l}20 \text { Healthy } \\
\text { participants }\end{array}$ & Glucose $/ 2 \mathrm{~h}$ \\
\hline 892 & 173 & $\begin{array}{l}\text { United Arab } \\
\text { Emirates (UAE) }\end{array}$ & Khanfaroosh & 45 & 3 & 126.2 & 50 & $\begin{array}{l}15 \text { Healthy } \\
\text { participants }\end{array}$ & Glucose $/ 2 \mathrm{~h}$ \\
\hline 893 & 173 & $\begin{array}{l}\text { United Arab } \\
\text { Emirates (UAE) }\end{array}$ & Balalet & 63 & 5 & 179.3 & 50 & $\begin{array}{l}15 \text { Healthy } \\
\text { participants }\end{array}$ & Glucose $/ 2 \mathrm{~h}$ \\
\hline 894 & 174 & $\begin{array}{l}\text { United Arab } \\
\text { Emirates (UAE) }\end{array}$ & Dried Bisr (mature unripe) dates & 54.6 & 15.2 & NA & 25 & $\begin{array}{l}15 \text { Healthy } \\
\text { participants }\end{array}$ & Glucose $/ 2 \mathrm{~h}$ \\
\hline 895 & 174 & $\begin{array}{l}\text { United Arab } \\
\text { Emirates (UAE) }\end{array}$ & Dried Tamr (mature ripe) dates & 54.3 & 14.3 & NA & 25 & $\begin{array}{l}15 \text { Healthy } \\
\text { participants }\end{array}$ & Glucose $/ 2 \mathrm{~h}$ \\
\hline 896 & 175 & Oman & Doughnut with water & 75.49 & 3.44 & $250(\mathrm{ml})$ water & 50 & $\begin{array}{l}12 \text { Healthy } \\
\text { participants }\end{array}$ & Glucose $/ 2 \mathrm{~h}$ \\
\hline
\end{tabular}


Table 1 continued

\begin{tabular}{|c|c|c|c|c|c|c|c|c|c|}
\hline & \multirow[t]{2}{*}{ Reference } & \multirow[t]{2}{*}{ Country } & \multirow[t]{2}{*}{ Food item } & \multicolumn{2}{|c|}{ Gl (glucose $=100)$} & \multirow{2}{*}{$\begin{array}{l}\text { Serving size }(\mathrm{g}) \text { per experimental } \\
\text { portion size }\end{array}$} & \multirow{2}{*}{$\begin{array}{l}\text { Available } \mathrm{CHO} \\
\text { (g) per } \\
\text { experimental } \\
\text { portion }\end{array}$} & \multirow{2}{*}{$\begin{array}{l}\text { Participants } \\
\text { (type and } \\
\text { number) }\end{array}$} & \multirow{2}{*}{$\begin{array}{l}\text { Reference } \\
\text { food and } \\
\text { time period }\end{array}$} \\
\hline & & & & Mean & SEM & & & & \\
\hline 897 & 175 & Oman & Doughnut with Omani coffee & 76.50 & 3.45 & $130(\mathrm{ml})$ coffee & 50 & $\begin{array}{l}12 \text { Healthy } \\
\text { participants }\end{array}$ & Glucose $/ 2 \mathrm{~h}$ \\
\hline 898 & 175 & Oman & Croissant with water & 67.46 & 2.47 & $250(\mathrm{ml})$ water & 50 & $\begin{array}{l}12 \text { Healthy } \\
\text { participants }\end{array}$ & Glucose $/ 2 \mathrm{~h}$ \\
\hline 899 & 175 & Oman & Croissant with Omani coffee & 65.32 & 3.69 & $130(\mathrm{ml})$ coffee & 50 & $\begin{array}{l}12 \text { Healthy } \\
\text { participants }\end{array}$ & Glucose $/ 2 \mathrm{~h}$ \\
\hline 900 & 175 & Oman & Cheese sandwich with water & 72.41 & 3.61 & $250(\mathrm{ml})$ water & 50 & $\begin{array}{l}12 \text { Healthy } \\
\text { participants }\end{array}$ & Glucose $/ 2 \mathrm{~h}$ \\
\hline 901 & 175 & Oman & Cheese sandwich with Omani coffee & 78.40 & 3.67 & $130(\mathrm{ml})$ coffee & 50 & $\begin{array}{l}12 \text { Healthy } \\
\text { participants }\end{array}$ & Glucose $/ 2 \mathrm{~h}$ \\
\hline 902 & 175 & Oman & Chicken sandwich with water & 65.68 & 3.00 & $250(\mathrm{ml})$ water & 50 & $\begin{array}{l}12 \text { Healthy } \\
\text { participants }\end{array}$ & Glucose $/ 2 \mathrm{~h}$ \\
\hline 903 & 175 & Oman & Chicken sandwich with Omani coffee & 70.61 & 3.66 & $130(\mathrm{ml})$ coffee & 50 & $\begin{array}{l}12 \text { Healthy } \\
\text { participants }\end{array}$ & Glucose $/ 2 \mathrm{~h}$ \\
\hline 904 & 175 & Oman & Fried egg sandwich with water & 73.38 & 4.46 & $250(\mathrm{ml})$ water & 50 & $\begin{array}{l}12 \text { Healthy } \\
\text { participants }\end{array}$ & Glucose $/ 2 \mathrm{~h}$ \\
\hline 905 & 175 & Oman & Fried egg sandwich with Omani coffee & 73.14 & 4.03 & $130(\mathrm{ml})$ coffee & 50 & $\begin{array}{l}12 \text { Healthy } \\
\text { participants }\end{array}$ & Glucose $/ 2 \mathrm{~h}$ \\
\hline 906 & 175 & Oman & Sambosa vegetable with water & 60.35 & 5.11 & $250(\mathrm{ml})$ water & 50 & $\begin{array}{l}12 \text { Healthy } \\
\text { participants }\end{array}$ & Glucose $/ 2 \mathrm{~h}$ \\
\hline 907 & 175 & Oman & Sambosa vegetable with Omani coffee & 57.25 & 3.97 & $130(\mathrm{ml})$ coffee & 50 & $\begin{array}{l}12 \text { Healthy } \\
\text { participants }\end{array}$ & Glucose $/ 2 \mathrm{~h}$ \\
\hline 908 & 175 & Oman & Fried vermicelli with water & 71.77 & 3.72 & $250(\mathrm{ml})$ water & 50 & $\begin{array}{l}12 \text { Healthy } \\
\text { participants }\end{array}$ & Glucose $/ 2 \mathrm{~h}$ \\
\hline 909 & 175 & Oman & Fried vermicelli with Omani coffee & 64.99 & 4.92 & $130(\mathrm{ml})$ coffee & 50 & $\begin{array}{l}12 \text { Healthy } \\
\text { participants }\end{array}$ & Glucose $/ 2 \mathrm{~h}$ \\
\hline 910 & 175 & Oman & Boiled vermicelli with water & 67.46 & 5.01 & $250(\mathrm{ml})$ water & 50 & $\begin{array}{l}12 \text { Healthy } \\
\text { participants }\end{array}$ & Glucose $/ 2 \mathrm{~h}$ \\
\hline 911 & 175 & Oman & Boiled vermicelli with Omani coffee & 64.02 & 5.26 & $130(\mathrm{ml})$ coffee & 50 & $\begin{array}{l}12 \text { Healthy } \\
\text { participants }\end{array}$ & Glucose $/ 2 \mathrm{~h}$ \\
\hline 912 & 175 & Oman & Red bean with white bread and water & 61.70 & 3.94 & $250(\mathrm{ml})$ water & 50 & $\begin{array}{l}12 \text { Healthy } \\
\text { participants }\end{array}$ & Glucose $/ 2 \mathrm{~h}$ \\
\hline 913 & 175 & Oman & Red bean with white bread and Omani coffee & 65.22 & 3.64 & $130(\mathrm{ml})$ coffee & 50 & $\begin{array}{l}12 \text { Healthy } \\
\text { participants }\end{array}$ & Glucose $/ 2 \mathrm{~h}$ \\
\hline 914 & 176 & Saudi Arabia & Hassawi rice & 59 & 5 & 150 & 25 & $\begin{array}{l}13 \text { Healthy } \\
\text { participants }\end{array}$ & Glucose $/ 2 \mathrm{~h}$ \\
\hline 915 & 176 & Saudi Arabia & Uncle Ben's rice & 54 & 7 & 150 & 25 & $\begin{array}{l}13 \text { Healthy } \\
\text { participants }\end{array}$ & Glucose $/ 2 \mathrm{~h}$ \\
\hline 916 & 177 & $\begin{array}{l}\text { Saudi Arabia/ } \\
\text { United } \\
\text { Kingdom }\end{array}$ & Khulas (dates) & 55.0 & 6.0 & NA & 50 & $\begin{array}{l}10 \text { Healthy } \\
\text { participants }\end{array}$ & Glucose $/ 2 \mathrm{~h}$ \\
\hline 917 & 177 & $\begin{array}{l}\text { Saudi Arabia/ } \\
\text { United } \\
\text { Kingdom }\end{array}$ & Khulas with Arabic coffee & 63.0 & 5.0 & NA & 50 & $\begin{array}{l}10 \text { Healthy } \\
\text { participants }\end{array}$ & Glucose $/ 2 \mathrm{~h}$ \\
\hline 918 & 178 & Saudi Arabia & Maktoomi & 71.0 & 11.1 & 68.51 & 50 & $\begin{array}{l}10 \text { Healthy } \\
\text { participants }\end{array}$ & Glucose $/ 2 \mathrm{~h}$ \\
\hline 919 & 178 & Saudi Arabia & Khudri & 61.7 & 7.4 & 67.06 & 50 & $\begin{array}{l}10 \text { Healthy } \\
\text { participants }\end{array}$ & Glucose $/ 2 \mathrm{~h}$ \\
\hline 920 & 178 & Saudi Arabia & Nabtat-ali & 59.9 & 6.9 & 69.27 & 50 & $\begin{array}{l}10 \text { Healthy } \\
\text { participants }\end{array}$ & Glucose $/ 2 \mathrm{~h}$ \\
\hline 921 & 178 & Saudi Arabia & Um-Kabar & 58.7 & 7.3 & 69.11 & 50 & $\begin{array}{l}10 \text { Healthy } \\
\text { participants }\end{array}$ & Glucose $/ 2 \mathrm{~h}$ \\
\hline 922 & 178 & Saudi Arabia & Ajwah & 55.9 & 5.9 & 70.13 & 50 & $\begin{array}{l}10 \text { Healthy } \\
\text { participants }\end{array}$ & Glucose $/ 2 \mathrm{~h}$ \\
\hline 923 & 178 & Saudi Arabia & Medjool & $55.3)$ & 6.8 & 70.54 & 50 & $\begin{array}{l}10 \text { Healthy } \\
\text { participants }\end{array}$ & Glucose $/ 2 \mathrm{~h}$ \\
\hline 924 & 178 & Saudi Arabia & Sabaka & 54.9 & 11.5 & 69.52 & 50 & $\begin{array}{l}10 \text { healthy } \\
\text { participants }\end{array}$ & Glucose $/ 2 \mathrm{~h}$ \\
\hline 925 & 178 & Saudi Arabia & Ruthana & 52.5 & 4 & 73.44 & 50 & $\begin{array}{l}10 \text { Healthy } \\
\text { participants }\end{array}$ & Glucose $/ 2 \mathrm{~h}$ \\
\hline 926 & 178 & Saudi Arabia & Rashodia & 50.9 & 6.5 & 67.27 & 50 & $\begin{array}{l}10 \text { Healthy } \\
\text { participants }\end{array}$ & Glucose $/ 2 \mathrm{~h}$ \\
\hline 927 & 178 & Saudi Arabia & Wannanah & 50.9 & 7.3 & 67.54 & 50 & $\begin{array}{l}10 \text { Healthy } \\
\text { participants }\end{array}$ & Glucose $/ 2 \mathrm{~h}$ \\
\hline 928 & 178 & Saudi Arabia & Shishi & 50.2 & 7.2 & 71.81 & 50 & $\begin{array}{l}10 \text { Healthy } \\
\text { participants }\end{array}$ & Glucose $/ 2 \mathrm{~h}$ \\
\hline 929 & 178 & Saudi Arabia & Sukkary & 43.4 & 4.7 & 77.63 & 50 & $\begin{array}{l}10 \text { Healthy } \\
\text { participants }\end{array}$ & Glucose $/ 2 \mathrm{~h}$ \\
\hline
\end{tabular}


Table 1 continued

\begin{tabular}{|c|c|c|c|c|c|c|c|c|c|}
\hline & \multirow[t]{2}{*}{ Reference } & \multirow[t]{2}{*}{ Country } & \multirow[t]{2}{*}{ Food item } & \multicolumn{2}{|c|}{$\mathrm{GI}($ glucose $=100)$} & \multirow{2}{*}{$\begin{array}{l}\text { Serving size }(g) \text { per experimental } \\
\text { portion size }\end{array}$} & \multirow{2}{*}{$\begin{array}{l}\text { Available CHO } \\
\text { (g) per } \\
\text { experimental } \\
\text { portion }\end{array}$} & \multirow{2}{*}{$\begin{array}{l}\text { Participants } \\
\text { (type and } \\
\text { number) }\end{array}$} & \multirow{2}{*}{$\begin{array}{l}\text { Reference } \\
\text { food and } \\
\text { time period }\end{array}$} \\
\hline & & & & Mean & SEM & & & & \\
\hline 930 & 178 & Saudi Arabia & Shaqra & 42.8 & 5.5 & 66.92 & 50 & $\begin{array}{l}10 \text { Healthy } \\
\text { participants }\end{array}$ & Glucose $/ 2 \mathrm{~h}$ \\
\hline 931 & 179 & Lebanon & Bourgoul A banadoura & 50.09 & 8.72 & 420 & 50 & $\begin{array}{l}12 \text { Healthy } \\
\text { participants }\end{array}$ & Glucose $/ 2 \mathrm{~h}$ \\
\hline 932 & 179 & Lebanon & Fattit hommos & 37.21 & 3.73 & 225 & 50 & $\begin{array}{l}12 \text { Healthy } \\
\text { participants }\end{array}$ & Glucose $/ 2 \mathrm{~h}$ \\
\hline 933 & 179 & Lebanon & Loubieh bzet & 12.76 & 4.90 & 240 & 50 & $\begin{array}{l}12 \text { Healthy } \\
\text { participants }\end{array}$ & Glucose $/ 2 \mathrm{~h}$ \\
\hline 934 & 179 & Lebanon & Meghleh & 49.50 & 7.69 & 390 & 50 & $\begin{array}{l}12 \text { Healthy } \\
\text { participants }\end{array}$ & Glucose $/ 2 \mathrm{~h}$ \\
\hline 935 & 179 & Lebanon & Mehshe malfouf & 67.93 & 7.89 & 525 & 50 & $\begin{array}{l}12 \text { Healthy } \\
\text { participants }\end{array}$ & Glucose $/ 2 \mathrm{~h}$ \\
\hline 936 & 179 & Lebanon & Pizza & 56.04 & 6.71 & 96 & 50 & $\begin{array}{l}12 \text { Healthy } \\
\text { participants }\end{array}$ & Glucose $/ 2 \mathrm{~h}$ \\
\hline 937 & 179 & Lebanon & Riz A dgeg & 57.34 & 6.67 & 600 & 50 & $\begin{array}{l}12 \text { Healthy } \\
\text { participants }\end{array}$ & Glucose $/ 2 \mathrm{~h}$ \\
\hline 938 & 179 & Lebanon & Riz Bi halib & 56.83 & 7.35 & 165 & 50 & $\begin{array}{l}12 \text { Healthy } \\
\text { participants }\end{array}$ & Glucose $/ 2 \mathrm{~h}$ \\
\hline 939 & 179 & Lebanon & Sfouf & 48.59 & 4.94 & 70 & 50 & $\begin{array}{l}12 \text { Healthy } \\
\text { participants }\end{array}$ & Glucose $/ 2 \mathrm{~h}$ \\
\hline 940 & 179 & Lebanon & Siyadieh & 14.62 & 3.24 & 430 & 50 & $\begin{array}{l}12 \text { Healthy } \\
\text { participants }\end{array}$ & Glucose $/ 2 \mathrm{~h}$ \\
\hline
\end{tabular}

Gl glycaemic index, NA not available.

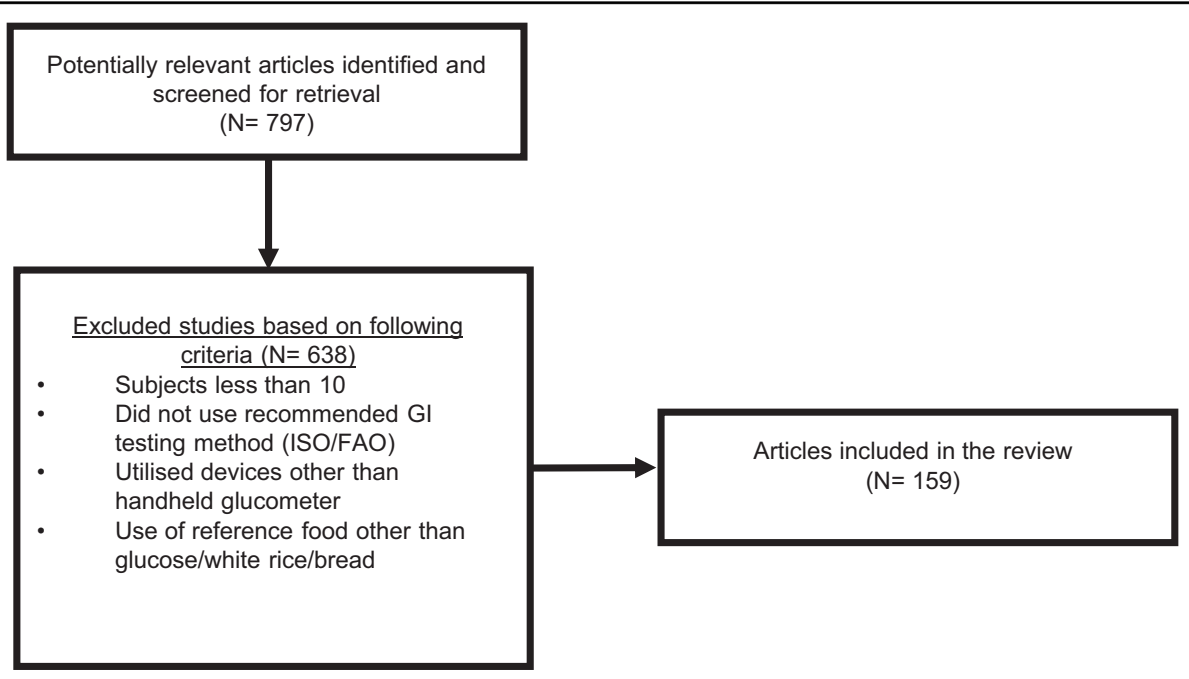

Fig. 1 Flowchart illustrating number of studies screened, excluded and included. $\mathrm{N}$ - number of studies, ISO - International Organisation for Standardisation, FAO - Food and Agriculture Organisation.

and application of GI both in research and clinical practice. Many of the staples consumed in these regions are high in GI, notably rice, flatbread, noodles, buns, paus, pastries and so on. The use of these GI tables will also enable consumers to make informed choices on how best to select low GI foods. The GI data compiled in this article consists of both single and mixed meals. This is a major advance to many GI tables that have focused on single foods. Mixed meals in this region are complex in relation to ingredients used and taste. Given its complexity, our table that includes the GI of mixed meals is a major advantage. It is hoped that this compendium will further stimulate additional data collection and enhance the utility of GI tables for a worldwide audience. 


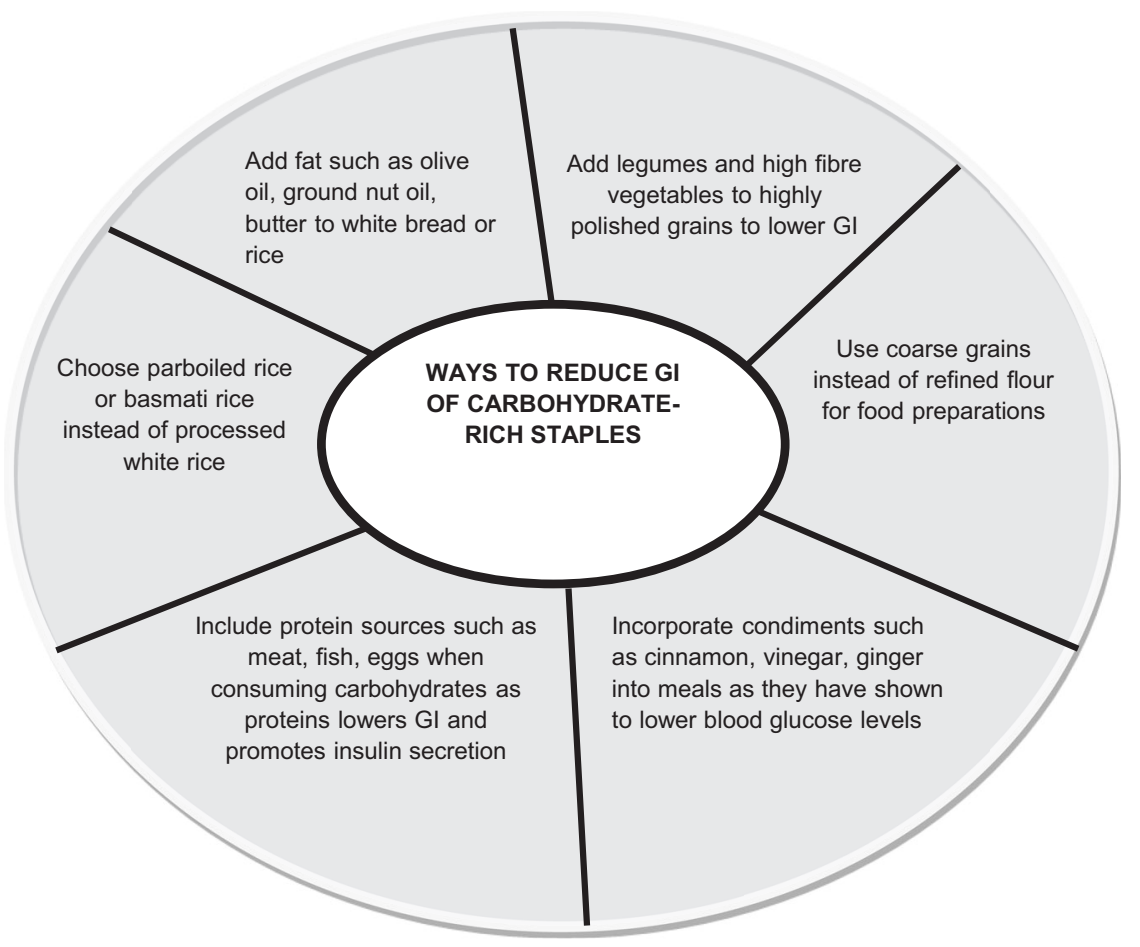

Fig. 2 Recommendations of ways to reduce the Gl of carbohydrate-rich staples. Figure shows how combination of food ingredients and foods may be used to reduce the glycaemic response of rice-based staples.

\section{Acknowledgements}

We thank A*STAR, International Medical University (IMU) and Wilmar International Limited for supporting this review. We would also like to thank Tan Le Sze (our student Intern) from the National University of Singapore for helping in the data collection. This study was supported by the Biomedical Science Institute Industry Alignment Fund (IAF-PP); Food Structure Engineering for Nutrition and Health (H17/01/a0/A11 and H18/01/a0/B11).

\section{Author details}

${ }^{1}$ Singapore Institute of Food and Biotechnology Innovation (SIFBI), Clinical Nutrition Research Centre (CNRC), 14 Medical Drive, \#07-02, Singapore 117599, Singapore. ${ }^{2}$ Department of Biochemistry, National University of Singapore (NUS), 8 Medical Drive, Singapore 117596, Singapore. ${ }^{3}$ Division of Nutrition and Dietetics, School of Health Sciences, International Medical University (IMU), No. 126, Jn Jalil Perkasa 19, Bukit Jalil 57000 Kuala Lumpur, Malaysia. ${ }^{4}$ Centre for Translational Research, Institute for Research, Development and Innovation (IRDI), International Medical University (IMU), No. 126, Jln Jalil Perkasa 19, Bukit Jalil 57000 Kuala Lumpur, Malaysia. ${ }^{5}$ Centre for Environmental and Population Health, Institute for Research, Development and Innovation (IRDI), International Medical University (IMU), No. 126, Jn Jalil Perkasa 19, Bukit Jalil 57000 Kuala Lumpur, Malaysia

\section{Conflict of interest}

The authors declare that they have no conflict of interest.

\section{Publisher's note}

Springer Nature remains neutral with regard to jurisdictional claims in published maps and institutional affiliations.

Received: 14 August 2020 Revised: 25 October 2020 Accepted: 16 November 2020

Published online: 06 January 2021

\section{References}

1. Cui, Z. \& Dibley, M. J. Trends in dietary energy, fat, carbohydrate and protein intake in Chinese children and adolescents from 1991 to 2009. Br. J. Nutr. 108, 1292-1299 (2012).

2. Mulla, U. Z., Cooper, R., Mishra, G. D., Kuh, D. \& Stephen, A. M. Adult macronutrient intake and physical capability in the MRC National Survey of Health and Development. Age Ageing 42, 81-87 (2013).

3. Schulze, M. B. et al. Glycemic index, glycemic load, and dietary fiber intake and incidence of type 2 diabetes in younger and middle-aged women. Am. J. Clin. Nutr. 80, 348-356 (2004).

4. McKeown, N. M. et al. Carbohydrate nutrition, insulin resistance, and the prevalence of the metabolic syndrome in the Framingham Offspring Cohort. Diabetes Care 27, 538-546 (2004).

5. Jenkins, D. et al. Glycemic index of foods: a physiological basis for carbohydrate exchange. Am. J. Clin. Nutr. 34, 362-366 (1981).

6. Atkinson, F. S., Foster-Powell, K. \& Brand-Miller, J. C. International tables of glycemic index and glycemic load values: 2008. Diabetes care 31, 2281-2283 (2008).

7. IDF. IDF Diabetes Atlas 9th edn (IDF, 2020).

8. Kelley, D. E. Sugars and starch in the nutritional management of diabetes mellitus. Am. J. Clin. Nutr. 78, 8585-864SS (2003).

9. Foster-Powell, K., Holt, S. H. \& Brand-Miller, J. C. International table of glycemic index and glycemic load values: 2002. Am. J. Clin. Nutr. 76, 5-56 (2002).

10. FAO/WHO. Carbohydrates in human nutrition: report of a joint FAONWHO expert consultation. FAO Food Nutr. Pap. 66, 1-140 (1998).

11. Brand-Miller, J., Hayne, S., Petocz, P. \& Colagiuri, S. Low-glycemic index diets in the management of diabetes: a meta-analysis of randomized controlled trials. Diabetes Care 26, 2261-2267 (2003).

12. Rizkalla, S. W. et al. Improved plasma glucose control, whole-body glucose utilization, and lipid profile on a low-glycemic index diet in type 2 diabetic men: a randomized controlled trial. Diabetes care 27, 1866-1872 (2004).

13. Salmeron, J. et al. Dietary fiber, glycemic load, and risk of NIDDM in men. Diabetes Care 20, 545-550 (1997).

14. Salmeron, J. et al. Dietary fiber, glycemic load, and risk of noninsulindependent diabetes mellitus in women. JAMA 277, 472-477 (1997a). 
15. Liu, S. et al. A prospective study of dietary glycemic load, carbohydrate intake and risk of coronary heart disease in US women. Am. J. Clin. Nutr. 71 1455-1461 (2000).

16. Holmboe-Ottesen, G. \& Wandel, M. Changes in dietary habits after migration and consequences for health: a focus on South Asians in Europe. Food Nutr. Res. 56, 18891 (2012)

17. Dickinson, S., Colagiuri, S., Faramus, E., Petocz, P. \& Brand-Miller, J. Postprandia hyperglycemia and insulin sensitivity differ among lean young adults of different ethnicities. J. Nutr. 132, 2574-2579 (2002).

18. Venn, B., Williams, S. \& Mann, J. Comparison of postprandial glycaemia in Asians and Caucasians. Diabet. Med. 27, 1205-1208 (2010).

19. Henry, C. et al. Glycaemic index of common foods tested in the UK and India. Br. J. Nutr. 99, 840-845 (2008).

20. Brouns, F. et al. Glycaemic index methodology. Nutr. Res. Rev. 18, 145-171 (2005)

21. Chia, M. The glycaemic index and glycaemic load of snack foods consumed by healthy adults. J. Obes. Weight Loss Ther. S2, 2-4 (2012).

22. Sun, L., Ranawana, D. V., Leow, M. K.-S. \& Henry, C. J. Effect of chicken, fat and vegetable on glycaemia and insulinaemia to a white rice-based meal in healthy adults. Eur. J. Nutr. 53, 1719-1726 (2014).

23. Tan, V., Wu, T., Henry, C. \& Lee, Y. S. Glycaemic and insulin responses, glycaemic index and insulinaemic index values of rice between three Asian ethnic groups. Br. J. Nutr. 113, 1228-1236 (2015).

24. Sun, L. et al. Glycaemic index and glycaemic load of selected popular foods consumed in Southeast Asia. Br. J. Nutr. 113, 843-848 (2015).

25. Sun, L., Wei Jie Tan, K. \& Jeyakumar Henry, C. Co-ingestion of essence of chicken to moderate glycaemic response of bread. Int. J. Food Sci. Nutr. 66 931-935 (2015).

26. Soong, Y. Y., Quek, R. Y. C. \& Henry, C. J. Glycemic potency of muffins made with wheat, rice, corn, oat and barley flours: a comparative study between in vivo and in vitro. Eur. J. Nutr. 54, 1281-1285 (2015).

27. Sun, L., Tan, K. W. J., Han, C. M. S., Leow, M. K.-S. \& Henry, C. J. Impact of preloading either dairy or soy milk on postprandial glycemia, insulinemia and gastric emptying in healthy adults. Eur. J. Nutr. 56, 77-87 (2017).

28. Tey, S. L., Lee, D. E. M. \& Henry, C. J. Fruit form influences postprandial glycemic response in elderly and young adults. J. Nutr. Health Aging 21, 887-891 (2017).

29. Tan, W. S. K. et al. The glycaemic index and insulinaemic index of commercially available breakfast and snack foods in an Asian population. Br. J. Nutr. 119, 1151-1156 (2018)

30. Camps, S. G. et al. Co-ingestion of rice bran soymilk or plain soymilk with white bread: effects on the glycemic and insulinemic response. Nutrients $\mathbf{1 0}$ 449 (2018).

31. Sun, L., Tan, K. W. J., Lim, J. Z., Magkos, F. \& Henry, C. J. Dietary fat and carbohydrate quality have independent effects on postprandial glucose and lipid responses. Eur. J. Nutr. 57, 243-250 (2018).

32. Mohd Yusof, B. N., Abd, Talib, R., Karim, N. A., Kamarudin, N. A. \& Arshad, F. Glycaemic index of four commercially available breads in Malaysia. Int. J. Food Sci. Nutr. 60, 487-496 (2009).

33. Robert, W. et al. Determination of the glycaemic index of selected Malaysian foods. Int. Med. J. 13, 255 (2006)

34. Robert, S. D., Ismail, A. A., Winn, T. \& Wolever, T. M. Glycemic index of common Malaysian fruits. Asia Pac. J. Clin. Nutr. 17, 35-39 (2008).

35. Karupaiah, T. et al. A transgressive brown rice mediates favourable glycaemic and insulin responses. J. Sci. Food Agric. 91, 1951-1956 (2011).

36. Robert, S. D. \& Ismail, A. A.-S. Glycemic responses of patients with type 2 diabetes to individual carbohydrate-rich foods and mixed meals. Ann. Nutr. Metab. 60, 27-32 (2012).

37. Ishak, W. R. W., Zin, C. A. J. C. M. \& Robert, S. D. Young corn ear addition improves some nutrients and lowering Glycemic Index of chiffon cake. Food Nutr. Sci. 5, 1545-1553 (2014)

38. Nicholas, D., Hazila, K., Chua, H. \& Rosniyana, A. Nutritional value and glycemic index of Bario rice varieties. J. Trop. Agric. Food Sci. 42, 1-8 (2014)

39. Jeevetha, S., Nisak, M., Ngan, H.-B, Ismail, A. \& Azlan, A. Relationship between amylose content and glycemic index of commonly consumed white rice. IOSR J. Agric. Vet. Sci. 7, 12-18 (2014).

40. CAJCM, Zin, Robert, S. D. \& Ishak, W. R. W. Effect of biscuits and muffins added with cornlettes powder on the glycemic responses of healthy individuals. Food Nutr. Sci. 5, 2195 (2014).
41. Robert, S. D., Ismail, A. A.-S. \& Rosli, W. I. W. Reduction of postprandial blood glucose in healthy subjects by buns and flatbreads incorporated with fenugreek seed powder. Eur. J. Nutr. 55, 2275-2280 (2016).

42. Se, C.-H., Chuah, K.-A., Mishra, A., Wickneswari, R. \& Karupaiah, T. Evaluating crossbred red rice variants for postprandial glucometabolic responses: a comparison with commercial varieties. Nutrients 8, 308 (2016).

43. Ng, S. H., Robert, S. D., WANW, Ahmad \& WRW, Ishak Incorporation of dietary fibre-rich oyster mushroom (Pleurotus sajor-caju) powder improves postprandial glycaemic response by interfering with starch granule structure and starch digestibility of biscuit. Food Chem. 227, 358-368 (2017).

44. Osman, N. M. H., Mohd-Yusof, B.-N. \& Ismail, A. Estimating glycemic index of rice-based mixed meals by using predicted and adjusted formulae. Rice Sci. 24, 274-282 (2017).

45. Sabeetha, S., Nisak, M. \& Amin, I. Glycemic index of selected watermelon (Citrullus lanatus). Int. Food Res. J. 25, 2547-2552 (2018).

46. Abu Bakar, N. A. F., Abd Rashid, A. A., Ishak, M. F. \& Jalil, A. M. M. Glycemic index of starch-based foods commonly consumed in Terengganu. Malays. Appl. Biol. 48, 129-138 (2019).

47. Drewnowski, A. et al. Sugars and sweeteners: science, innovations, and consumer guidance for Asia. Asia Pac. J. Clin. Nutr. 28, 645 (2019).

48. Supparmaniam, H., Hussin, N. \& Jalil, A. M. M. Glycaemic index, palatability, acceptability and perceived satiety of cookies prepared with durian (Durio zibethinus murr.) and B-glucan. Malays. Appl. Biol. 48, 89-99 (2019).

49. Amiruddin, N, Zahary, M, Bhaskar, R. \& Mhd Jalil, A. Glycaemic index palatability and acceptability of energy drinks prepared with $\beta$-glucan and whey protein. Food Res. 4, 421-430 (2020).

50. Chapagai, M. K. et al. Glycaemic index values and physicochemical properties of five brown rice varieties cooked by different domestic cooking methods. Funct. Foods Health Dis. 6, 506-518 (2016).

51. Nounmusig, J., Kongkachuichai, R., Sirichakwal, P., Wongwichain, C. \& Saengkrajang, W. Glycemic index, glycemic load and serum insulin response of alternative rice noodles from mixed sago palm flour (Metroxylon spp.) and chiang rice flour. Burapha Sci. J. 23, 839-851 (2018).

52. Chusak, C., Pasukamonset, P., Chantarasinlapin, P. \& Adisakwattana, S. Postprandial glycemia, insulinemia, and antioxidant status in healthy subjects after ingestion of bread made from anthocyanin-rich riceberry rice. Nutrients 12, 782 (2020).

53. Kongkachuichai, R., Charoensiri, R., Meekhruerod, A. \& Kettawan, A. Effect of processing conditions on bioactive compounds and glycemic index of the selected landrace rice variety in pre-diabetes. J. Cereal Sci. 102994 (2020).

54. Marsono, Y. Glycemic index of selected Indonesian starchy foods. Indonesian Food Nutri. Progr. 8, 15-20 (2001).

55. Marsono, Y. Indeks Glisemik Umbi-Umbian (Gycemic index of tuber foods). Agritech 22, 13-16 (2002).

56. Marsono, Y., Wiyono, P. \& Noor, Z. INDEKS GLISEMIK KACANG-KACANGAN [Glycemic index of selected legumes]. J. Teknol. dan. Ind. Pangan 13, 211 (2002)

57. Marsono, Y. \& PTdS, Kanoni Snap bean (Phaseolus vulgaris) and Yardlong bean (Vigna sesquipedalis): glycemic index and its hypoglycemic effect in Sprague Dawley rats. Biota X 183-191 (2005).

58. Hasan, V., Astuti, S. \& Susilawati, S. Indeks glikemik oyek dan tiwul dari umbi garut (Marantha arundinaceae L.), suweg (Amorphallus campanullatus BI) dan singkong (Manihot utillisima). J. Teknol. Ind. Has. Pertan. 16, 34-50 (2012).

59. Astawan, M., Wresdiyati, T., Widowati, S. \& Saputra, I. Aplikasi Tepung Bekatul Fungsional Pada Pembuatan Cookies Dan Donat Yang Bernilai Indeks Glikemik Rendah (Application of functional bran in making cookies and donuts with low glycemic index value). J. Pangan 22, 385-394 (2013).

60. Idril, N. I., Diana, A. \& Wargahadibrata, A. F. Preliminary study: glycemic index of brown and white rice variant IR64 in healthy adult men. Int. J. Integr. Health Sci. 1, 37-41 (2013).

61. Jailani, F., Kusumawardani, S., Puspitasari, C., Maula, A. \& Purwandari U. Annealled purple yam (Dioscorea alata var. purpurea) flour improved gelatinisation profile, but increased glycemic index of substituted bread. Int. Food Res. J. 20, 865-871 (2013).

62. Rimbawan, R. \& Nurbayani, R. Nilai indeks glikemik produk olahan gembili (Dioscorea esculenta). J. Gizi dan. Pangan 8, 145-150 (2013).

63. Avianty. S. \& Ayustaningwarno, F. Indeks glikemik snack bar ubi jalar kedelai hitam sebagai alternatif makanan selingan penderita diabetes melitus tipe 2. J. Aplikasi Teknol. Pangan 3, 98-102 (2014).

64. Pentadini, F., Silvia, A., Sri Hartini, A. T. (eds). Determination of glycemic score on processed food from whole wheat flour (Triticum aestivum L.) Dewata's 
variety in terms of amylose content and starch digestibility. In International Conference on Research, Implementation and Education of Mathematics and Sciences. C55-62 (2014)

65. Haryani, A., Andini, S. \& Hartini, S. Kadar gizi, pati resisten, dan indeks glikemik biskuit gandum utuh (Triticum aestivum L) varietas DWR-1621. J. Teknol. Pangan dan. Has. Pertan. 12, 1-12 (2015).

66. Diniyah, N., Firdaus, L., Windrati, W. S., Prasetyo, A. \& Subagio, A. Indeks Glikemik Beras Analog dari Mocaf dengan Substitusi Jagung. Ubi Jalar Ungu dan. Wortel. War. Ind. Has. Pertan. 33, 66-73 (2016).

67. Indrastati, N. \& Anjani, G. Snack Bar Kacang Merah Dan Tepung Umbi Garut Sebagai Alternatif Makanan Selingan Dengan Indeks Glikemik Rendah. J. Nutr. Coll. 5, 546-554 (2016).

68. Kurniawati, M., Budijanto, S. \& Yuliana, N. D. Karakterisasi dan indeks glikemik beras analog berbahan dasar tepung jagung. J. Gizi dan. Pangan 11, 169-174 (2016).

69. Wijanarka, A., Sudargo, T., Harmayani, E. \& Marsono, Y. Changes in resistant starch content and glycemic index of pre-gelatinized gayam (Inocarfus fagifer Forst.) flour. Pakistan J. Nutr. 15, 649-654 (2016).

70. Hidayat, B., Akmal, S., Muslihudin, M. \& Suhada, B. Assessment of corn-based rice analogues made from modified corn flour and cassava starch which processed by granulation method as functional food. Assessment 61, 19-24 (2017).

71. Lestari, L. A., Huriyati, E. \& Marsono, Y. The development of low glycemic index cookie bars from foxtail millet (Setaria italica), arrowroot (Maranta arundinacea) flour, and kidney beans (Phaseolus vulgaris). J. Food Sci. Technol. 54, 1406-1413 (2017)

72. Nurjanah, N., Julianti, E. D. \& Sahara, E. Aplikasi Pati Aren Termodifikasi Ekstrak Daun Jambu Biji Merah Dalam Pengembangan Produk Berindeks Glikemik Rendah (Applications of arenga starch modified with red guava leaf extract in development of a low glycemic index product). Nutr. Food Res. 39, 75-86 (2017).

73. Putri, S. Kajian Aktivitas Indeks Glikemik Brownies Kukus Substitusi Tepung Ubi Jalar Termodifikasi. J. Kesehat. 8, 18-29 (2017).

74. Saputrie, A., Murwani, R. \& Johan, A. Low glycemic index noodle snack from yellow sweet potato (Ipomoea Batatas) and pumpkin (Cucurbita Moschata) blend. Int. Conference on Translational Medicine and Health Sci. 1, 121-127 (2017).

75. Trisnawati, W. Analisis Indeks Glikemik dan Komposisi Gizi Keripik Simulasi Substitusi Tepung Bekatul dengan Tepung Labu Kuning. J. Aplikasi Teknol. Pangan 6, 143-147 (2017).

76. Karimuna, S. R., Paridah, P. \& Jufri, N. Penentuan indeks glikemik sikkato (sinonggi, kasuami, kambuse dan kabuto) pada subjek non diabetes mellitus. Preventif J. 3, 1-5 (2018).

77. Lestari, O. \& Purwayantie, S. The glycemic index and organoleptic test of Pekawai (Durio kutejensis) chips. Pro Food 3, 235-239 (2018).

78. Nugraheni, M., Hamidah, S. \& Auliana, R. Glycemic index of Coleus tuberosus crackers rich in resistant starch type III. Int. Food Res. J. 25, 314-320 (2018).

79. Susanti, A., Wijanarka, A. \& Nareswara, A. S. Penentuan indeks glikemiks dan beban glikemik pada cookies tepung beras merah (Oryza nivara) dan biji kecipir (Psophocarpus tetragonolobus L). IImu Gizi Indones. 2, 69-78 (2018).

80. Yulianto, W., Suryani, C., Susiati, A. \& Luwihana, S. Evaluation of chromium fortified-parboiled rice coated with herbal extracts: resistant starch and glycemic index. Int. Food Res. J. 25, 2608-2613 (2018).

81. Arysanti, R. D., Sulistiyani, S. \& Rohmawati, N. Indeks Glikemik, Kandungan Gizi, dan Daya Terima Puding Ubi Jalar Putih (Ipomoea batatas) dengan Penambahan Buah Naga Merah (Hylocereus polyrhizus). Amerta Nutr. 3, 107-113 (2019).

82. Agustia, F. C., Subardjo, Y. P., Ramadhan, G. R. \& Betaditya, D. Glycemic index of flakes made from Mocaf-Black rice and bean flour as alternative snacks for people with type 2 diabetes mellitus. Ann. Trop. Public Health 22, S333 (2019)

83. Lestari, O. A. \& Dewi, Y. S. K. (eds). Total consumption of honey which provides low response to glycemic index and glycemic load. Proc. Int. Conf. Food Agric. 1, 349-353 (2019).

84. Puspita, W., Sulaeman, A. \& Damayanthi, E. Snack bar berbahan pati sagu (Metroxylon sp.), tempe, dan beras hitam sebagai pangan fungsional berindeks glikemik rendah. Indonesian J. Nutr. 8, 11-23 (2019).

85. Manullang, V. A., Rahadiyanti, A., Pratiwi, S. N. \& Afifah, D. N. Glycemic index starch, and protein digestibility in tempeh gembus cookies. J. Food Qual. 2020, 1-6 (2020)
86. Nurjanah, N., Muchtadi, D., Palupi, N. \& Widowati, S. Chemical characteristics and glycemic index of processed products from corn starch modified with green tea polyphenols. EES 443, 012029 (2020).

87. Surayya, N. A. et al. Sifat organoleptik dan indeks glikemik produk sorgum bar yang diformulasi menggunakan berbagai jenis penyalut nira. J. Pangan dan Agroindustri 8, 56-67 (2020).

88. Trinidad, T. P. et al. Glycaemic index of different coconut (Cocos nucifera)-flour products in normal and diabetic subjects. Br. J. Nutr. 90, 551-556 (2003).

89. Trinidad, T. P. et al. Glycemic index of Sunfibre (Cyamoposis tetragonolobus) products in normal and diabetic subjects. Int. J. Food Sci Technol. 39 1093-1098 (2004)

90. Trinidad, T. P., Mallillin, A. C., Sagum, R. S. \& Encabo, R. R. Glycemic index of commonly consumed carbohydrate foods in the Philippines. J. Funct. foods 2, 271-274 (2010).

91. Sugiyama, M., Tang, A., Wakaki, Y. \& Koyama, W. Glycemic index of single and mixed meal foods among common Japanese foods with white rice as a reference food. Eur. J. Clin. Nutr. 57, 743-752 (2003).

92. Ito, Y. et al. Postprandial blood glucose and insulin responses to pregerminated brown rice in healthy subjects. J. Med. Investig. 52, 159-164 (2005)

93. Oku, T. et al. Effects of cake made from whole soy powder on postprandial blood glucose and insulin levels in human subjects. Int. J. Food Sci. Nutr. $\mathbf{6 0}$ 224-231 (2009).

94. Oku, T., Nakamura, M. \& Nakamura, S. Consideration of the validity of glycemic index using blood glucose and insulin levels and breath hydrogen excretion in healthy subjects. Int. J. Diabetes Mellitus 2, 88-94 (2010).

95. Sato, S. et al. Glycemic index and glucose utilization of rice vermicelli in healthy subjects. Biol. Pharm. Bull. 33, 1385-1393 (2010).

96. Taguchi, Y. et al. Evaluation of herbal foods on a-glucosidase activity and glycemic index. Food Sci. Technol. Res. 16, 39-44 (2010).

97. Nomura, N., Miyoshi, T., Hamada, Y. \& Kitazono, E. Glycemic index of boiled BARLEYmax ${ }^{\circledR}$ in healthy Japanese subjects. J. Cereal Sci. 102959 (2020).

98. Yoshimoto, J. et al. Palatable noodles as a functional staple food made exclusively from yellow peas suppressed rapid postprandial glucose increase. Nutrients 12, 1839 (2020).

99. Ryu, J.-H. et al. Sugar composition and glycemic indices of frequently consumed fruits in Korea. Korean J. Nutr. 45, 192-200 (2012).

100. Kim, D.-Y., Kim, Y. \& Lim, H. Glycaemic indices and glycaemic loads of common Korean carbohydrate-rich foods. Br. J. Nutr. 121, 416-425 (2019).

101. Yang, Y.-X. et al. Glycemic index of cereals and tubers produced in China World J. Gastroenterol. 12, 3430 (2006).

102. Li, M. et al. Postprandial glycaemic and insulinaemic responses to GMresistant starch-enriched rice and the production of fermentation-related $\mathrm{H} 2$ in healthy Chinese adults. Br. J. Nutr. 103, 1029-1034 (2010).

103. Ren, $X$. et al. In vitro starch digestibility and in vivo glycemic response of foxtail millet and its products. Food Funct. 7, 372-379 (2016).

104. Shao, S.-y et al. Glycemic index, glycemic load, and glycemic response to pomelo in patients with type 2 diabetes. Curr. Med. Sci. 37, 711-718 (2017).

105. Zhu, R. et al. Postprandial glycaemic responses of dried fruit-containing meals in healthy adults: results from a randomised trial. Nutrients 10, 694 (2018).

106. Zhu, R. et al. Acute effects of non-homogenised and homogenised vegetables added to rice-based meals on postprandial glycaemic responses and in vitro carbohydrate digestion. Br. J. Nutr. 120, 1023-1033 (2018).

107. Zhu, R. et al. Acute effects of three cooked non-cereal starchy foods on postprandial glycemic responses and in vitro carbohydrate digestion in comparison with whole grains: a randomized trial. Nutrients 11, 634 (2019).

108. Lin, M.H. A., Wu, M.-C., Lu, S. \& Lin, J. Glycemic index, glycemic load and insulinemic index of Chinese starchy foods. World J. Gastroenterol. 16, 4973 (2010).

109. Lai, M. H. et al. Predicted glycemic index and glycemic index of rice varieties grown in Taiwan. Cereal Chem. 93, 150-155 (2016).

110. Yang, C.-H., Chang, C.-W. \& Lin, J. White rice glycemic index measured in venous and capillary blood samples. Food Sci. Technol. Res. 23, 297-304 (2017).

111. Yang, C.-H., Lin, M.-H. A. \& Lin J. The effect of adding Chinese food supplements to rice on glycemic response. Chiang Mai Univ. J. Nat. Sci. 16, 191-206 (2017).

112. Chen, Y.-J., Sun, F.-H., Wong, S. H.-S. \& Huang, Y.-J. Glycemic index and glycemic load of selected Chinese traditional foods. World J. Gastroenterol. 16, 1512 (2010). 
113. Lok, K. Y. et al. Glycaemic index and glycaemic load values of a selection of popular foods consumed in Hong Kong. The. Br. J. Nutr. 103, 556-560 (2010).

114. Bahado-Singh, P., Wheatley, A., Ahmad, M., Morrison, E. S. A. \& Asemota, H. Food processing methods influence the glycaemic indices of some commonly eaten West Indian carbohydrate-rich foods. Br. J. Nutr. 96, 476-481 (2006).

115. Anju, T. \& Sarita, S. Suitability of foxtail millet (Setaria italica) and barnyard millet (Echinochloa frumentacea) for development of low glycemic index biscuits. Malays. J. Nutr. 16, 361-368 (2010).

116. Megala, P. \& Hymavathi, T. Inulin and fructooligosaccharides incorporated functional fruit bars. World Acad. Sci. Eng. Technol. 59, 600-605 (2011).

117. Premanath, M., Basavana Gowdappa, H., Mahesh, M., Suresh \& Babu, M. A study of glycemic index of ten indian fruits by an alternate approach. E-Int. Sci. Int. Sci. Int. Sci. Res. J. Res. J. 3, 11-18 (2011).

118. Durgadevi, R. \& Nazni, P. Comparative study of processed amaranth grains on glycemic indices in niddm subjects. Int. J. Pharm. Med. Biol. Sci. 1, 194-205 (2012).

119. Shobana, S. et al. Glycaemic index of three Indian rice varieties. Int. J. Food Sci. Nutr. 63, 178-183 (2012)

120. Bisht, A. \& Srivastava, S. Efficacy of millets in the development of low glycemic index sweets for diabetics. Malays. J. Nutr. 19, 215-222 (2013).

121. Katare, C. \& Sharma, S. Effect of dried bottle gourd pulp supplemented snacks on glycemic status of subjects in normal health. Int. J. Food Nutr. Sci. 2 , 104 (2013)

122. Neelam, Y., Kanchan, C., Alka, S. \& Alka, G. Evaluation of hypoglycemic properties of kodo millet based food products in healthy subjects. IOSR J. Pharm. 3, 14-20 (2013).

123. PriyankaSingh, N. Y., Mishra, P. K. \& Sheikh, S. Utilization of rice bran for development of chapatti and its glycemic response in NIDDM patients. Int Res. J. Pharm. Appl. Sci. 3, 244-248 (2013).

124. Srinivasa, D. et al. Glycaemic index (Gl) of an Indian branded thermally treated Basmati rice variety: a multi centric study. J. Assoc. Phys. India 61, 716-720 (2013)

125. Bora, P. \& Kulshrestha, K. Development of low glycemic index green gram husk incorporated fiber rich food products and their intervention for health benefits. Int. J. Food Nutr. Sci. 3, 196-203 (2014).

126. Chaturvedi, N., Shukla, K. \& Singh, A. Post-prandial glucose response to ficus religiosa based products in normal subjects and their outcome on glycemic index. Int. J. Adv. Res. 2, 219-226 (2014).

127. Shukla, K. \& Srivastava, S. Evaluation of finger millet incorporated noodles for nutritive value and glycemic index. J. Food Sci. Technol. 51, 527-534 (2014).

128. Beniwal, P. \& Jood, S. Development of low glycemic index noodles by legume and cereal by-products incorporation. Int. J. Health Sci. Res. $\mathbf{5}$ 381-387 (2015)

129. Bora, P. \& Kulshrestha, K. Fiber rich snack food products incorporated with green gram husk and their suitability for diabetics. Asian J. Dairy Food Res. 34, 300-306 (2015).

130. Eagappan, K., Mathew, M. M. \& Sasikumar, S. Assessment of glycaemic index and glycaemic load in selected banana varieties. Int. J. Res. Health Sci. [Online] 3, 89-93 Available from: http://www.ijrhs.com/issues.php? $\mathrm{val}=$ Volume $3 \& \mathrm{iss}=\mid \mathrm{ssue} 1$.

131. Patil, K. B., Chimmad, B. V. \& Itagi, S. Glycemic index and quality evaluation of little millet (Panicum miliare) flakes with enhanced shelf life. J. Food Sci. Technol. 52, 6078-6082 (2015)

132. Prasad, M. P. R., Rao, B. D., Kalpana, K., Rao, M. V. \& Patil, J. V. Glycaemic index and glycaemic load of sorghum products. J. Sci. Food Agric. 95, 1626-1630 (2015).

133. Joshi, S. \& Srivastava, S. Barnyard millet as a substitute of rice in preparation of khichdi for diabetics. Int. J. Sci. Res. 5, 1798-1802 (2016).

134. Mohan, V. et al. Glycemic Index of a Novel High-Fiber White Rice Variety Developed in India-A Randomized Control Trial Study. Diabetes Technol. Ther. 18, 164-170 (2016).

135. Narayanan, J., Sanjeevi, V., Rohini, U., Trueman, P. \& Viswanathan, V. Postprandial glycaemic response of foxtail millet dosa in comparison to a rice dosa in patients with type 2 diabetes. Indian J. Med. Res. 144, 712-717 (2016)

136. Santhi Sirisha, K. \& Vijaya Lakshmi, V. Estimation of glycemic index of ragi recipes incorporated with curry leaf powder. Int. J. Recent Adv. Multidiscip. Res. 3. 1936-1939 (2016)

137. Singh, P., Kulshrestha, K., Kumbhar, B. \& Kumar, S. Study on glycemic indices of carrot enriched food products. Progress. Hortic. 48, 110-113 (2016).
138. Chaturvedi, N., Agarwal, A. \& Raj, N. Glycemic indices of Kale leaves based chakli and twisters on normal human subjects. Int. J. Sci. Res. 6, 4 (2017).

139. Kaur, K., Kaur, H. \& Bains, K. Development and nutritional evaluation of cereal and pulse based biscuits for diabetic patients. Br. J. Appl. Sci. Technol. 21, 1-8 (2017).

140. Kaur, K. Nutritional evaluation and glycemic response of extruded products developed from cereal pulse blends. Chem. Sci. Rev. Lett. 6, 939-946 (2017)

141. Shanmugam, S. et al. Even minimal polishing of an Indian parboiled brown rice variety leads to increased glycemic responses. Asia Pac. J. Clin. Nutr. 26 829-836 (2017).

142. Vijayakumar, G. et al. Glycemic index (Gl) and glycemic load (GL) of commonly used breakfast foods in Kerala. Asia Pac. J. Res. 2320, 5504 (2017).

143. Chaturvedi, N., Raj, N. \& Agarwal, A. Value added Indian flat breads with Ashwagandha and its glycemic response among normal healthy subjects. Asian J. Dairy Food Res. 37, 73-76 (2018).

144. Chauhan, S. \& Singh, U. Impact of processing on glycemic index of maize based flour under in vivo condition. J. Pharmacogn. Phytochem. 7, 2021-2023 (2018).

145. Chockaligam, A., Rao, D., Sarikonda, S., Reddy, K. \& Reddy, D. Effect of DiaBliss Herbal Sugar (DHS) in patients with type-ll diabetes mellitus. Int. J. Diabetes Res. 7, 31-35 (2018).

146. Korrapati, D. et al. Development of low glycemic index foods and their glucose response in young healthy non-diabetic subjects. Prev. Nutr. Food Sci. 23, 181 (2018).

147. Shobana, S. et al. Development and evaluation of nutritional, sensory and glycemic properties of finger millet (Eleusine coracana L.) based food products. Asia Pac. J. Clin. Nutr. 27, 84-91 (2018).

148. Tomer, V., Kaur, A., Kaur, A. \& Kumar, A. Glycaemic index of Indian flatbreads (rotis) prepared using multigrain flour and whole wheat flour. Ann. Biol. 34 143-147 (2018).

149. Joseph, J. Nutritional, glycemic and ecological assessment of green jackfruit for diabetes in Kerala. Int. J. Diabetes 1, 14-18 (2019).

150. RamyaBai, M. et al. Glycemic index and microstructure evaluation of four cereal grain foods. J. Food Sci. 84, 3373-3382 (2019).

151. Geetha, K., Yankanchi, G. M., Hulamani, S. \& Hiremath, N. Glycemic index of millet based food mix and its effect on pre diabetic subjects. J. Food Sci. Technol. 57, 2732-2738 (2020).

152. Mammen, R. et al. Safety and influence of a novel powder form of coconut inflorescence sap on glycemic index and lipid profile. Bioact. Carbohydr. Diet. Fibre 23, 100217 (2020)

153. Hettiaratchi, U., Ekanayake, S. \& Welihinda, J. Glycaemic indices of three Sri Lankan wheat bread varieties and a bread-lentil meal. Int. J. Food Sci. Nutr. $\mathbf{6 0}$ 21-30 (2009).

154. Widanagamage, R. D., Ekanayake, S. \& Welihinda, J. Carbohydrate-rich foods: glycaemic indices and the effect of constituent macronutrients. Int. J. Food Sci. Nutr. 60, 215-223 (2009).

155. Pirasath, S., Thayaananthan, K., Balakumar, S. \& Arasaratnam, V. Effect of dietary curries on the glycaemic index. Ceylon Med. J. 55, 118-122 (2010).

156. Hettiaratchi, U., Ekanayake, S., Welihinda, J. \& Perera, M. Glycemic and insulinemic responses to breakfast and succeeding second meal in type 2 diabetics. Int. J. Diabetes Dev. Ctries 31, 199-206 (2011).

157. Hettiaratchi, U., Ekanayake, S. \& Welihinda, J. Sri Lankan rice mixed meals: effect on glycaemic index and contribution to daily dietary fibre requirement. Malays. J. Nutr. 17, 97-104 (2011).

158. Hettiaratchi, U, Ekanayake, S. \& Welihinda, J. Chemical compositions and glycemic responses to banana varieties. Int. J. Food Sci. Nutr. 62, 307-309 (2011)

159. Pirasath, S., Thayananthan, K., Balakumar, S. \& Arasaratnam V. Effect of soluble fiber on glycaemic index. Galle Med. J. 17, 23-31 (2012).

160. Pirasath, S., Thayananthan, K., Balakumar, S. \& Arasaratnam, V. Glycemic index values of some Jaffna fruits. Funct. Foods Health Dis. 2, 25-34 (2012).

161. Anuruddhika Subhashinie Senadheera, S. P. \& Ekanayake, S. Green leafy porridges: how good are they in controlling glycaemic response? Int. J. Food Sci. Nutr. 64, 169-174 (2013).

162. Muthalib, A., Naser, K. A., Sivakanesan, R. \& Nageeb, M. Effects of consumption of traditional Sri Lankan meals on glycaemic response in healthy individuals. Sri Lanka J. Diabetes Endocrinol. Metab. 4, 12-16 (2014).

163. Perera, M., Sivakanesan, R., Abeysekara, D. \& Sarananda, K. Effect of vegetable mixed curry on glycaemic index and glycaemic load of soy flour incorporated traditional Sri Lankan breakfast foods in healthy adults. Pakistan J. Nutr. 13, 616-621 (2014) 
164. Pirasath, S., Thayananthan, K., Balakumar, S. \& Arasaratnam, V. Thosai mixed with side dishes altered the glycaemic index. Batticaloa Med. J. 6, 24-28 (2014).

165. Gunathilaka, M. \& Ekanayake, S. Effect of different cooking methods on glycaemic index of Indian and Pakistani basmati rice varieties. Ceylon Med. J. 60, 57-61 (2015)

166. Pirasath, S., Balakumar, S. \& Arasaratnam, V. Glycemic index of traditional foods in Northern Sri Lanka. Endocrinol. Metab. Synd. 4 (2015).

167. Senavirathna, R. M. I. S. K., Ekanayake, S. \& Jansz, E. R. Traditional and novel foods from indigenous flours: nutritional quality, glycemic response, and potential use in food industry. Starch-Stärke 68, 999-1007 (2016).

168. Manokaran, S. et al. Determination of glycaemic responses of low fat milk incorporated with whey proteins and oats powder. J. Clin. Nutr. Diet. 4, 1-4 (2018).

169. Prasantha, B. D. R. Glycemic index of four traditional red pigmented rice. Integr. Food Nutr. Metab. 5, 1-3 (2018).

170. Miller, C., Dunn, E. \& Hashim, I. The glycaemic index of dates and date/ yoghurt mixed meals. Are dates 'candy that grows trees'?. Eur. J. Clin. Nutr. 57, 427-430 (2003)

171. Alkaabi, J. M. et al. Glycemic indices of five varieties of dates in healthy and diabetic subjects. Nutr. J. 10, 59 (2011)

172. Alkaabi, J., Al-Dabbagh, B., Saadi, H., Gariballa, S. \& Yasin, J. Effect of traditional Arabic coffee consumption on the glycemic index of Khalas dates tested in healthy and diabetic subjects. Asia Pac. J. Clin. Nutr. 22, 565-573 (2013).

173. Al, Dhaheri et al. Glycaemic index and glycaemic load values of commonly consumed foods in the United Arab Emirates. Br. J. Nutr. 117, 1110-1117 (2017).

174. Jarrar, A. H., Kamal-Eldin, A., Bataineh, Ma \& Al Dhaheri, A. S. Glycemic index (Gl) and glycemic load (GL) values for dried bisr and tamr dates. Emir. J. Food Agric. (2019).

175. Ali, A., Al-Hakmani, M., Waly, M. \& Essa, M. Glycemic index of commonly consumed snack foods in Oman. Int. J. Nutr. Pharmacol. Neurol. Dis. 10, 50-56 (2020).

176. Al-Mssallem, M. Q., Hampton, S. M., Frost, G. S. \& Brown, J. E. A study of Hassawi rice (Oryza sativa L.) in terms of its carbohydrate hydrolysis (in vitro) and glycaemic and insulinaemic indices (in vivo). Eur. J. Clin. Nutr. 65, 627-634 (2011).

177. Al-Mssallem, M. Q. \& Brown, J. E. Arabic coffee increases the glycemic index but not insulinemic index of dates. Saudi Med. J. 34, 923-928 (2013).

178. AlGeffari, M. A., Almogbel, E. S., Alhomaidan, H. T., El-Mergawi, R. \& Barrimah, I. A. Glycemic indices, glycemic load and glycemic response for seventeen varieties of dates grown in Saudi Arabia. Ann. Saudi Med. 36, 397-403 (2016).

179. Daher, C., Farhat, A., Moukarzel, S. \& El-Said, R. Glycemic index of commonly consumed Lebanese mixed meals and desserts. Asian J Clin. Nutr. 2, 48-57 (2010). 